Columbia Law School

Scholarship Archive

\title{
Leading with Conviction: The Transformative Role of Formerly Incarcerated Leaders in Reducing Mass Incarceration
}

\author{
Susan Sturm \\ Columbia Law School, ssturm@law.columbia.edu \\ Haran Tae \\ haran.tae@yale.edu
}

Follow this and additional works at: https://scholarship.law.columbia.edu/faculty_scholarship

Part of the Criminal Law Commons, and the Law and Society Commons

\section{Recommended Citation}

Susan Sturm \& Haran Tae, Leading with Conviction: The Transformative Role of Formerly Incarcerated Leaders in Reducing Mass Incarceration, (2017).

Available at: https://scholarship.law.columbia.edu/faculty_scholarship/2033

This Report is brought to you for free and open access by the Faculty Publications at Scholarship Archive. It has been accepted for inclusion in Faculty Scholarship by an authorized administrator of Scholarship Archive. For more information, please contact scholarshiparchive@law.columbia.edu, rwitt@law.columbia.edu. 


\section{TABLE OF CONTENTS}

$\begin{array}{ll}\text { Executive Summary } & 1\end{array}$

$\begin{array}{ll}\text { I. Introduction } & 4\end{array}$

II. Leaders with Conviction as Organizational Catalysts:

Introducing their Alchemy of Experience, Education, and Employment 13

III. Ground Truth: First-hand Experience with the Criminal Justice System 15

A. Narrating the Unseen $\quad 16$

B. Connecting the Dots: Understanding the Pathway into the Justice System 19

C. Understanding What Enables Personal Transformation 23

D. Building Racial Literacy $\quad 25$

$\begin{array}{ll}\text { IV. Education: An Equalizer and Game Changer } & \mathbf{2 7}\end{array}$

A. Education's Legitimizing and Leadership-enhancing Role 28

B. The Power of Integrating Formal Knowledge and Practice 31

V. Boundary-spanning Employment and Activism

VI. Superconductors of Social Capital: Cross-Cutting Communication and Legitimacy $\quad 39$

VII. The Multiplier Effect of Bonding, Bridging and Linking Social Capital 44

A. Bonding Capital Backed By Bridges and Linkages $\quad 46$

B. Bridging Capital Enhanced by Strong Ties with Directly Affected Communities 51

C. Linking Communities and Influencers to Make Institutional and Policy Change 57

D. Organizational Catalysts In Action $\quad 62$

VIII. Building Formerly Incarcerated Leadership: Structural Features At Play $\quad 69$

$\begin{array}{ll}\text { A. Relationships with Champions at Critical Junctures } & 69\end{array}$

B. Education and Training to Cultivate Leadership $\quad 74$

C. Building Leaders with Conviction into Institutional and Policy Design $\quad 75$

IX. Conclusion and Recommendations $\quad 77$

$\begin{array}{ll}\text { Appendix A: Methodology } & 78\end{array}$

$\begin{array}{ll}\text { Sampling Strategy } & 78\end{array}$

Interview Process and Protocols

Appendix B: Study Participants $\quad 81$

Appendix C: Leading with Conviction \& Emerging Leaders $\quad 83$

$\begin{array}{lr}\text { References } & 89\end{array}$ 


\section{Executive Summary}

This report, published by JustLeadershipUSA and the Center for Institutional and Social Change at Columbia Law School, documents the roles of formerly incarcerated leaders engaged in work related to reducing incarceration and rebuilding communities, drawing on indepth interviews with 48 of these leaders conducted over a period of 14 months. These "leaders with conviction"1 have developed a set of capabilities that enable them to advance transformative change, both in the lives of individuals affected by mass incarceration and in the criminal legal systems that have devastated so many lives and communities. Their leadership assumes particular importance in the era of the Trump Presidency, when the durability of the ideological coalitions to undo the failed apparatus of mass incarceration will be tested.

Our analysis of these interviews indicates that a particular set of qualities equips this group of formerly incarcerated leaders to serve as organizational catalysts. Organizational catalysts are individuals with knowledge, influence, and credibility who are in a position to mobilize change. They operate at the intersection of communities and systems that do not usually interact, and bring a track record of commitment and an ability to communicate across different backgrounds and cultures. They can transform organizations and networks by (1) mobilizing varied forms of knowledge to promote change, (2) developing collaborations in strategic locations, (3) cultivating new organizational catalysts, and (4) maintaining pressure and support for action.

The leaders share three important characteristics contributing to their evolution into organizational catalysts: (1) first-hand experience with the criminal legal system, (2) education that legitimizes and enhances their knowledge and leadership capacity, and (3) jobs and activist positions placing them at the intersection of different communities and systems. This combination affords them multifaceted insight into the needs, barriers, and opportunities for transformation, as well as the legitimacy and influence needed to mobilize change based on that knowledge.

In other words, the leaders with conviction have developed the capacity to mobilize unusually diverse forms of social capital-a term scholars use to refer to resources that are shared through networks of relationships. The leaders use their social capital both as an engine of mobility for those affected by mass incarceration and as a vehicle for catalyzing change. Their varied knowledge and experience equip them to speak the language of many different communities, and thus to communicate effectively with different audiences. They build trust with people who have experienced consistent stigmatization and dispel myths among people who hold stereotypes that have prevented them from learning the realities of the criminal justice system. They overcome the barriers to communication that flow from the widespread stigmas and stereotypes associated with having a criminal record.

1 This language came from Glenn E. Martin and JustLeadershipUSA. 
As such, formerly incarcerated leaders are bonders (maintaining ties and sharing resources among those with a common identity linked to experiencing and seeking to transform the criminal justice system), bridgers (connecting individuals who would not ordinarily come in contact), and linkers (linking those with direct experience and knowledge of criminal justice to people in positions to influence public policy and change the public narrative). They combine bonding, bridging, and linking social capital, in service of reducing incarceration and building thriving communities, by:

- Remaining deeply tied to individuals and communities affected by incarceration as they become upwardly mobile, while infusing these relationships with resources and relationships developed through their education, employment, and activism. Leaders with conviction may provide the only meaningful connection that justice-involved individuals and communities have to high quality social capital.

- Bringing their narrative and multiple forms of knowledge into venues where they form relationships with influential people who have had little or no direct contact with people who have been in prison, and who have had no exposure to people who have turned their lives around and become leaders. Their education and boundary-spanning employment puts them in contact with many high-impact situations and people beyond the reach of many people who have been to prison.

- Developing relationships with people who influence institutional and public policy and shape public discourse and have had limited interaction with those directly affected by mass incarceration, and linking them with each other and with communities directly affected by mass incarceration. Their growing connections to the policy world enable them to build a movement among people with shared interests, and link that movement to people in positions to reshape public policy.

Three structural supports emerged from this study as crucial building blocks of leaders with conviction: (1) relationships with people who believe in them and support their development, including when they struggle, (2) education and training that cultivates their identity and capacity as leaders, and (3) institutional and policy design that makes them full participants in the decision-making process. 
Three policy recommendations flow from the extensive findings reported here:

1. Design public policy to encourage and reward individuals and organizations who use their social capital to support the recovery and leadership development of people who have experienced incarceration or are at risk of doing so.

2. Make high-quality higher education supporting leadership development available as a matter of policy to people in and after prison. Support education, training, and counseling that provides opportunities for individuals to discover and develop their strengths and leadership capacities, including their capacity to participate in public policy making and organizational leadership, and to enable people to advocate for themselves.

3. Incorporate the direct and meaningful participation of leaders with conviction into agenda setting, decision-making, and implementation of policies related to criminal justice and community change. 


\section{Introduction}

On December 7, 2015, a group of formerly incarcerated leaders met with federal officials at the White House to discuss how to reduce mass incarceration in the United States. The leaders described "an inspirational conversation" with high-level policy makers from nine different agencies who were part of an interagency task force. This meeting was a milestone in a much broader campaign to reduce incarceration, reform the criminal justice system, and address the collateral consequences of mass incarceration.

That campaign has extended far beyond the federal government. In the past several years, a movement has taken root across the country that has built ideological coalitions around the shared goal of reducing mass incarceration. Local, state, and national initiatives have been launched to change sentencing policies; reduce policy barriers to successful reentry; open up opportunities in education, job placement, housing, and healthcare; and reverse the school-toprison pipeline. Cities and states across the country have undertaken to reduce incarceration and reimagine jails and prison, with the support of major foundations. ${ }^{2}$ The Obama administration recognized the disastrous consequences of mass incarceration, and built interagency collaborations that "expand opportunities and reduce barriers for justice-involved people, supporting second chances for those who have paid their debt to society" (The Federal Interagency Reentry Council, 2016).

For many of these initiatives, leadership by those directly affected by mass incarceration has played a significant yet largely unheralded role in driving that work forward. For decades, people who have experienced incarceration have been working to reduce the profoundly negative impact of the criminal justice system on individuals, families, and communities. In the 1970s, for example, Eddie Ellis was one of the early members of a think tank behind the walls of New York's Green Haven prison. That think tank conducted cutting edge research, as well as forums, discussion groups, and seminars with prison activists, academics, cultural groups, and community residents.

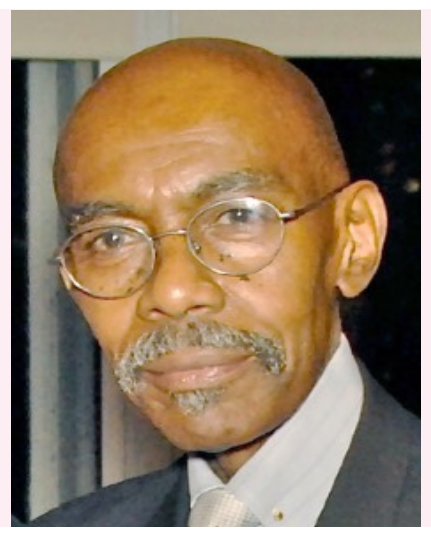

"The fact that more than 85 percent of prisoners in the state are black or Latino and-most phenomenal of all-that 75 percent of the state's entire prison population comes from just seven neighborhoods in New York City," said Mr. Ellis, citing accepted research data culled by prisoners themselves in a prisoner's "think tank" at Green Haven prison in Stormville, N.Y. New York Times, December 23, 1992, http://centerfornuleadership.org/2013/11/ the-seven-neighborhood-study-cited-in-nyt-in-1992-and-still-true-today/

\footnotetext{
${ }^{2}$ For examples, see the John D. and Catherine T. MacArthur Foundation, The Safety and Justice Challenge, http:// www.safetyandjusticechallenge.org/; the Vera Institute, https://www.vera.org/ending-mass-incarceration? gclid=CPGouaiRntACFQ5YDQodYBoHWg; the Ford Foundation, https://www.fordfoundation.org/the-latest/news/commoncause-on-criminal-justice-reform/.
} 
In its earliest days, the Vera Institute-one of the preeminent criminal justice policy organizations in the United States-regularly included as part its planning teams people who had been involved with the justice system, had been incarcerated, and were recovering from addiction. Several reentry and advocacy organizations, such as the Osborne Association, College and Community Fellowship, Fortune Society, and Legal Services for Prisoners with Children, include significant representation by incarcerated and formerly incarcerated people in their leadership and staffing.

Recognized and supported leadership by people with first-hand experience in the criminal legal system has been the exception rather than the norm. During the four-decade period when the United States pursued punitive policies that produced the highest incarceration rate in the world, this constituency continued to press for change, often with little fanfare and scarce resources.

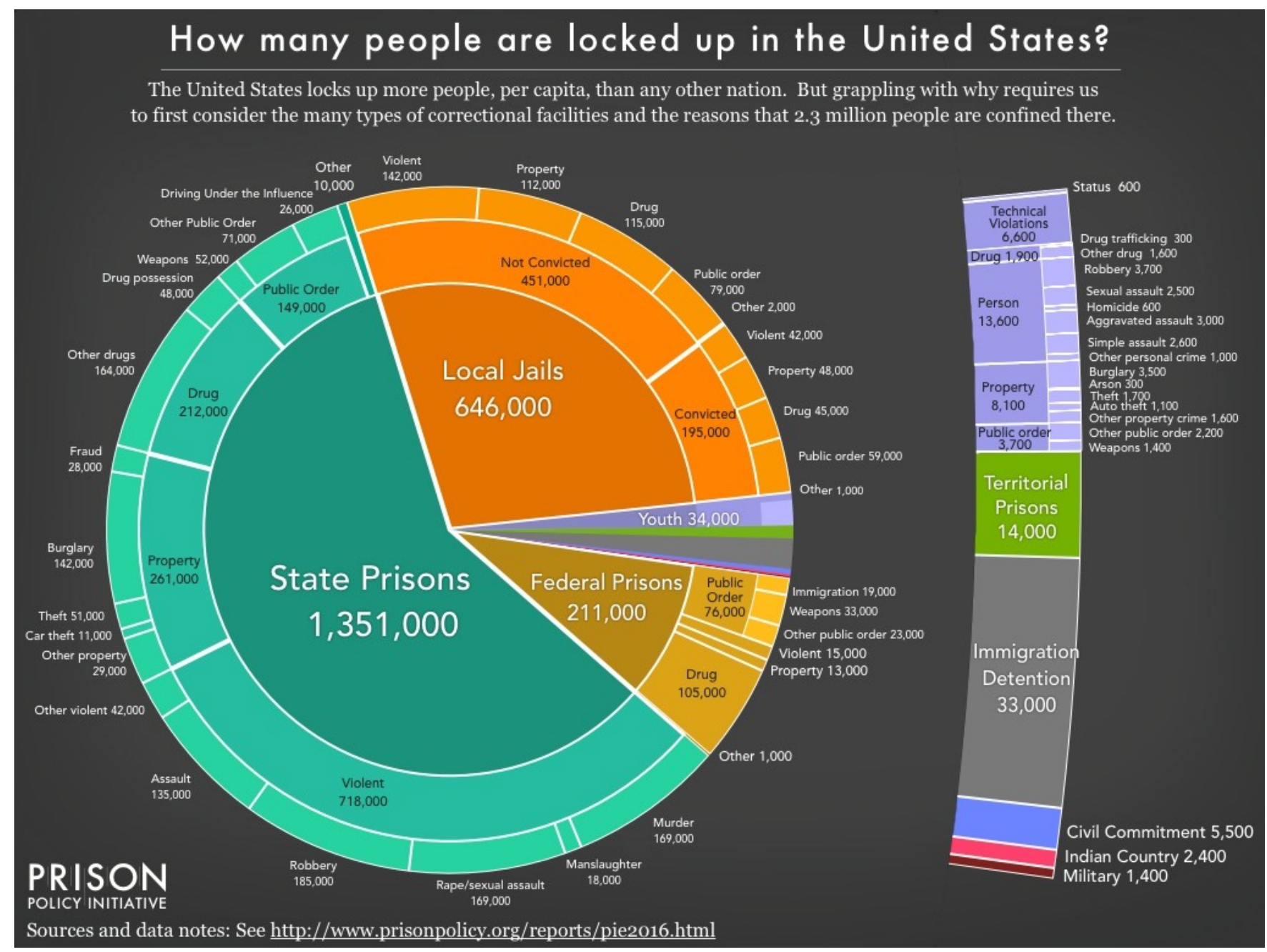

Their advocacy continued during a time when Congress banned Pell grant funding for higher education in prisons and jails, and reduced or capped funding for crucial poverty-reducing social and governmental services, such as education, health care, safe and affordable housing, and transportation (National Research Council, 2014). 
Despite the scant investment in their advancement, a subgroup of these justice-involved people has developed leadership capabilities that enabled them to become particularly effective catalysts for change, both in the lives of individuals directly affected by mass incarceration and in the interlocking systems that often devastated lives and communities. During the era of the Trump presidency, which threatens a return to federal policies that contributed to the crisis of mass incarceration, formerly incarcerated leadership assumes even greater significance. This report documents and analyzes the roles of these "leaders with conviction."3

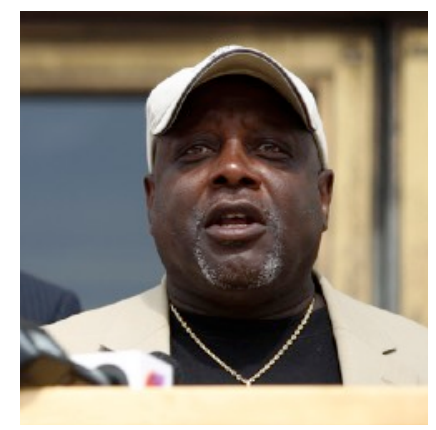

Dorsey Nunn, Co-Founder of All of Us or None, speaks during a news conference at the Rene C. Davidson Courthouse in Oakland on Aug. 4, 2015
For these individuals, the long path from prison to public leadership was neither easy nor direct. Dorsey Nunn's story illustrates both the pathway and the promise of leadership by people who rebuilt their lives after their experience with the criminal legal system. Nunn grew up in a poor, largely black neighborhood. The schools he attended did not teach that he or his peers "could be great businessmen or great anything else," he recalled. By high school, he had lost faith in education, left school, and focused his attention on drugs and the informal economy. At that point, his drug use commingled with "extreme indignation over racism," in his words. At the age of 17, Nunn had two children and minor skirmishes with the law. By the time he was 19 , before he had even learned to shave, he was sentenced to prison for life.

Once in prison, Nunn's relationship to education changed. He realized that the people in his neighborhood were systematically undereducated, and began to invest in his own education. While in prison, Nunn earned both his high school equivalency degree and his Associate's degree. He also took political and cultural education classes led by older peers in the prison. Through this process, he accepted personal responsibility for his actions leading to his incarceration and their consequences, even as he came to understand the larger systemic forces shaping his choices. He joined an organization called Self-Advancement Through Education, which required its members to take a pledge that they would return to the community an asset instead of a liability. Nunn took that pledge. On his way to the front gate when he was being paroled, he promised not to forget the people he was leaving behind.

Since he left prison in 1981, every job Nunn has held has been in service of the full restoration of the rights of people who experience incarceration. He struggled with and ultimately overcame addiction, going on to start a drug treatment organization called Free at Last. He received support from lawyers, advocates, and family members who believed in him, stuck by him, and gave him the opportunity to do work that mattered deeply to him. He is now the Executive Director of Legal Services for Prisoners with Children (LSPC). Working in collaboration with other organizers who had been in prison, Nunn also co-founded All of Us or None 
(AOUON), a grass-roots civil and human rights organization fighting for the rights of currently and formerly incarcerated people and their families. AOUON's goal, as stated on its website, is to "strengthen the voices of people most affected by mass incarceration and the growth of the prison-industrial complex."

With Nunn's leadership, AOUON initiated the Ban the Box campaign, which calls for removing the question and checkbox, "Have you been convicted by a court?" from applications for employment, housing, public benefits, insurance, loans, and other services. AOUON started this movement in San Francisco, which passed the first "ban the box" ordinance after Nunn and dozens of others filled the chambers of the San Francisco Board of Supervisors to demand that the question about felony convictions be removed from city employment applications and saved for later in the hiring process.

AOUON has since worked with legal organizations and community groups around the country. The "Ban the Box"

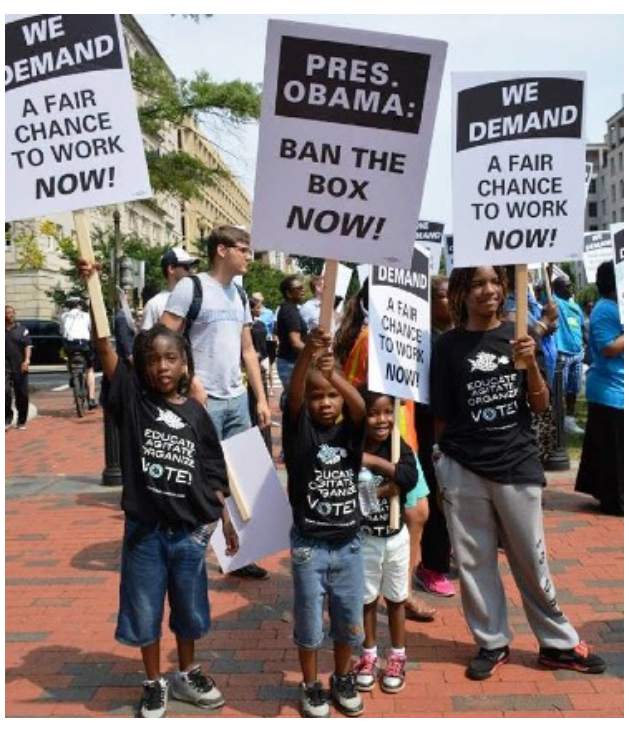

Young activists at AOUON Ban the Box Rally in Washington D.C., July 2015 campaign has broadened into a national effort to eliminate questions about a person's arrest or conviction history from all applications. Currently over 1/3 of the country is living in a jurisdiction where the box has been banned. Nunn connected to other formerly incarcerated leaders, who launched these campaigns in their own communities. According to Nunn:

We decided to push Ban the Box to organize people with criminal records, not the other way around, meaning we did not organize people with records only to pass Ban the Box policies. That was not our primary objective. For us the larger objective was to get people with criminal records to become organized and active in the fight against mass incarceration and the second-class status that comes with a criminal record. (Atkinson and Lockwood, 2015).

Nunn has become an advisor to government agencies, advocates, and policy makers across the country. He is also part of an umbrella organization called the Formerly Incarcerated Convicted People and Families Movement (FICPFM), a network of organizations led by people who have been incarcerated and are committed to ending mass incarceration and promoting full restoration of civil and human rights. In September 2016, FICPFM hosted a conference attended by more than 500 formerly incarcerated and convicted people and their family members, who gathered in Oakland to set a nationwide agenda for criminal justice reform. This event marked the first-ever coalition of reform groups from 35 states, and exemplified a new

\footnotetext{
${ }^{4}$ The Development of All of Us or None. Fall Newsletter. Volume 1, Issue 1. Retrieved from http://www.prisonerswithchildren.org/wp-content/uploads/2013/01/AOUN-Newsletter-9-12-121.pdf.
} 
generation of criminal justice activism aiming to build a national movement with a transformational agenda (North, 2016).

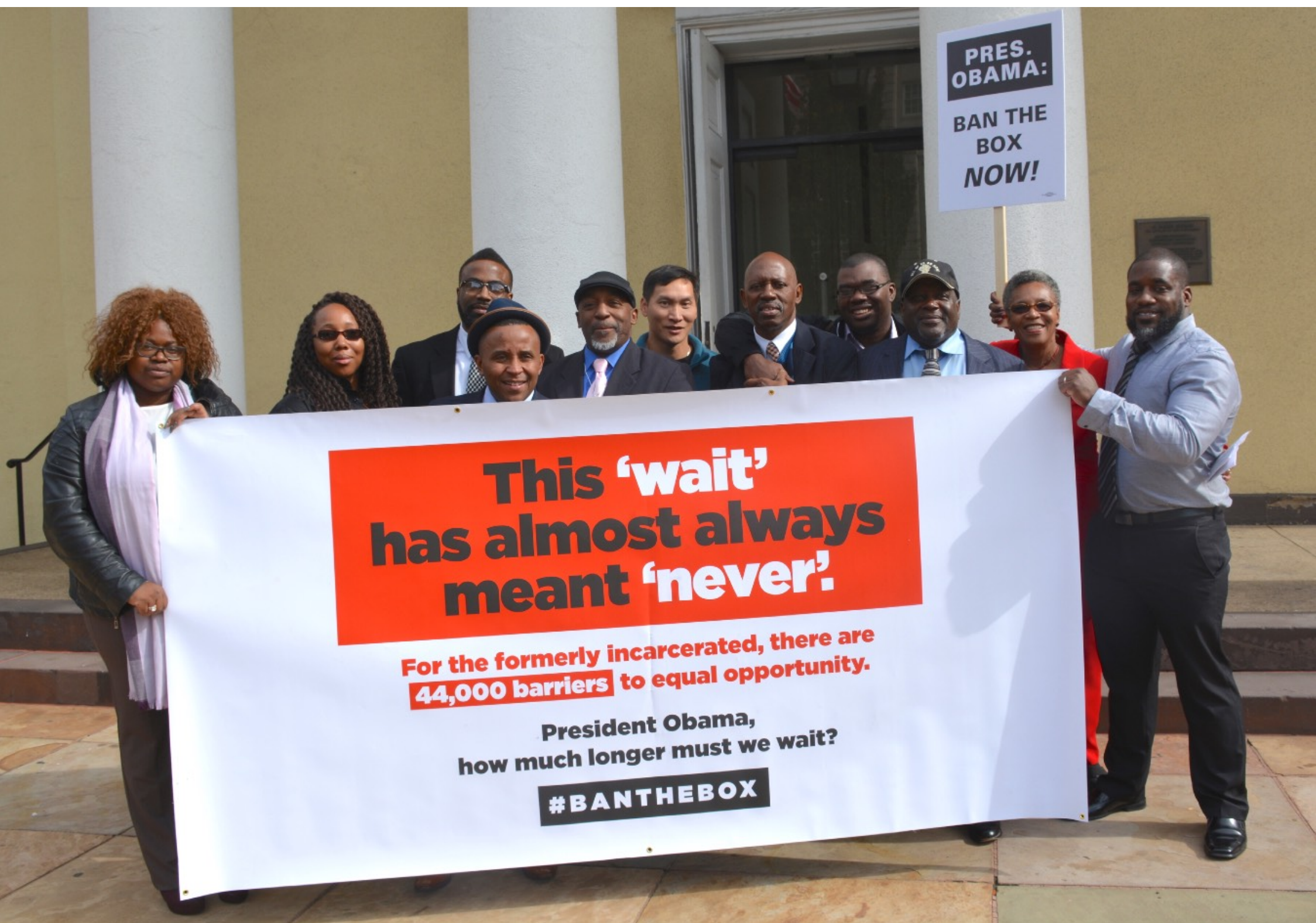

Dorsey Nunn and members of the FICPFM demand President Obama to \#BantheBox in Washington, D.C., October 2015

Nunn's typical schedule illustrates how he moves between vastly different communities, all of whom have a stake in decarceration. One day, he's handing out bicycles to children on behalf of their incarcerated parents, or mentoring people in prison so they can pursue education and employment, or organizing family members of those who are currently incarcerated. The next day, he's advising state policy makers, advocating for legislative reform, speaking at a national conference, or meeting with White House officials about reorienting national policy. In each situation, he works closely with other formerly incarcerated leaders.

Dorsey Nunn is far from unique. He is part of a much larger group of women and men who have weathered the challenges of incarceration and become leaders determined to change the system and rebuild their communities. His story illustrates the key ingredients of what makes this group of people who have experienced prison effective leaders. 
The importance of building this leadership is receiving growing recognition. In just the last few years, organizations ranging from the Vera Institute to the Ford Foundation to the Department of Homeland Security to the US Department of Justice have created roles and policies that put those closest to the problem of mass incarceration in positions to shape national criminal justice and education policy. Despite growing recognition of the importance of leadership by those directly affected by mass incarceration, however, there has been limited systematic inquiry into what "leaders with conviction" bring to the table and how they enable change.

This report begins to fill this gap in research and public understanding by documenting the roles of 48 formerly incarcerated leaders engaged in work related to reducing incarceration and rebuilding communities. It draws on in-depth interviews conducted over a period of fourteen months, along with five interviews with prominent policy makers who have worked closely with formerly incarcerated leaders, as well as reports, videos, and articles by and about the leaders and scholarship on mass incarceration, leadership, and systems change.

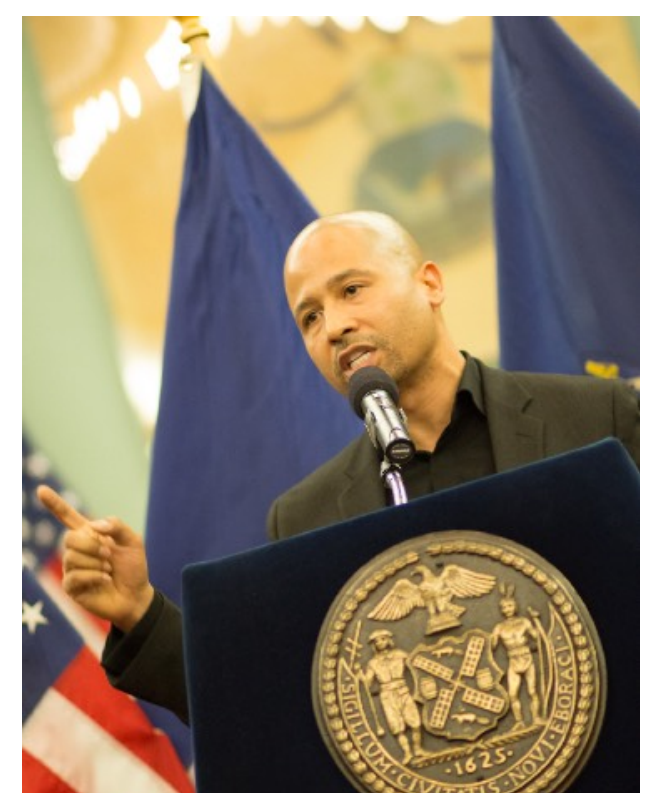

JustLeadershipUSA Founder \& President Glenn E. Martin speaks at NY City Council's "Let Freedom Ring" Awards Ceremony, February 2017

The report grew out of a conversation between Glenn Martin, the founder and President of JustLeadershipUSA ("JLUSA") and Susan Sturm, the Director of the Center for Institutional and Social Change at Columbia Law School ("CISC") in 2014. Martin's long-standing commitment to leadership by people directly affected by the criminal justice system began while he was in prison. His first foray into advocacy occurred while he was on the Inmate Liaison Committee in prison and got himself in trouble with corrections officers by populating the Committee with college graduates and calling out correctional staff who deviated from the prison Memorandums and Directives.

After leaving prison, Martin spent four years learning more about how the criminal justice system operates, where it emerged from, how it grew, and how it became what it is today. He served as a legal assistant at the Legal Action Center, where he advocated for individuals with criminal convictions, drafted educational materials, and provided technical assistance. He rose to the position of Co-Director of Legal Action Center's National H.I.R.E network; 5 in that position he advanced major legislation to remove barriers to employment in six states and successfully advocated for US EEOC Guidance on Arrest and Criminal Convictions. He then moved to the Fortune Society, where he served as the Vice President of Development and Public Affairs, and created and directed the David Rothenberg Center for Public Policy ("DRCPP”). While in those

\footnotetext{
${ }^{5}$ Established by the Legal Action Center, the national Helping Individuals with criminal records Re-enter through Employment (HIRE) Network is both a national clearinghouse for information and an advocate for policy change.
} 
roles, Martin had the benefit of leadership training that honed his capacity to communicate effectively to diverse audiences, cultivate leadership in others, grow an organization, operate effectively in national policy arenas, and be reflective about his leadership.

Martin's personal experience with effective leadership development, along with his growing sense of urgency about the importance of building a movement that goes beyond incremental change and is led by people who have been through criminal justice system, compelled him to start JLUSA.

JLUSA seeks to use the experience, wisdom and commitment of "leaders with conviction" to develop new and transformative ways of reducing mass incarceration, changing the public narrative, and rebuilding communities. The organization identifies and trains formerly incarcerated leaders to advance the goal of cutting America's correctional population in half by 2030. JLUSA is one of a group of organizations, led by individuals who are formerly incarcerated, at the forefront of this movement to decarcerate and transform the criminal justice system. ${ }^{6}$

Martin has built three long-standing principles into the design of JLUSA, forged from his decades of involvement with the criminal justice system: (1) the need to transform a fundamentally broken criminal justice system in the United States, (2) the importance of an affirmative vision of a just system as the driving force for change, and (3) the idea, now core to JLUSA's mission, that "those closest to the problem are closest to the solution."

Given JLUSA's commitment to cultivating leaders with conviction, Martin wanted to better understand the roles formerly incarcerated leaders actually play in advancing change, what can enable them to play that role, and the impact of their participation. He raised this question with Susan Sturm, who for years had been researching the role of education in transforming lives and communities affected by the criminal justice system, as well as the impact of leadership by directly affected communities. Martin and Sturm had worked together closely on Building Pathways of Possibility, a collaborative conference that brought formerly incarcerated leaders together with policy makers to shift public policy from incarceration to education. Sturm has conducted multi-method research and published reports exploring the role of people directly affected by incarceration-and the organizations and networks they lead-as agents of transformative change (Sturm, Skolnick \& Wu, 2013; Sturm and Nixon, 2015; Nixon and Sturm, 2015).

Together, Sturm and Martin set out to document the pathways and strategies of formerly incarcerated individuals who occupy leadership positions and are working on mass

\footnotetext{
${ }^{6}$ Appendix B of this report provides the names and bios of the JLUSA fellows who have completed the training.
} 
incarceration and community revitalization. ${ }^{7}$ They were interested in understanding: (1) how individuals who have experienced incarceration became leaders, (2) whether they share particular roles, strategies, or strengths related to their experiences with the criminal justice system, (3) what kinds of changes resulted from their leadership, and (4) how policies and practices enable people to exercise their roles as leaders with conviction in ways that enhance their impact.

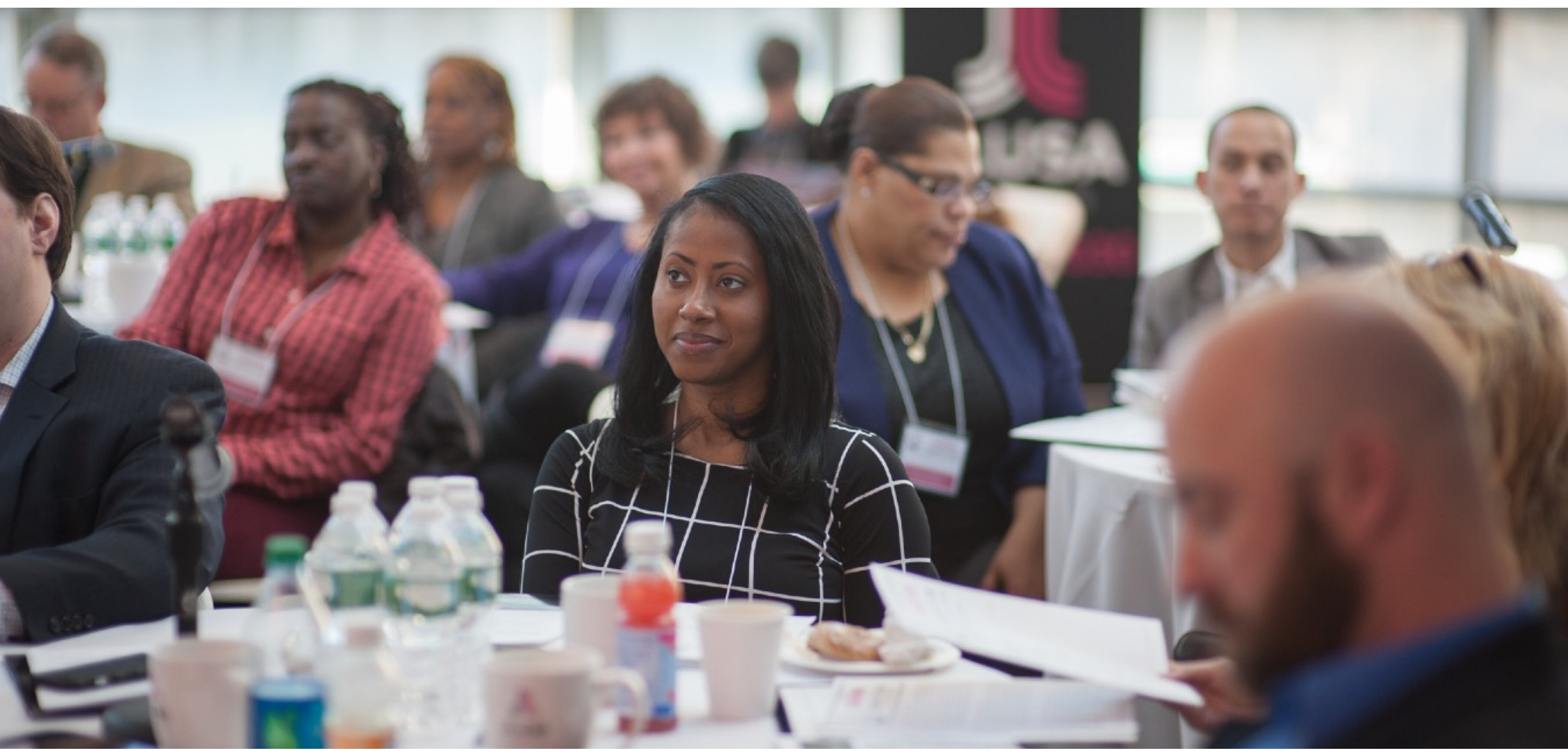

2015 Leading with Conviction Alumna Jamira Burley at the first LwC2015 training forum, January 2015.

This group of formerly incarcerated leaders has features that equip them to serve as organizational catalysts. Organizational catalysts are people with knowledge, influence, and credibility who are in a position to mobilize change (Sturm, 2006).

leaders to serve as organizational catalysts. Organizational catalysts are people with

For purposes of selecting individuals to participate in the study, leadership was defined to include individuals who occupy positions where they are involved in advancing change related to the issue of mass incarceration that goes beyond improving the lives of individuals they directly serve, and who reached these positions after having been incarcerated and going through a process that enabled them to assume their leadership position.

Analysis of these interviews has identified a set of features that equip this group of formerly incarcerated

\footnotetext{
${ }^{7}$ Martin participated in framing the study, developing the research questions and methodology, piloting the interview protocol, and identifying potential study participants. Sturm supervised the research, conducted the data analysis, and wrote the report, with the assistance of Haran Tae. A description of the methodology is provided in Appendix A.
} 
knowledge, influence, and credibility who are in a position to mobilize change (Sturm, 2006). They operate at the intersection of communities and systems that do not usually interact, and bring a track record of commitment and the ability to communicate across different backgrounds and cultures. They can transform organizations and networks by (1) mobilizing varied forms of knowledge to promote change, (2) developing collaborations in strategic locations, (3) cultivating new organizational catalysts, and (4) maintaining pressure and support for action.

The research identifies patterns cutting across the interviews that make them into organizational catalysts. They have a unique combination of information and insight that comes

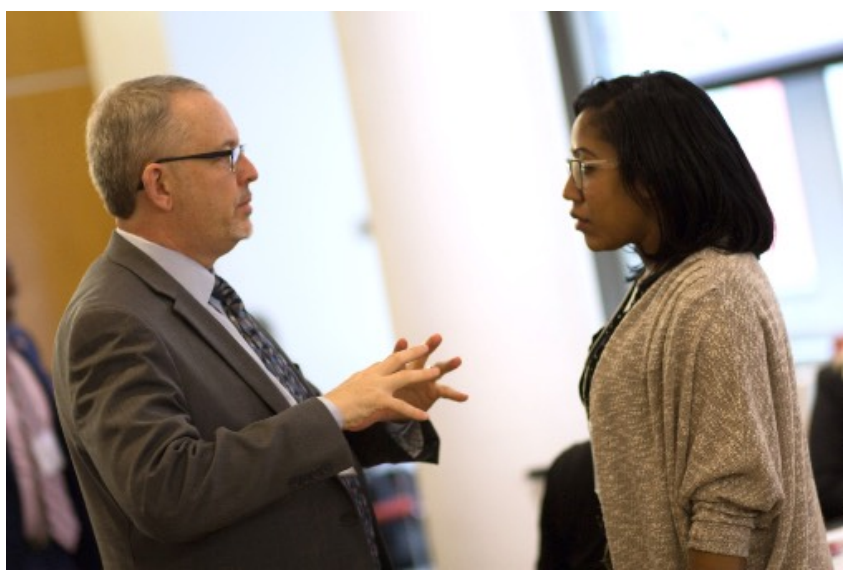

LwC2015 Cohort Fellow Steve Gordon speaks with LwC2017 Cohort Fellow, Shae Harris, January 2017 from their experiences with the criminal justice system, post-secondary education, and boundary-spanning positions. This combination enables formerly incarcerated leaders to do something quite unusual. Many of them have developed the literacy and legitimacy needed to link worlds that often remain separate. Their leadership remains deeply rooted in communities affected by incarceration, even as they branch out to hold positions affording them access to resources and power. They have developed an unusual mix of relationships and resources, which scholars call social capital. They remain bonded to a community affected by incarceration, while they also develop ties through their education, employment, and activism that enable them to serve as bridges between these different worlds. Their growing connections to the policy world enable them to build a movement among people with shared interests, and link that movement to people in positions to reshape public policy.

This Report provides a window into the insights, roles, and impact of leaders with conviction in promoting positive change. Section II introduces the key elements comprising the leaders' roles as organizational catalysts. Section III examines the insights developed through first-hand experience. Section IV explores the role of education, particularly post-secondary education, in building their leadership. Section $V$ discusses the leaders' boundary-spanning employment and activism. Section VI describes the resulting capacity to communicate and earn legitimacy with multiple constituencies. Section VII ties the previous sections together, providing an analysis of the leaders' position as brokers with bonding, bridging, and linking social capital. Section VIII summarizes features of the environment that foster the development of formerly incarcerated leaders. Section IX concludes and offers recommendations. 


\section{Leaders with Conviction as Organizational Catalysts: Introducing their Alchemy of Experience, Education, and Employment}

Like the leaders described in the introduction, Abrigal Forrester has taken many journeys in his course of his life: from being a straight-A schoolboy, to dealing drugs, to going to prison, to graduating from college, to running a community development agency, to attending White House convenings as an advocate for criminal justice reform. This combination-experience with incarceration and the injustices that propel certain populations into the criminal justice system, education, and boundary-spanning employment and activism -is what makes him such a highly effective organizational catalyst.

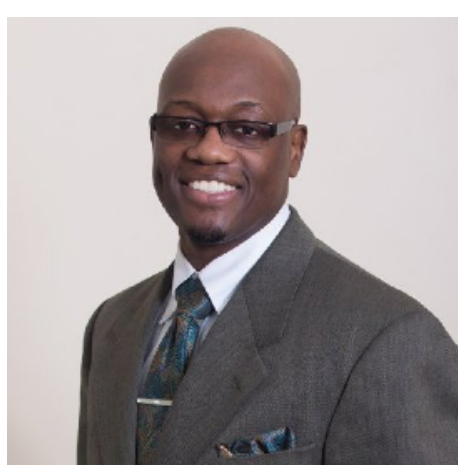

Abrigal Forrester

Forrester's childhood experiences sensitized him to the turning points that can orient young people toward prison. Forrester grew up as a black boy in a poor, racially segregated community in Dorchester, Massachusetts, which sat on a divide between a mostly Irish and Caucasian neighborhood and one that was mostly black. His father had left his family when Forrester was five. From first to fifth grade, he was an A student, and also excelled in tennis. On his way to and from school, he had to run a gauntlet of racial attacks from white people opposed to school integration.

Forrester's relationship to school changed after he entered sixth grade at one of the toughest middle schools in the city. He then tested into a magnet school for high achievers, where he enrolled in seventh grade. In part out of rebellion against his father, he did no work, acted out, and was kicked out after one year. In eighth grade he returned to the middle school closer to his neighborhood, where the social threats he experienced came mostly from peers who fought over

Forrester learned first-hand about the experience of prison-the sense of injustice born of an unduly long sentence for a first offense, the fear of death, and the personal reflection that ultimately launched him on the path toward leadership. sneakers, jackets, and social status. Forrester moved from sixth to ninth grade without doing any work or receiving any academic or social support. He hit his teen years during the height of the crime and drug wave of the late 1980s and early 1990s. His high school experience was no different, and he was ultimately pushed out of high school; he was educated on the streets by older peers who guided him into the drug world. He began trafficking, and was arrested for selling cocaine to an undercover agent.

Forrester's first offense came with a mandatory 10-year sentence. He thus began a new chapter learning first-hand about the experience of prison-the sense of injustice born of an unduly long sentence for a first offense, the fear of death, and the personal reflection that ultimately 
launched him on the path toward leadership. He asked himself, "How does that young person who was an A student in elementary school end up with ten years of incarceration in his 20's?" He realized the impact of the traumatic events in his own life that he never had the opportunity to process, as well as the systemic factors that tracked so many people like him into the justice system. He found a handful of teachers, corrections officials, and peers who were willing to invest in his success. He discovered ways that relationships and communities of support could enable him to translate trauma and struggle into qualities that equipped him to persevere and become a leader.

Along with his journey through the criminal justice system, Forrester pursued higher education. Before going to prison, Forrester had obtained his high school equivalency diploma from a community based organization. After prison, he immediately enrolled in community college, which he pursued while working full time. He obtained his Associate's degree, and went on to earn a Bachelor's Degree in Psychology. He also completed a program on non-profit management and leadership. His education enabled him to hone his communication skills, become more comfortable in policy and academic settings, and learn theory that amplified the knowledge he developed through his personal experience. At

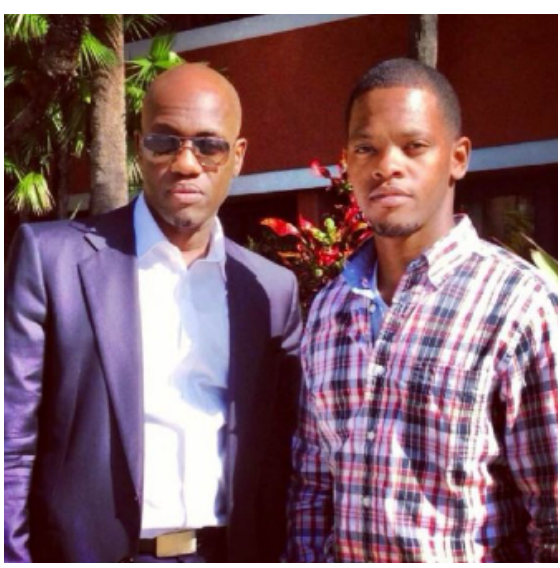

Abrigal Forrester \& James Mackey, a graduate of YouthBuild Columbus.

the same time, he observed how "textbook approaches" to reentry taught in many of these programs differed from those informed by "a lot of unwritten behavioral, psychological things that many people didn't understand."

Forrester brought these two arenas of learning together in the process of accumulating experience as a change agent seeking to change the criminal justice and reentry ecosystem, while also making a difference in the lives of people who go through those systems. After a short and successful stint as a janitor at MIT, a referral by a friend from prison enabled Forrester to land a position as a placement specialist and trainer for STRIVE, an organization that connects justice-involved individuals with jobs and resources they need to rebuild their lives. The executive director who hired him for the job was the first to tell Forrester that his knowledge and skills made him an expert, and that he had special gifts in developing training, mentoring, and curriculum design. Forrester found himself drawing on his experience growing up, as well as his education. He became STRIVE's lead trainer and earned a reputation for successfully transforming his own life, as well as for effective gang intervention. Community based organizations as well as corrections agencies brought him on as a consultant to develop and implement transition programs both in the community and inside corrections facilities.

As he gained more experience and legitimacy, Forrester assumed positions with greater opportunity to influence policy, all the while remaining involved in mentoring younger women and men on the pathway from prison to public life. He was promoted to various leadership 
The leaders with conviction share three important characteristics: (1) first-hand experience with the criminal legal system, (2) education that legitimizes and enhances their knowledge and leadership capacity, and (3) jobs and activist positions placing them at the intersection of different communities and systems. positions, which included working first with local and state policy and then adding national advocacy initiatives involving opportunity youth. As part of that work, he met with the leadership of the Department of Justice and the Department of Education, including then-Secretary of Education Arne Duncan, He served as the Director of Criminal Justice Initiatives for Youth Build, and is now the Director of Community Action in a community development organization that builds affordable housing. In that role, he operates as a hub of collaborative partners invested in community action initiatives that build youth leadership, workforce development, and educational success. He remains

deeply involved in the lives of people in the community, and recently went back to his first high school, from which he'd been kicked out in 1985, to share his story.

In taking this journey through disparate worlds, Abrigal Forrester has become an organizational catalyst. Forrester's trajectory is far from unique among the leaders we interviewed. They share three important characteristics: (1) first-hand experience with the criminal legal system, (2) education that legitimizes and enhances their knowledge and leadership capacity, and (3) jobs and activist positions placing them at the intersection of different communities and systems. The next three sections explore these characteristics in-depth, showing how each ingredient contributes to formerly incarcerated leaders' development into organizational catalysts.

\section{Ground Truth: First-hand Experience with the Criminal Justice System}

All of the people we interviewed have been in the custody of the criminal legal system. They have all experienced the judicial system and incarceration, and many of them have served time in different types of prisons and jails. They have interacted with an array of responsible personnel along the way, including police, bail officials, prosecutors, defense lawyers, judges, probation officers, correctional officers, parole officers, social workers, and other government personnel. They carry with them not only their own experience of prison, but also those of the people who served time with them.
The leaders spoke repeatedly of inhumane conditions and practices they witnessed in prison, and of uncaring and apathetic actors who allow these conditions to persist. The emotional impact of enduring these conditions produced a sense of urgency about sharing this information with people in a position to change them, as well as with the broader public. 
Although we did not specifically inquire as to the nature of the leaders' convictions, most referenced or discussed the crimes leading to their incarceration in talking about their experiences with the criminal legal system. They had been incarcerated for everything from white-collar crimes and drug offenses to armed robbery and homicide. For some, their incarceration was a singular and relatively confined (albeit hugely transformative) event in their life's timeline, while for others, incarceration was a recurring cycle they broke, after much reflection and intentional change. Some served relatively short prison sentences; others had spent decades behind bars.

These experiences provide these leaders with direct knowledge about the operation of the criminal legal system, how people move into and through that system, and the cumulative impact of their interactions with many other systems such as education, social welfare, public housing, and health care. For the leaders individually and collectively, this experience builds a reservoir of ground truth-personal knowledge of how these systems actually function, interact, fail, and change. This ground truth is one of the building blocks of the organizational catalyst role. This section describes four capacities that result from this unique position: (1) narrating the unseen, (2) connecting the dots, (3) mapping the recovery process, and (4) building racial literacy.

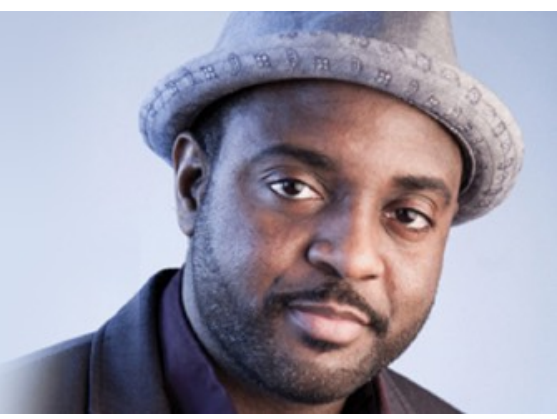

"All around us, there are men and women made invisible, their spirits wiped out by policies that we don't notice." - Reginald Dwayne Betts, Yale Law School, class of 2016.

\section{A. Narrating the Unseen}

Leaders with conviction provide detailed knowledge of conditions and practices that remain invisible to outsiders. The inner workings of the criminal justice system frequently occur behind closed doors. Many of those who work in the system have strong incentives not to disclose problematic dynamics. The leaders spoke repeatedly of inhumane conditions and practices they witnessed in prison, and of uncaring and apathetic actors who allow these conditions to persist. The emotional impact of enduring these conditions reverberated throughout the

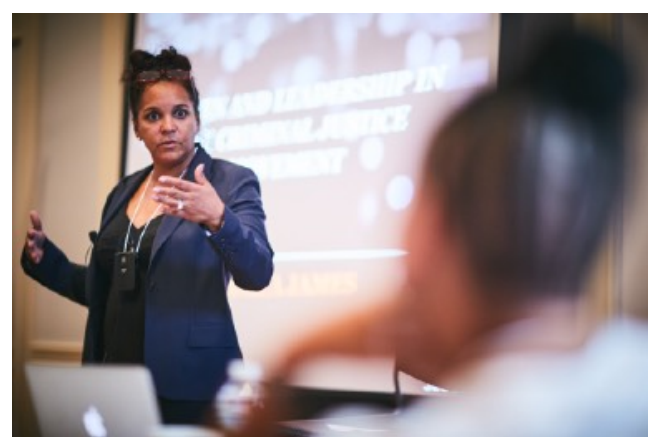

Andrea James, Founder and Executive Director, Families For Justice As Healing and the National Council For Incarcerated and Formerly Incarcerated Women and Girls interviews, and produced a sense of urgency about sharing this information with people in a position to change them, as well as with the broader public.

Person after person spoke passionately about the brutality and dysfunction of the system, and its dehumanizing and degrading impact. Andrea James-who is now organizing a national 
network of formerly incarcerated women aimed at expanding awareness of how prison and jail impact women, their children, and their communities--described the failure of the women's prison where she was incarcerated to meet minimal sanitation standards and its violation of basic norms of human decency:

I immediately from day one looked around and saw a list of things that were just horrific injustices, from leaving sanitary pads on the floor, like the women were animals, to mice to no soap, which to me was just, "Are you kidding me?" Everybody needs to wash their hands after using the restroom, but we're women on top of it. The toilets were constantly backing up. So every morning after a certain hour, the stench from the toilets overwhelmed the septic system. I knew that there were things that were not fair, that they should not be price-gouging incarcerated people to use a telephone, that the prison shouldn't be getting a kickback for it ... So there were those kinds of just basic human dignity things. I wasn't going to stand for it. I didn't want to be treated like that. You don't treat human beings like this.

James also observed a "sea of black women" in prison--separated from their children from the time of their arrest, some not even knowing where their children were, and locked in prison for decades without family visitation. The pervasiveness of this tragedy conveyed a lack of collective concern about the impact of these practices on women and their families.

\section{URGENT CARE REQUESTS MAP}

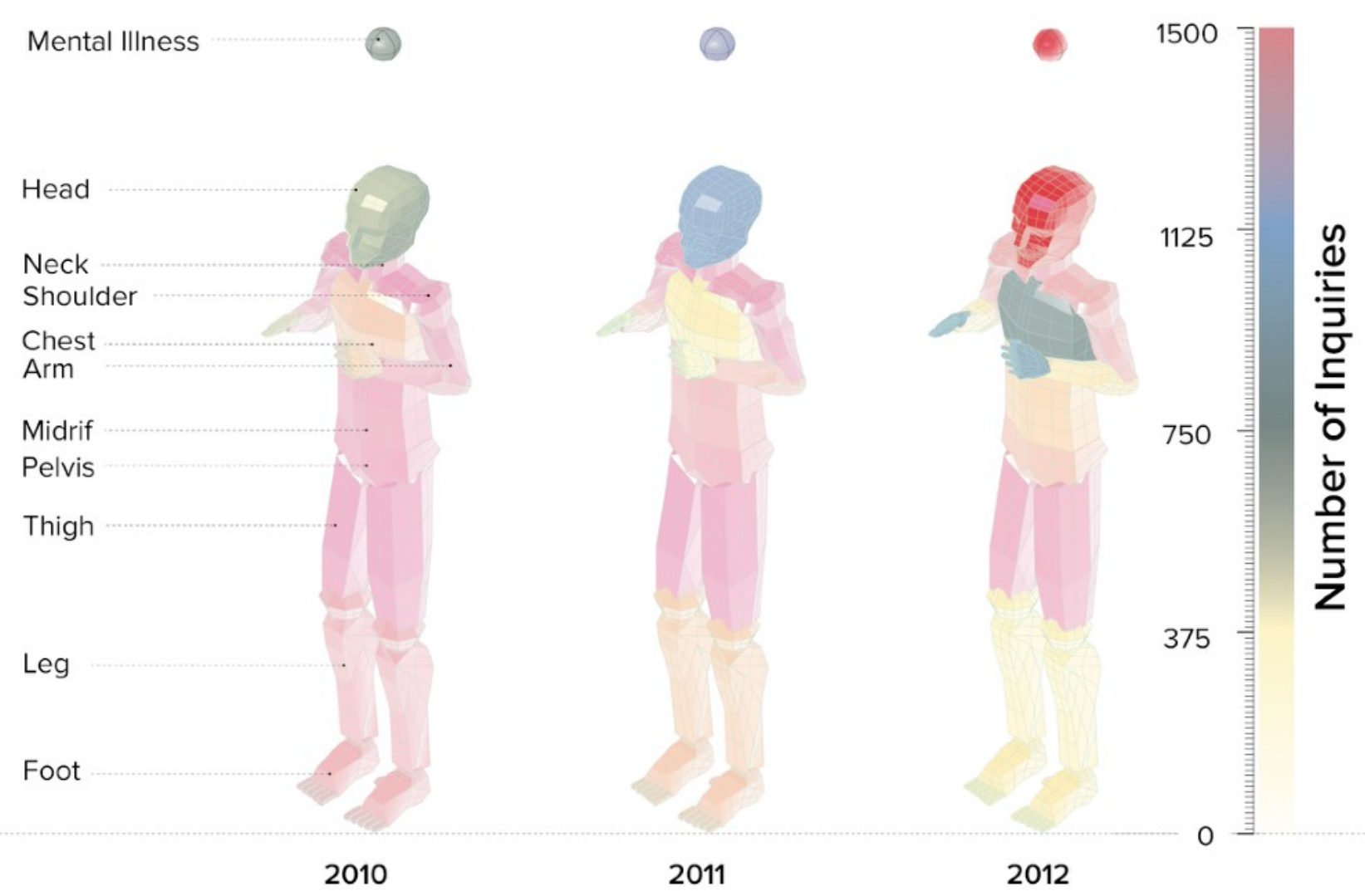

Visual depiction of injuries leading to urgent care requests, mapped by parts of the body experiencing injury.

From Body Scape by Nishant Chacko Jacob (2016). (p. 5) 
The leaders vividly described the hidden, and often difficult-to-prove, arbitrariness that characterizes the workings of America's criminal justice system. One leader recounted how he'd benefited from a personal relationship between his lawyer and the judge, which led to a more lenient sentence than others who had committed a similar crime. This experience showed him how people's fates are being determined by "who you know and how you can manipulate and work the system rather than having anything to do with actual justice."

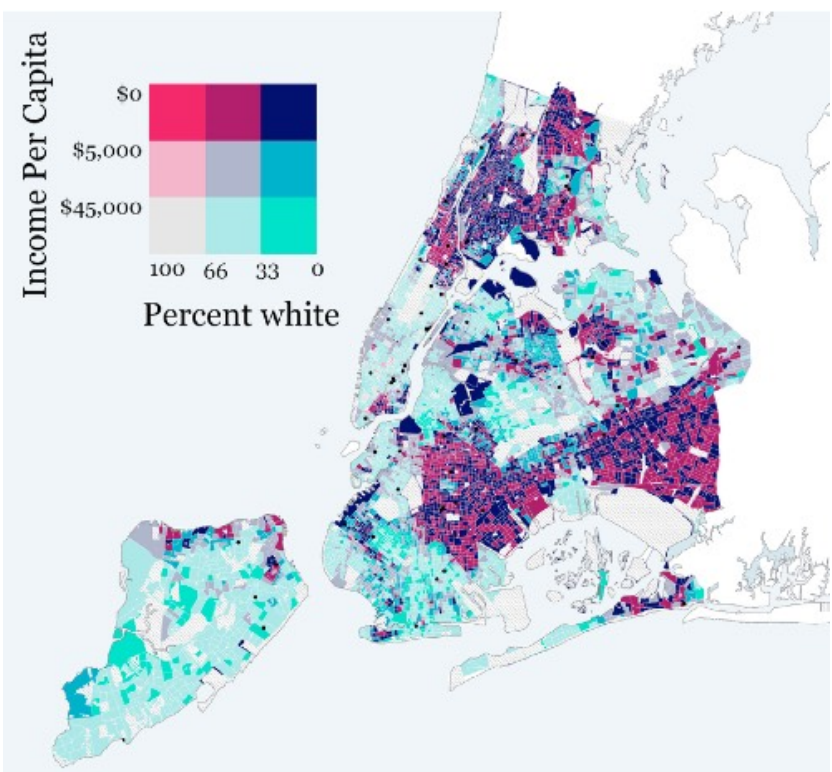

Stella loannidou, Reorienting New York: Explicating Injustices in the Third City, showing residential segregation and relationship between race and income.

These first-hand accounts shed light on the unseen ways in which money, or the lack thereof, shapes the experience of the criminal legal system. People with money were able to get better treatment, better representation, and shorter sentences. Many also spoke of exorbitant prison phone call rates and arbitrary restrictions on visitation, which discourage and even prevent family members from maintaining regular communication with their incarcerated relatives. When these critical relationships deteriorate, people reentering the community already stymied by inadequate job and life skills, and the stigma of incarceration - find reintegration even more difficult.

Some leaders detailed the operation of corruption, illegality, and brutality, along with retaliation in response to attempts to bring these conditions to light. This personal experience of systemic injustice made the individuals question the legitimacy of the system, and for many, forged them into leaders willing to challenge the system.

Everyone interviewed had direct experience with the array of barriers facing people when they leave prison, and the lifetime punishment that affects those with criminal records. Almost everyone interviewed was required to disclose their criminal record in an application process, and this process undermined their ability to obtain jobs, licenses, education, housing, public benefits, or some other opportunity that they needed to rebuild their lives and families. One leader described this widely shared experience of having to "check the box":

I did struggle with answering that question on the job application, and I had some horrible experiences ranging from people who just chucked my application in the garbage because I answered the question, to people who called me in for an interview even though I had checked the box on the application, but then proceeded to ask me really humiliating questions and it was just really a hard experience. 
The leaders drew on their own experiences to show the impact of these arbitrary and inhumane conditions on people's lives and to build understanding of the need for institutional and policy change, shaped by the insights of people closest to these problems.

\section{B. Connecting the Dots: Understanding the Pathway into the Justice System}

A second aspect of the leaders' ground truth involves their understanding of how different systems (such as the criminal legal system, the education system, the health care system, and the public benefits system) interact in ways that increase the likelihood of incarceration. Their experience moving through these different systems gives them a unique understanding of how these negative synergies affect individuals, and how policies contribute to that dynamic.

\section{Lifetime Likelihood of Imprisonment of U.S. Residents Born in 2001}

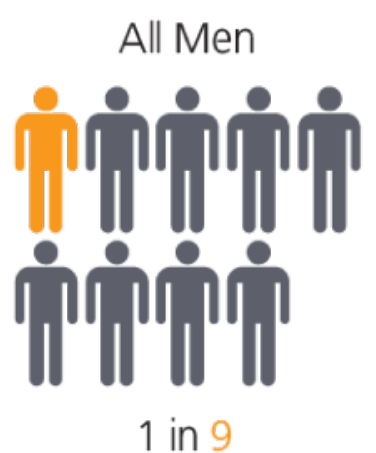

All Women

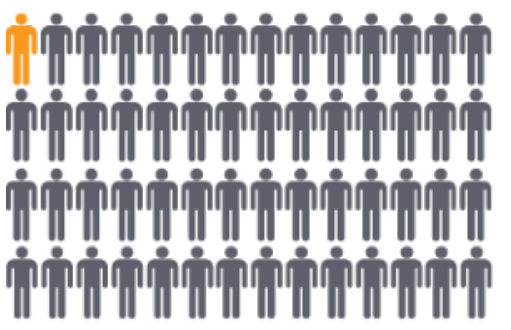

1 in 56

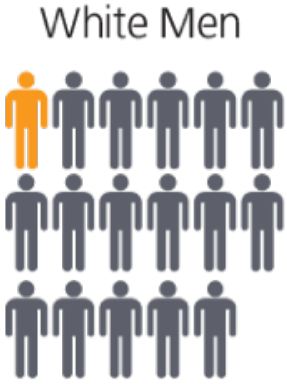

1 in 17

White Women

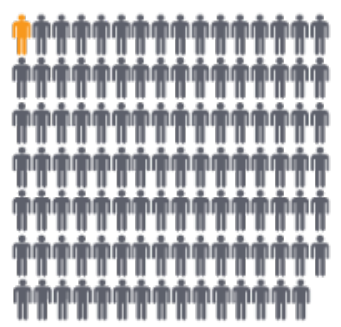

1 in 111

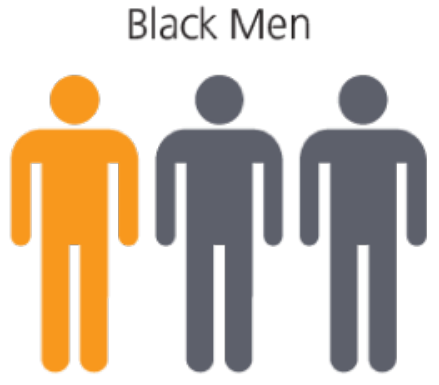

1 in 3

Black Women

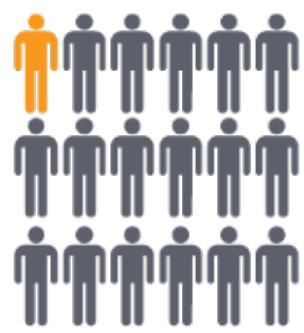

1 in 18

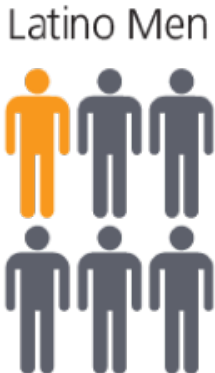

1 in 6

Latina Women

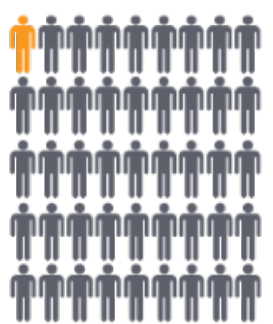

1 in 45

Source: Bonczar, T. (2003). Prevalence of Imprisonment in the U.S. Population, 1974-2001. Washington, DC: Bureau of Justice Statistics.

THE SENTENCING PROJECT

Many of the leaders grew up in poor communities that lacked adequate housing, education, health care, and support for youth experiencing trauma. About half of the leaders went to schools that ultimately pushed them into the streets and on the pathway to prison. Like Abrigal Forrester, many recalled the experience of being good students in elementary school, only to be thrown off course by interactions at school or in the community that discouraged or prevented them from continuing their education. As one leader put it, "I will never forget that being a smart black male in the public school wasn't something that was ever promoted." 
The leaders' moving through different systems (such as the criminal legal system, the education system, the health care system, and the public benefits system) gives them a unique understanding of how these negative synergies affect individuals, and how policies contribute to that dynamic.
Another leader, who "ended up with two Associate's degrees, a Bachelor's degree, and a Master's degree, and was class valedictorian" recalled being "kicked out of every school I ever went to."

Most of the people of color we interviewed described racially charged interactions with police, particularly when they were adolescents. They experienced being over-policed and underserved. Rather than serving as pillars of their success, the public institutions they encountered-schools, police, social service agencies, and courts-often left them worse off.

The traumas they experienced, often left unattended, took many forms. Some of those interviewed described earlier involvement with gangs, or having a drug or alcohol addiction that contributed to their incarceration. Many experienced the death of a family member or friend. Some discussed sexual or domestic violence at an early age; some recalled bouncing from home to home in a foster care system that failed to provide continuity of care and simply dropped them when they aged out.

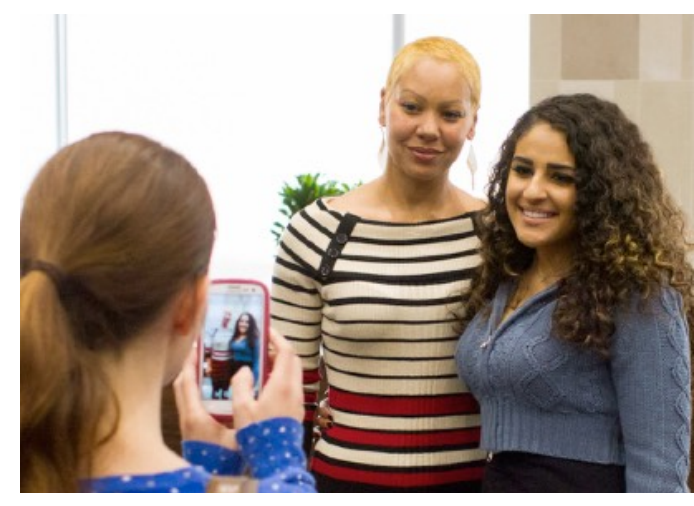

Sara Kruzan poses for a photo with participants of her human sex trafficking seminar
Some of the leaders drew on their past experiences to shed light on the pathway that leads young people experiencing trauma into criminal activity. Sara Kruzan's experience is a case in point. Kruzan grew up in poverty, living on public assistance in a neighborhood with a mother who had bipolar disorder. Her mother started abusing her when she was very young. She started out in school as a very strong student and leader. As the abuse increased, she tried to get help, but was ineligible for mental health services due to limitations placed on MediCal recipients. Despite a dramatic decline in her academic performance, no one at her school intervened. Faced with continuing abuse, she found it difficult to sustain her engagement in school.

At the age of 11, Kruzan was sexually molested, and
Kruzan has come to understand the importance of interpreting the choices of young people who have experienced trauma through the lens of the evolving situations they face - the limited options, immature brain development, and ongoing abuse that shaped her own decision making. She has also learned to identify and communicate about the many missed opportunities to intervene, and the policy environment and incentives that often discourage people from doing so. 
experiences of limited options that forced them to make desperate decisions that put them at risk: "Do I eat, do I feed my kids or do I feed my addiction; do I pay my rent or do I pay my car note?" They described getting entangled with numerous public agencies-the prison system, the welfare system, the foster care system, the health care system, and other systems of social control-that imposed piecemeal and conflicting requirements.
The leaders described the harm they experienced as a result of the failure of lawyers, judges, social workers, and other gatekeepers to connect the dots across systems.

The leaders also described the harm they experienced as a result of the failure of lawyers, judges, social workers, and other gatekeepers to connect the dots across systems.

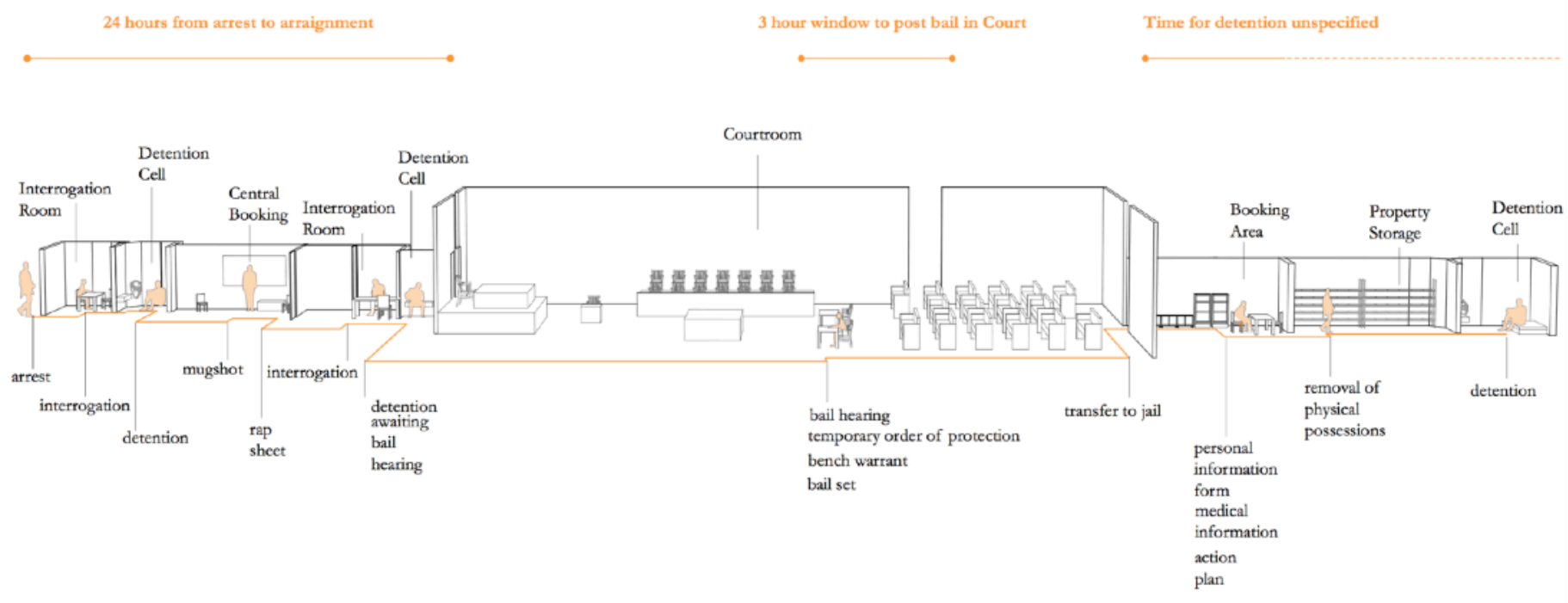

A study by Clara Dykstra as part of \#CLOSErikers Architectural Studio led by Laura Kurgan at Columbia University, documenting a 3 hour window for posting bail, en route from arrest to Rikers Island.

One leader learned about the immigration consequences of his felony conviction only when he faced deportation years later. Many leaders faced unanticipated limitations on housing, employment, and public benefits. A leader, who spent three years awaiting trial, observed a pattern of people accepting plea bargains with a felony conviction and long probation terms, never having been informed that they would be susceptible to re-incarceration for relatively minor actions during their long period of probation supervision, as well as to the ongoing discrimination associated with a felony conviction:

They put you on probation first and some lawyer will tell you this is how it is and you go home. They don't tell you all the rights that you're going to lose, all the employment discrimination, the housing discrimination and everything else. Nor will they tell you about the rights you're going to lose the next time a cop pulls you over. So you sign it and you get say three years' probation and 18 months goes along and you're 19 years old; they scoop you up for whatever, they smell weed. And no, you have no more rights. Now all the 
evidence gets in and now the standard for you staying out of prison isn't whether you're guilty beyond a reasonable doubt. The standard is: are they reasonably satisfied you failed to keep the peace or keep the terms of your probation, which may just be like hanging out with nefarious characters.

Going through the criminal justice process may be the only way to see how multiple systems actually converge in the lives of individuals and create arbitrary barriers for people experiencing reentry. The leaders had done just that.

\section{Understanding What Enables Personal Transformation}

The leaders we interviewed all had to figure out what it would take to change course, recover from the traumas they experienced, and move toward a productive and meaningful life. Each described going through a process of struggle, reflection, and renewal. Many of them identified crucial turning points; they described interventions that enabled them to believe in the possibility of their own transformation, and that fostered the resilience to persist in the face of barriers and setbacks. That insight also became a part of their ground truth.

Many leaders described the transformation of their identity (for example, from formerly incarcerated to student to leader) as they grew into leadership roles. They have also shepherded others through a similar process. One leader described the process that forged her resilience and transformation:

\section{I'm always pulling from a situation that I} experienced while incarcerated or prior to going to prison or trying to remember what was it that got me to push through. Was it curiosity, was it determination, was it anger? Because it wasn't one specific feeling at one time. People who are incarcerated are no different than those who are not incarcerated. For people who are athletes, where do they pull their strength from? Where do they get their determination from or their motivation to succeed or to win? So the principle for those who are incarcerated-the outcome might be different, but the ability to pull and try to find it and identify with it is still universal.

\section{Experience also taught the leaders the} importance of peers as a force for transformation both in and after prison, one that helped people overcome their skepticism about change and take themselves seriously as leaders.
Many leaders described the transformation of their identity (for example, from formerly incarcerated to student to leader) as they grew into leadership roles. They have also shepherded others through a similar process.
The leaders also described the dynamics that had prevented them from taking advantage of resources that could have assisted them in the past. They communicated the sense of futility and hopelessness about the future that pervaded their community and that had discouraged them from taking advantage of the opportunities and resources that were offered. Until those opportunities appeared real and within reach, the 
leaders themselves had not taken them seriously. For example, one leader dismissed college as an option when he was younger because he did not see any college graduates in his community. He did not believe that he would even be alive the next year; college seemed like a distant world that had nothing to do with him. He observed a more general pattern that people without hope that they will have a future are not inclined to seize on offers such as college scholarships.

Experience also taught the leaders the importance of peers as a force for transformation both in and after prison, one that helped people overcome their skepticism about change and take themselves seriously as leaders:

When I was incarcerated, there were men who I connected with, who connected with me, who saw things in me, just like people who see things in me on this side in the sense of my professional development. Who saw things, who saw values, who saw potential in me, who had expectations of me, before I even knew myself.

One individual described his relationship with an older incarcerated person who helped him recognize his leadership ability and encouraged him to use that leadership to change people's lives for the better:

He said, "I want to talk to you as if you're my son. You're bright, intelligent, and I don't know if you know this but when you talk people listen. When you stand up to say something, your gang members, they listen." He said, "Most of the time you're not saying anything, but people listen to whatever you've got to say." And he said, "I think you should find something to help change people's lives and something to help you to turn your life around because people listen to you." And every day he would see me on the compound he would ask, "What have you learned?" Or tell me something to help me change my life.

Along the same lines, another leader described a pivotal interaction with a fellow incarcerated person:

He once told me, "You can talk about prison for the rest of your life and make a living doing it and actually do something good in the world." And he was like, "Most people have to search for what it is that they want to do and most people don't even have a shot at doing good in the world." And he was like, "Yo, you can do this." And so he had a huge influence on me.

Experts who had extensive experience cultivating the leadership of people who have spent time in prison have observed that the capacities enabling people to transcend trauma also equip them with the resilience necessary for transformative leadership. Piper Anderson,

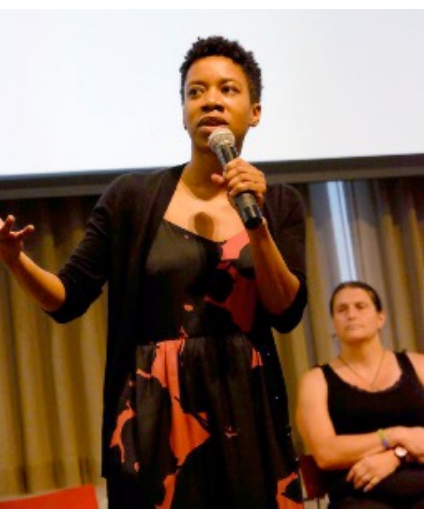

Piper Anderson, a professor at NYU's Gallatin School and consultant to JLUSA 
a professor at NYU's Gallatin School with extensive experience in prisons and communities, drew a connection:

What I heard again and again is having a really clear and tangible vision of what you want to create is what allows you to transcend the trauma that you have experienced. You can move into different experiences, empathize with people, and listen. Going into different spaces requires a level of risk taking, but because these leaders are connected to the larger purpose, they can do that. Anyone who has survived anything knows the importance of being adaptable. That is a lot of what the leaders demonstrate again and again.

David Mensah, a trainer and coach with extensive leadership development experience and the senior training consultant for JLUSA, also observed that the capacity for transformative leadership and the commitment to personal transformation was evident in leaders with conviction.

The leaders' own experience of turning their lives around has thus provided them with ground truth about how to support others facing similar challenges. They have insight about policies and practices that could enable people who have never had a first chance to have a meaningful second chance to realize their own potential for success.

\section{Building Racial Literacy}

Finally, many interviewees demonstrated an unusually nuanced and systematic understanding of race and its relationship to mass incarceration and structural inequality. People who self-identified as black or Latino experienced school and residential segregation, as well as racially tinged interactions with teachers and police beginning at an early age. Prison served as the space where many first connected their personal experience of marginalization with a larger systemic and historical analysis. This connection yielded insights about the structural dimensions of

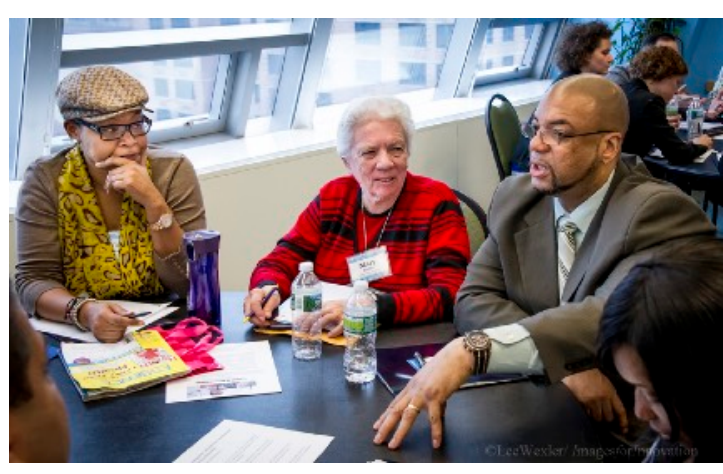

Stanley Richards, Senior Vice President of Fortune Society, speaks with attendees of the New York Reentry Education Network's Pathways of Possibility Conference, February 2013 discrimination, which prompted many leaders to name, discuss, and mobilize to change these underlying patterns:

I ended up doing eight years and through that process I started really getting into black people's history. When I mean black people, I mean a broad term of black peopleDominican people, Puerto Rican people, people in Africa, people in Asia-and just when I started to understand colonialism, it sparked a new way of seeing the world. And I understood the world that I'm living in and then what I witnessed personally growing up in my neighborhood and what I saw my mother goes through and the people around me go through; I understood that we were put in a really bad position and that we're not fighting each other even though on a micro level we may think it's between each other. I'm starting 
to understand different ways of having that kind of vision to see what's going on, and then I'm trying to use some of the skills that I learned from my block and from having conversations with other brilliant people around the world to make certain kinds of changes.

While in prison, many of the leaders lived in close proximity to people from very different backgrounds, races, and identities, and interacted under conditions of relative equality. For people of color who grew up in middle-class neighborhoods, the experience of prison transformed a more intellectual knowledge of racial disparities into a visceral and deep understanding:

I walked into the prison and it was overwhelming just to see the sea of black and Latina women who were serving these really unconscionably long sentences and it just broke my heart. I knew all this stuff both professionally and personally, but it wasn't until I actually walked into that federal prison myself as an incarcerated woman and lived there for two years that I really began to understand the magnitude of what the war on drugs and the war on poverty, criminalizing poverty and addiction has done in this country.

White individuals who spent time in prison also reported being transformed by seeing the impact of race discrimination on the life prospects of people of color they met in prison, as well as by the unfairness of the policies contributing to those disparities:

One of the things about going to prison is, older middle-class guys like me rarely have occasion to become really friendly with gang kids, I mean kids that were selling dope. I had a good friend there that was in prison for 12 years for selling cocaine. It became real clear to me what an outrage the drug war was. I thought it was a bad idea, but I didn't understand subjectively its costs. And l've got to change that, eliminate it if we're going to address this massive issue. But being first-hand, I got to be buddies with a lot of these guys, and there are a couple of them that once I got out of jail I really tried to help get re-established. It had a big impact.

Individuals with very different racial identities spoke about the power of unifying across racial and class lines, fueled by a shared sense of injustice and common purpose:

Whenever I sit in the room with formerly incarcerated people it's just like that's what we share. But l've also seen whites in that room and the race thing goes away. We were all in a horrible situation. I don't care what you look like;

These cross-racial experiences contributed to the leaders' capacity to build collaborations that span race, class, and generation. Amidst deep racial divides, the leaders described experiences enabling them to build multi-racial collaborations focused on making positive change in each others' lives and communities. 
we all went through it. You know what it's like. We all want to change the system. We've got to work together to do it.

These cross-racial experiences contributed to the leaders' capacity to build collaborations that span race, class, and generation:

What intrigued me the most was it didn't matter the person's race; it didn't matter the person's social class; it didn't matter the person's faith. These people were able to identify with one truth and that was an injustice. And I thought that's what people will come together for-when they see a true injustice. All the other coats that people wear no longer exist when it comes to injustice. And I want to inspire that. We as human[s] have some kind of interwoven connection with one other.

In short, amidst deep racial divides, the leaders described experiences enabling them to build multi-racial collaborations focused on making positive change in each others' lives and communities.

This section has shown that leaders with conviction possess unique forms of knowledge, acquired through their personal struggles and highly relevant to reducing mass incarceration. We now turn to the role of education, which emerged as a second crucial factor enabling the leaders to mobilize their ground truths in service of change.

\section{Education: An Equalizer and Game Changer}

Every leader we interviewed has pursued a course of study-either formal or informal-that involved them in critical inquiry. All but one of the leaders participating in the study have experienced some college, and almost all of them now have a postsecondary degree, ranging from the associate to the doctorate level. 38 out of 48 leaders have college degrees (at least an Associate's degree), five have JDs, and 27 out of 48 were either currently pursuing or have already received graduate or doctorate level degrees. Most of the leaders came to prison without a college degree, and pursued higher education during or after prison. Seven of the leaders had college or post-graduate degrees before they went to prison, and five had applied to or had been attending college before they were incarcerated. Some had not completed high school before entering prison. Some leaders started college in prison and continued to pursue their education after they returned to the community; others who did not have access to college in prison began their post-secondary education after they returned home. ${ }^{8}$

Higher education in particular served two significant functions: First, it empowered individuals to see themselves as leaders and prompted others to recognize their legitimacy as such.

\footnotetext{
${ }^{8}$ Some of the leaders who started college in prison lost access to those programs when laws were passed prohibiting Pell and TAP grants for college in prison.
} 
Second, it broadened and deepened people's knowledge base and expanded their modes of communication. These features of education supplied invaluable ingredients in the mix that equips leaders with conviction as organizational catalysts.

\section{A. Education's Legitimizing and Leadership-enhancing Role}

Success in the role of organizational catalyst depends upon having legitimacy as a leader in one's own eyes and in the eyes of important stakeholders. Education frequently stood out in the leaders' accounts of how they came to see themselves as leaders, along with how they gained legitimacy that enabled them to be a force for positive change.

For many who were not exposed to meaningful education as children, education in and after prison provided a crucial step toward claiming an identity as someone with the capacity to make a positive contribution and to catalyze significant change. One leader described how education enabled her to transcend the label of "criminal" assigned to her in prison, setting in motion a process that shifted her identity to "student" and ultimately, to "leading expert on education and criminal justice policy":

For many who were not exposed to meaningful education as children, education in and after prison provided a crucial step toward claiming an identity as someone with the capacity to make a positive contribution and to catalyze significant change.

I was fortunate enough, while incarcerated, to end up in a prison that allowed me to continue my education. So I was able to get an Associate's degree in prison. And during that period it was really transformational for me, as education is. In prison you sometimes lose yourself. You lose your ability to identify as anything other than a criminal. And I think that's how prison in many ways is set up and reinforced.

Another individual highlighted his pursuit of higher education as the defining experience that equipped him both to turn his life around and to exercise leadership. This individual had been exposed to a gang at the age of 6 , and joined the Crips at the age of 13 . He started using drugs at a young age and became addicted to cocaine at the age of 15 . He stopped doing any schoolwork when he joined the Crips, and continued this pattern as a football player in high school:

When you're an excellent football player in a high school that has a very good football program, you don't have to do any work. Trust me. You don't. All you gotta do, especially back then, is score touchdowns and you'll get a C. I went all three years of high school but right after football season in the 12th grade, I dropped out.

He became a drug dealer, spent time in and out of jail, and ultimately was sentenced to prison for a drug offense. Like some other leaders, the birth of his child was a real turning point for him. He became intent upon being there for his child, enlisted the help of his family, and overcame the crack addiction and alcoholism that he had struggled with for years. He then 
enrolled in a community college, and during his first year realized "hey, sober and clean, I can learn. And I can do this school thing." He then spent the next 12 years completing his education. He took five years to get his Associate's degree, working two jobs at the same time. He went on to get his Bachelor's degree and a post-graduate degree after that. He then took a position teaching undergraduates and working with non-profits focused on helping individuals, families, and communities with the reentry process. For him, "the ability to educate myself and to commit to education as a life-long process" was "the most valuable characteristic that I developed throughout my recovery, re-entry, and leadership development."

Through their educational pursuits, often in combination with efforts to tackle problems and develop programs ranging from college in prison to addressing AIDS, many people rediscovered leadership roles they had played as children but had not identified in those terms.
Many of the leaders discovered the power to have a positive impact by using their own education to improve the situation of others around them. This realization sometimes began with simple acts of helping peers:

I loved to read and I could read very well. And so there were a lot of folks in prison who couldn't read. People were like "Could you read this and tell me what this says, can you help me write this out, answer this letter, help me with my legal work in the law library?" And so that automatically put me there.

Individuals found their way into leadership roles in prison in part because of the "premium" that attached to college education, the skills needed to act when they saw something wrong, and the courage to "challenge authority to make them do what they're supposed to do by us." Through their educational pursuits, often in combination with efforts to tackle problems and develop programs ranging from college in prison to addressing AIDS, many people rediscovered leadership roles they had played as children but had not identified in those terms. Some found themselves drawing on roles they previously played as athletes:

Even though I was a point guard and a point guard is a leadership role out on the court, I still never really thought of myself as a leader in those situations because I felt like the people around me were either more gifted than I was or maybe braver than I was or whatever. But prison was the first place where my intelligence and my gifts for words made people look to me for direction.

Others reconnected with leadership experiences they had as part of religious communities:

It came naturally for me to encourage other people and I think it started because I grew up in the church and in church that's what we mainly do. We encourage others to try to push them forward, and I have been doing that all my life. And so when I get around people it 
was a natural thing for me to try to help and push people forward. That's the reason why it's come full-circle. Now I work with people and I try to encourage them.

Many of the leaders credited their educational and advocacy experiences in prison with the rediscovery of their leadership:

And so I think my advocacy work and my organizing work started way back in third grade and continued on and certainly was cultivated while I was in prison. It was nurtured there. In prison I got a chance to apply a lot of the thinking that I had done and to influence individuals. And then of course, once I was seen as a leader, then Education served to legitimate individuals in the eyes of people who would otherwise dismiss leaders with conviction. Education helped establish credibility. the seriousness of that role sunk in.

In addition to enabling individuals to embrace their identity as leaders, education served to legitimate individuals in the eyes of people who would otherwise dismiss leaders with conviction. Education helped establish credibility. One individual described experiencing this shift in legitimacy once people learned that, in addition to having first-hand knowledge of prison, he was educated:

It's the education that brings people up to snuff to have the same conversation with you or make you respect that, okay this guy has a B.A. It makes people stop and listen for a second and not just easily dismiss a person. Some people dismiss you just by the fact that you've been formerly incarcerated. Why should I be listening to you? But then when you open your mouth and you start talking, then they be like, "Whoa, whoa, wait a minute; this guy is smarter than I gave him credit for."

Several leaders also spoke about education as an important source of cultural capital needed to be effective in the worlds of work and politics. One person talked about "little things to polish me off because even though I was polished, I was a little gruff because I just didn't know a lot of things. I didn't know about office politics and stuff like that, so I would say things and people would take it out of context, and misunderstand me." His education provided him with a ways of speaking and navigating that enabled middle class people to trust and respect him, leading him to quote Horace Mann's reference to education as "the great equalizer."

Another individual described how his college education made him a go-to person to serve on panels and participate in policy discussions:

It came to be known that I could hold my own on a panel with lawyers and psychologists and psychiatrists. And so I was a person that was often invited to speak. I've been interviewed by judges at conferences. But it's been a way to tease out my narrative as a 
way to say something larger about the issues, and honestly l've been invited because l'm a good speaker but also because l've been to college and l've been doing well in college. And so the organizers would always say, "Look, this is the face that we can present and in some ways it can't be dismissed."

Individuals described the difficulty they experienced being taken seriously before they obtained the educational credentials to overcome presumptions and stereotypes about people who had been to prison.

Thus, education plays a crucial role of bringing leadership capacity to light and increasing the receptiveness of influential stakeholders to the insights of leaders with conviction. The interviews show that, along with this legitimacy, education provides important conceptual tools that enhance the power of first-hand knowledge.

\section{B. The Power of Integrating Formal Knowledge and Practice}

Education arms people who have been incarcerated with theories and data they use to frame their own and others' experiences. The interviews illustrated how this theory-practice combination expanded the depth and diversity of knowledge about the causes and strategies for addressing pressing problems such as poverty, racial inequality, the school to prison pipeline, and mass incarceration. Education enables the leaders to buttress their life experience with theory and research, and to critically assess that research in light of lived experience. One leader aptly summarized this combination of his academic achievements, combined with his personal experience:

I can look through the lens of sociology, anthropology, history-all the different lenses that academic training gives you. But I also have direct experience. I'm been impacted by the social conditions, just like l've experienced prison directly. I see it from the point of view a person that has lived it. Aside from academic credentials, I also have a Ph.D. in the streets.

Education during and after prison provided the opportunity and critical perspective enabling people to place their experience in a broader context. One leader noted:

I got a college education while I was on the inside. I earned a two-year liberal arts degree and I learned a lot about other people and other cultures, and that kind of changed my frame and my thinking about where I fit into the world.

Another leader observed that education provided a language and framework that expanded his definition of justice:

What I learned from that education was how much more I have in common with other people-and our differences. And so suddenly justice meant that if you violated someone else, then you're violating yourself. If you're part of this larger picture, why would you do 
something to damage a space that you're an integral part of? So that's part of how my definition of justice changed.

Many of those interviewed discovered synergies between their academic and their real world knowledge. One leader used his psychology degree to help him interpret his experience in working with families that had experienced trauma, as well as to improve the theory in light of his experience:

I would bring a lot what I was learning in my classroom into the job training center but I would apply the life experiences of ex-offenders to that psychological theory. I would marry that cycle of truth and experience that's relative to the population. And that was important for me because that's when people could grasp, like "Oh, wow, that's what's happening to me."

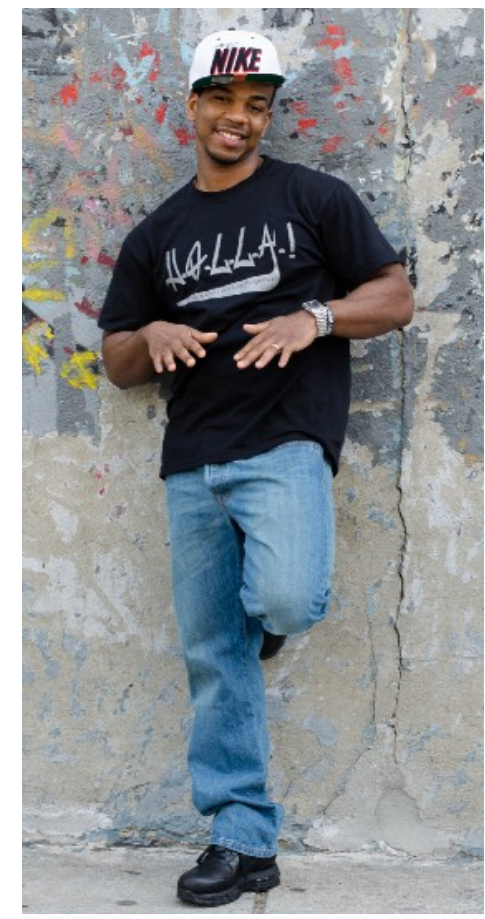

Cory Greene, Co-Founder of H.O.L.L.A. (How Our Lives Link Altogether)
Another individual with a bachelor's degree in criminal justice and organizational behavior found that "I've been able to mix all that stuff up into real time, real world action." That action has included developing programs and policies to address gun violence at a more systemic level, rather than simply seeking to reform or imprison individuals who have grown up in contexts that normalize violence and romanticize the street life. He is pursuing graduate education to figure out how to enable young people in urban communities to realize their potential early on:

I love supporting young people; I love learning from young people, particularly young people in urban spaces. I'm reminded of myself growing up in New York City, of how much potential I had. But somehow it was years that potential was on hold because I was blinded by what I thought was good, the street life. So it's probably good that I'm in graduate school now because I get to think about that work as an intellectual project in supporting young people in their social-political developmental and not just providing the services.

Several of the leaders described linking research about the importance of education with their own transformation experience. One individual got her master's degree while she was involved in creating a college program in prison, and was able to use this cross-fertilization to enhance her impact as a researcher, a teacher, and policy designer:

I was advancing and giving back at the same time. I was doing so much teaching while I was doing research, and part of doing that research would be the template to show the 
After incarceration, several leaders continued to pursue research that tested what they had learned in prison, in effect becoming ethnographers of their own experience through selfreflection and speaking with others who had been incarcerated. Several leaders observed that formal education gave them a structure for conducting inquiry and a language to communicate what they were seeing. Cory Greene, currently pursuing his $\mathrm{PhD}$ in the Critical Social/ Personality Psychology Program at the Graduate Center, CUNY, explicitly applies the research methodologies he learned in graduate school to his youth development and community organizing work. Greene, who is also the Community Relations/Training Manager with the Center for NuLeadership on Urban Solutions, co-founded an organization called H.O.L.L.A. (How Our Lives Link Altogether), and is using participant action research as a tool to cultivate the leadership of historically marginalized urban youth living in under-resourced communities.

We also saw many examples of individuals using their education to fill gaps in the knowledge they needed to enhance their impact. One individual explained his process of examining himself and his skill set and deciding that he needed more education to enhance his ability to deal with trauma:

I had a lot of really strong organizing and political knowledge thus far, but I think the piece that I felt that I was missing was the piece that talked about trauma and how trauma impacts people's ability to make decisions that are considered rational.

For some leaders, the understanding gleaned from processing their individual experience through the lens of history and theory allowed them to move away from a subjective posture of anger and frustration, and towards an activist goal of changing the system.
As result, he decided to enhance his masters in community organizing with an advanced degree in clinical social work.

Education also provided individuals with a critical perspective equipping them to understand the larger systemic dynamics that had to be addressed to advance meaningful change. One individual described his development of "a critical analysis of the economy, the political, social, and international situation, and it's one that I have shaped myself, based on my own experiences and my education." Another individual used statistical and sociological research on racial disparities in the criminalization of drug use to expose those same patterns in the availability of drug treatment rather than arrest in the community his program served.

Education afforded some leaders with the opportunity to process their experiences through the lens of history and theory. Many of the leaders interviewed found that college-level courses in 
political science, history, critical race theory, or criminal justice played a particularly important role in their leadership development. About a quarter were pursuing or had received advanced degrees in relevant fields.

In addition to formal education, most of the leaders had thought critically about these issues through informal education while in prison; many spoke about think tank-like gatherings where participants collectively discussed readings, race, politics, and criminal justice policy. The informal educational settings in prison can be just as important as the formal settings in fostering leadership and critical thinking. In addition, some leaders described informal education as the catalyst for their decision to pursue a formal degree.

For some leaders, the understanding gleaned from processing their individual experience through the lens of history and theory allowed them to move away from a subjective posture of anger and frustration, and towards an activist goal of changing the system. One leader described how formal study of mass incarceration helped channel her personal commitment to change into forming an organization, run by formerly incarcerated individuals, that spearheads educational and policy initiatives tackling mass incarceration:

So getting out of prison, I felt very charged to do something about a system that I felt was severely unjust. And I think that initial charge was based on my personal experiences. But then once I was able to pursue a bachelor's degree and continue on to a master's degree and eventually continue to get a doctorate degree, I started to understand the system a little bit better and I realized mass incarceration has really been probably the greatest social issue in America since slavery. And it really empowered me to want to make change.

Individuals who pursued legal education described an exponential impact on their ability to be an effective advocate. The leaders with law degrees illustrated their capacity to understand things "three dimensionally" as a result of their personal experience, legal education, and positions as organizers and legal experts:

We understand things from direct experience, from our lives. And for me it goes from being on welfare to going to foster homes to then the prison experience and getting out experience and having to work for minimum wage when you feel confident that you're worth more than that. We also understand from a community level because we've been organizers. We've worked with so many different people. We understand that it's not just our own individual experience; it's "what about if I knew about 5,000 people's experience? What's the pattern here? How can we combine to make changes and then also understanding how to do media work and social work?" And then thirdly, being an expert from a legal perspective and knowing the law and fighting it out, knowing the constitutional issues. So a lot of people have one of those aspects, whether it be direct experience, community work or legal expert. Some people have two and they're considered to be 
Thus, the combination of first-hand experience and education equips leaders with conviction with unusually diverse sources of knowledge and legitimacy. It also enables them to obtain jobs and other activist positions where they can have an impact on individuals, communities, and public policies. These boundary-spanning positions, along with the additional knowledge they afford, are the third contributing element that makes these leaders such effective catalysts for change.

\section{Boundary-spanning Employment and Activism}

The leaders we interviewed hold jobs and activist positions that situate them to work across a wide range of organizations, networks, and systems. They blend their paid positions with other activities linked to their mission of positive social change. Many of them hold positions established to facilitate systems alignment, collaboration, and coalition building. These varied roles enable them to serve as brokers and connectors of distinct communities and systems that would ordinarily not interact.

\section{LEADERSHIP AT A GLANCE}

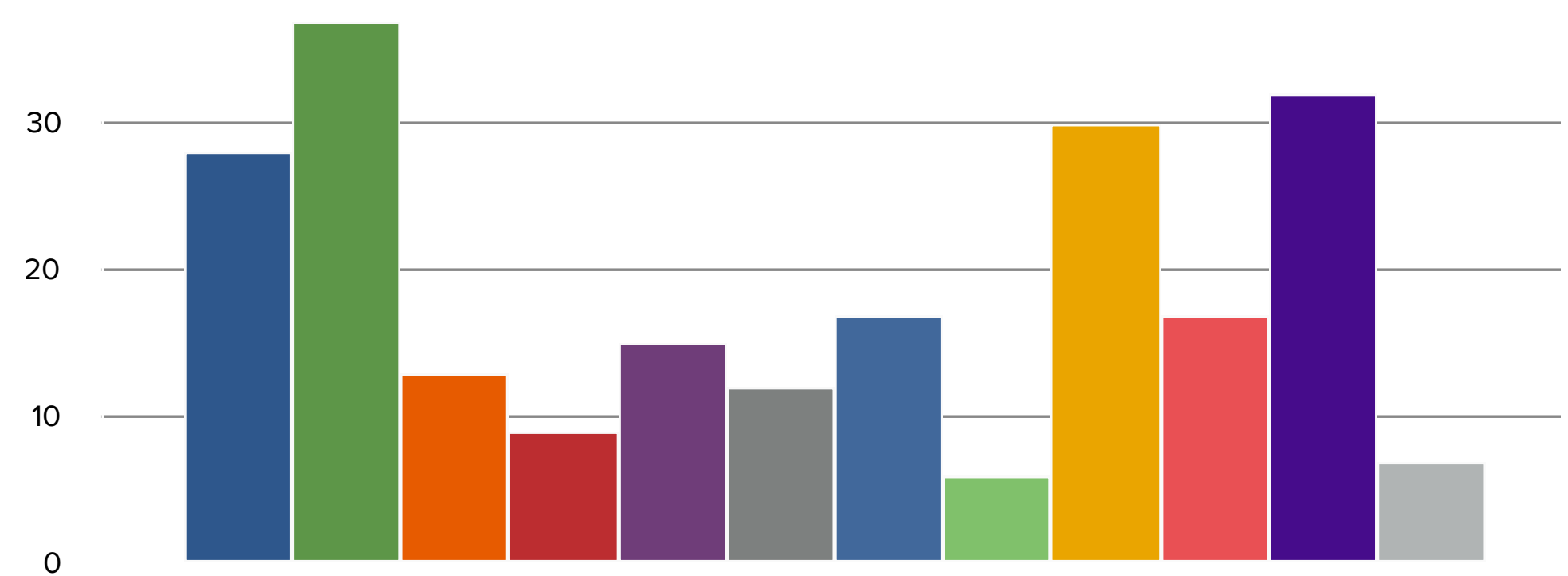

Number of Leaders

Leadership Development

Serve on Commissions / Boards

- Public Speaking / Media

Teaching

Advocacy

Reentry-Related Work
Policy-related work

Leading Organizations to Support the Formerly Incarcerated Writing

Training / Technical Assistance

Community Development \& Change

Legal Aid

The leaders hold a wide array of jobs and positions in a variety of different fields, spanning the private, public, and non-profit sectors, and including government agencies, law firms, consulting 
firms, and academia. In addition to working, some were also enrolled in graduate- and doctorate-level degree programs in fields such as social work, criminal justice, and law. Many of the leaders also volunteer for community based organizations and mentor others; they experience their involvement in this work as a calling:

From the day I got out, I've been doing this work. I started doing this work because I made a commitment to a lot of the brothers that I left behind that when I got out I would do this work. And when I was in prison I was doing this work. I was doing advocacy work in prison while I was in college. If you count the time when I was doing it in prison, l've been committed to this work for over 30 years.

Leaders hold leadership roles in local faith-based

One leader described how working at these different levels, going from lineworker to manager to policy maker, positions him to draw on his own criminal justice experience and his work with youth in those policy settings. This range of perspectives enables him to anticipate how seemingly little things, like the timing of curfews or application deadlines, might have a big impact on the success of an intervention. organizations, youth outreach programs and peer mentoring programs as well as in direct services organizations providing legal representation or reentry assistance in areas such as housing, drug rehabilitation, and employment. Several leaders have been involved in community development and revitalization; one leader, for

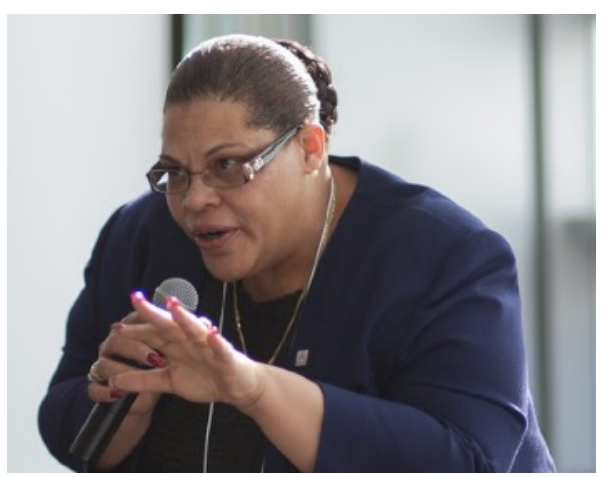

Dr. Patrice Palmer speaks at JLUSA's first Leading with Conviction Forum, January 2015 example, helped spearhead a large-scale project that repurposed an old correctional facility into a community reentry center.

Many of the leaders first engaged with these social issues while still in prison, and then proceeded to work in a community based organization as a case worker or frontline worker before moving up in the organization to local and state advocacy and policy positions, and ultimately becoming involved at the national level. One leader described how working at these different levels, going from line-worker to manager to policy maker, positions him to draw on his own criminal justice experience and his work with youth in those policy settings. This range of perspectives enables him to anticipate how seemingly little things, like the timing of curfews or application deadlines, might have a big impact on the success of an intervention. Another individual explicitly observed an evolution in his role "from the city then the county then the state." This trajectory provided him with knowledge about how the systems affect each other in practice, and the ability to develop a corresponding network of relationships, which he now calls upon to facilitate smooth transitions and remove barriers facing formerly incarcerated people. 
While in prison, many of the leaders occupied roles that required them to learn how to communicate effectively with line staff and prison administrators. One person served as a liaison between staff and prisoners, and figured out how to present information to the prison administration in a compelling manner that produced greater accountability for corrections officers who violated established rules. Another leader learned about the perspectives and challenges of correctional staff through the experience of organizing the first graduation ever in his prison: "I had to interact with a lot of different kind of people. I had to interact with the CO's and civilians and interact with my peers. I even had to talk to vendors on the outside to make sure that we had things straight." Yet another learned how to exercise her power so she did not overly threaten the prison administration. This lesson included picking her battles so that she could shepherd the development of higher education and AIDS programming in prison. After prison, these experiences-and the accompanying relationships they yielded-served the leaders well in their efforts to promote higher education in prison, health care for formerly incarcerated people, and many other issues of importance to communities affected by incarceration.

Every leader we interviewed is working on criminal justice policy in some capacity. They have tackled issues including sentencing, immigration reform, stop and frisk, collateral consequences of incarceration, children of incarcerated parents, parole eligibility, juveniles tried as adults, and conditions of confinement. Many lead or participate in various criminal justice reform networks and coalitions.
Because of their experience with criminal justice issues, many leaders have testified before congressional committees, served on government task forces and working groups, and advised government officials on policy decisions. A significant proportion also has also joined established commissions and boards.

Every leader we interviewed is working on criminal justice policy in some capacity. They have tackled issues including sentencing, immigration reform, stop and frisk, collateral consequences of incarceration, children of incarcerated parents, parole eligibility, juveniles tried as adults, and conditions of confinement. Many lead or participate in various criminal justice reform networks and coalitions. Some leaders engage in activism in the form of litigating, lobbying, and creating model legislation. Others take a more grassroots approach of community organizing and mobilizing campaigns.

Many leaders have served as educators. Some provided training and technical assistance to organizations. Several leaders helped create and conduct training programs for criminal justice officials, and assisted in designing curriculum for educational programs inside prisons. Some have trained probation and parole officers; one leader led trainings for all parole agents in the county and district, as well as for the highway patrol. Some have worked with wardens and agency leadership to help them improve the culture of criminal justice organizations and better 
understand what enables people in prison to successfully transition home. Some are teachers and professors in private and public colleges and universities, as well as in prison education programs and college programs designed for formerly incarcerated students.

JLUSA has undertaken to cultivate this kind of leadership in people who have experienced the criminal legal system and have been identified as strong leaders. JLUSA fellows are engaged in significant leadership positions operating at the local, state, and national level. Appendix C provides a summary of their positions and roles.

These individuals occupy hybrid roles that place them at the junction of very different worlds. Some of the leaders are working while pursuing higher education degrees, or have positions both in academia and in the community. At the same time, they are continuing to mentor people currently involved in the criminal justice system, either in

This position at the intersection of multiple worlds enables leaders with conviction to bring together people who otherwise would never be exposed to each other. prison or in the community. Some of them are still on parole themselves. Several of the leaders are licensed ministers, and many have strong ties to religious communities, which they also draw on in their work. This position at the intersection of multiple worlds enables leaders with conviction to bring together people who otherwise would never be exposed to each other.

Some leaders are also public speakers and writers who have appeared regularly in the media, published books, poetry, and articles, created criminal justice-related publications, or served on editorial boards. A few have jobs involving radio and film. Many are in roles combining advocacy with writing, speaking, or participating in policy.

The positions leaders occupy frequently involve facilitating transitions, and thus explicitly invite them to connect different parts of the criminal legal system, as well as to build links between criminal justice, education, and other systems that have to figure out how to collaborate. Some of them have held roles as transition specialists, charged with helping people navigate the adjustment to the community when they leave prison and helping people manage the barriers that accompany having a criminal record. The commissions and advisory boards they have joined tend to focus on aligning systems and coordinating policies relating to reentry, and reducing the barriers that currently plague returning citizens. Many have served on bodies charged with connecting the silos that have characterized the agencies interacting with people when they return home from prison, and creating a continuum of support that bridges nonprofit and government agencies as well as the many different sectors (housing, health care, education, employment, family services etc.) that affect wellbeing upon reentry. The leaders were explicit about playing this bridging role of bringing together different systems to better support formerly incarcerated people. 
Finally, many of the leaders participate in social activities in their communities, ranging from coaching to being active in the parent associations in schools to informal mentoring to participating on boards of community based organizations and civic associations.

We have now described each element of the alchemy equipping leaders with conviction to become organizational catalysts: criminal justice experience, education fostering critical thinking, and boundary-spanning employment and activism. The next section will explore what this combination enables them to do.

\section{Superconductors of Social Capital: Cross-Cutting Communication and Legitimacy}

The previous three sections have laid out the leaders' unusual portfolio of knowledge and relationships. The resulting synergy equips them to be "multi-lingual": they can speak the language of youth on the street, of students in college, and of government officialdom. It helps them earn legitimacy both with the communities they seek to benefit and with the decisionmakers they seek to transform. It yields opportunities and roles in which the leaders can link networks and organizations that occupy separate worlds, bringing them to multiply their impact -a capacity that some network theorists have labeled "superconductors" (Kitsak et al, 2010).

In other words, the leaders with conviction have developed the capacity to mobilize unusually diverse forms of social capital-a term scholars use to refer to resources that are shared through networks of relationships (Putnam, 2000; Bourdieu, 1986; Coleman, 1988).

Social capital includes knowledge that people need to advance their goals, such as information about how to apply to college with a criminal record or about how the criminal justice system operates on the ground, described earlier in this report. It encompasses mutual norms and expectations operating within a network of relationships, such as the shared expectation that people coming out of prison can become students, scholars, and leaders. It also includes access to opportunities for advancement, such as willingness to vouch for people when they apply for jobs, education, or housing. In fact, research has shown that workers find out about new jobs more from personal contacts than from any other method (Granovetter, 1973; Fernandez et al, 2000). Finally, social capital consists of timely access to decision-makers in a position to influence policy, along with knowledge about how those kinds of decisions are made.

Social capital is crucial to social mobility; it enables people to grow, develop, and recover from failure by providing them information and support. Research has documented its role, for example, in enabling educational access and success (Coleman \& Hoffer, 1987; Pascarella \& Terenzini, 1991; Sturm \& Nixon 2015), and has linked the decline of neighborhood safety and wellbeing to accompanying declines in trust and social support (Sampson, 2012; Sharkey, 2013). Exclusion from social networks and other valuable supports is the "Achilles' heel" that prevents 
people in poor communities, especially those with high incarceration rates, from attaining upward socioeconomic mobility (Burton \& Welsh, 2014; Lin, 2000). The deficit of positive social capital (particularly in communities with strong networks encouraging illegal activity) increases the likelihood that people in resource-starved communities will spend time in prison (Sampson, 2012; Sharkey, 2013).

Social capital also pays a central role in mobilizing social change. Social movements develop through the cultivation of social networks; relationships provide the base for activism and collective action. Social movements also create social capital, by building new identities around shared goals and expanding social networks (Putnam, 2000; Minkoff, 1997). They encourage practices of collaboration, which increase opportunities for building relationships of mutual support (Gamson, 1991).

The leaders use their different kinds of social capital both as an engine of mobility for those affected by mass incarceration and as a vehicle for catalyzing change. Their varied knowledge and experience equip them to speak the language of many different communities, and imbue their communication with information and legitimacy attuned to each audience. They can build trust with people who have experienced consistent stigmatization and dispel myths among people who hold stereotypes that have prevented them from understanding the realities of the criminal justice system. They can thus overcome the barriers to communication that flow from the widespread stigmas and stereotypes associated with having a criminal record.

\section{The leaders' adaptability of communication and crosscutting legitimacy derives from:}

- Experience across social classes

- Spending time in different worlds, with different communication styles

- Participating in diverse forms of communication that can be tailored to suit audiences with varied purposes

- Using their personal narrative to concretize and humanize the issue of incarceration and build understanding

- Developing multiple sources of legitimacy that matter to people with divergent backgrounds

Over the course of their lives, many of the leaders have moved from one social class to another, giving them the experience of what it means to live in these very different worlds. For some, their path to leadership has included living in poverty, making a living on the streets, surviving prison, and rising to significant positions of leadership in local, state or federal organizations. They know first-hand how expectations, opportunities, and support vary for people in different social classes. This experience provides a base for connecting people from diverse backgrounds. As one leader put it: 

regular job. And not many people get to walk in all those worlds in one lifetime.

Many of the leaders continue to have feet in both worlds, and to identify with both. One leader, who now co-directs a center in higher education institution, has used her dual identities to build a network of students, faculty, community members, and policy makers focused on criminal justice issues:

Rather than disappearing into an academic world, both my colleague and I are part of the community of people that have come home from prison. Having our feet in those two worlds means that the way that we work always is about our identity... I am an academic, I have a Ph.D., that's great, I'm glad I have it, but my identity remains one of somebody who is able to wear different hats, and always open about the hat of being somebody that's part of the community of people that have come home from prison that want to make a difference. And I think that that's really critical.

Many of the leaders describe situations where they adapt the form of language they use to the setting they are in. They remarked on the value of this ability in doing change work. Leaders spoke about being able to successfully blend in and socialize with people from different walks of life, adapting to their mode of communication while still relating to everyone on a fundamentally human level.

Their different roles also mean that the leaders continue to

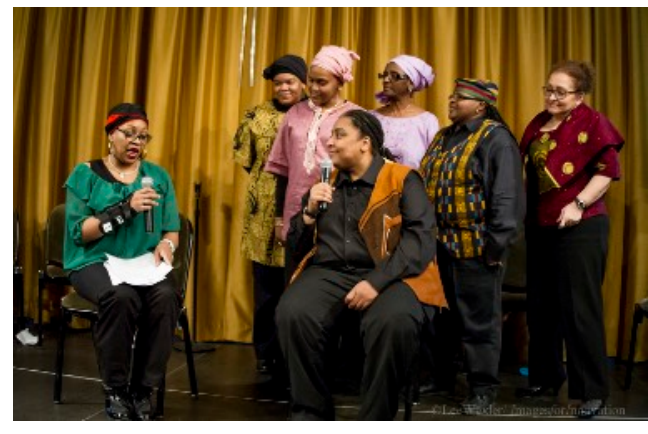

College and Community Fellowship's Theater for Social Change move between many different worlds. Through practice, they retain their familiarity with these different communication styles, and adapt their language to the context they are in. This keeps them from losing sight of the concerns and experiences of those most affected by incarceration-something the leaders observed happening all too often with other advocates who become national spokespeople.

Some of the leaders speak comfortably in the languages of policy, programs, personal experience, narrative, and research. This combination affords them many ways of communicating complex or challenging ideas, as well as the ability to be persuasive with people who value distinct kinds of knowledge. In addition to public speaking and direct communication, other forms of communication include theater for social change, radio hosting, poetry, and spoken word. For some, writing has become an important mode of communication, and they draw on their exposure both to the street and to the academy to be able to write in many different styles and reach different audiences. One person described writing to "tie in personal experiences with larger social critiques," which is "a very powerful way of delivering messages, informing people, and educating folks." Another person, who did her master's 
degree in prison, published articles in academic journals while still behind bars, bridging the incarcerated and scholarly communities across prison walls.

A crucial dimension of their capacity to reach people involves sharing their own narratives, particularly when located within a broader change agenda. The leaders shared many experiences of telling their story in a way that had profound impact on those in the room:

Some of the leaders have used their experience and relationships to shift a community's approach to mass incarceration from a problem about those "other people" to one that affects all of us and warrants the conclusion that "we are all justice-involved."
I've always had this gift of telling of my experience. So at an event where they had children; they had women; they had college professors present, but the ninth graders were in the front, I first told the story in the thirdperson. I said there were women in prison and hanging out. And then I said, "Do you know who that woman was?" And of course, some of the kids looked at me and said, "That was you!" They got it. It was really nice. Then one of the guys got up and said, "Can I give you a hug? ... Because my foster mother told me that both my mother and father were [in prison] ... and you just helped me understand them as human beings."

Some of the leaders have used their experience and relationships to shift a community's approach to mass incarceration from a problem about those "other people" to one that affects all of us and warrants the conclusion that "we are all justice-involved." One leader took this approach in a forum with students, staff, and faculty in a community college. Another did so in his religious community:

So if you go to the faith community and you point out to them how many people from their church are now incarcerated, how many men and women in your church have sons, grandsons, daughters, granddaughters, nieces, nephews, how many of them have those family members that are incarcerated? Then all of a sudden, it's not a political issue, it's a personal issue because so many people from this church have somebody who's locked up and they're not being treated fairly and the sentence is wrong. Once you hear the stories, then people are more willing to take on the systemic issue.

Leaders were also able to use their own experiences to encourage people to challenge their assumptions and misconceptions about people who have been incarcerated, as well as to draw a link between trauma and incarceration:

Frequently now I find myself in situations where someone makes a flippant remark about people deserving to be incarcerated and what goes on in there. I really take the time to describe what people are going through or what they've been through; people are willing to listen. I talk a lot about abuse, whether it's domestic abuse, sexual abuse of men and 
women, and the impact that that has. I talk about trauma as an impact. Also mental health is such a huge issue. And more and more people are understanding that ... So I take every opportunity to educate people on the outside. And for the most part, they're always kind of in awe and they are amazed to understand, and it's humanizing offenders.

Many leaders described the experience of reducing stereotypes just by being and acting in ways that challenged people's preconceptions:

I'm trying to change the opinion and the discourse and the discussion on crime and punishment in the state, so I use my own story as an example. I use it to educate people with misconceptions or prejudices, people who just have opinions and stereotypes. So I just start talking about it. "Yeah, I was in prison and this is what happened." People are kind of intrigued by that. They say, "Oh, you were in prison? You seem to be so knowledgeable, you seem to be so well adjusted." So I use my situation to inform people, to

Experience in prison, along with the leaders' success in overcoming the barriers facing people coming home, make them credible messengers for people whose experiences have led them to distrust people in power. break that stereotype.

One leader who serves on a state Board of Corrections illustrated how first-hand knowledge, used in conjunction with policy and data analysis, gave him the credibility he needed to reach policy makers, agency leaders, and judges:

It is a reality that when I was incarcerated, there were a bunch of Department of Corrections policies, but the officers that I saw never followed them. So I draw on that reality. And I think my experience gives credibility to what I am saying. I am not talking from the perspective of, I read this policy and I am assuming. I am reading this policy and I am telling you how it's going to happen. That gives almost like a 3-D insight to that policy.

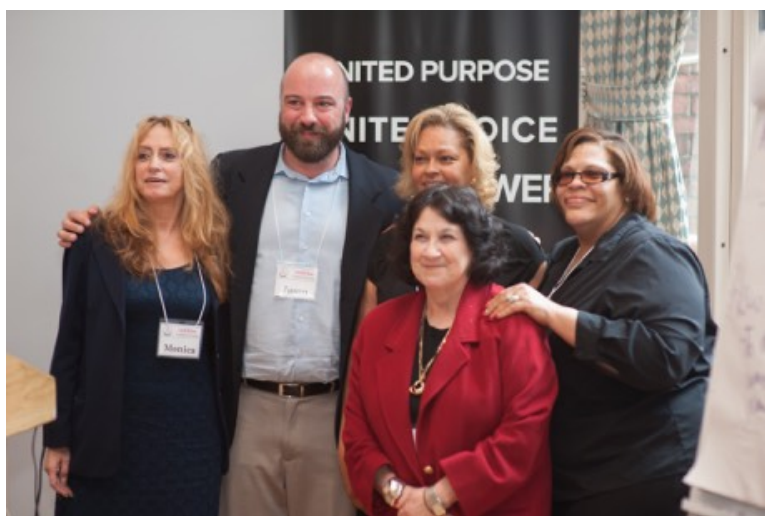

2015 Leadina with Conviction Cohort Fellows
At the same time, the leaders have legitimacy with people directly affected by incarceration, including youth, people in prison, and people who are going through the process of reentry. Experience in prison, along with the leaders' success in overcoming the barriers facing people coming home, make them credible messengers for people whose experiences have led them to distrust people in power.

Leaders with conviction can speak in the language of "we" rather than "you;" they can use concrete examples that resonate with youth in their communities and people who remain 
incarcerated. They draw on their own experience to demonstrate that they understand the challenges people face; they hold themselves out as living proof of the possibility of a better future. One individual, who now leads efforts to reduce gun violence, helps young people see that the qualities that made them leaders of their gangs or drug rings also enable them to be to become entrepreneurs and change agents:

The point that he was making is, "Look, man, if you were trying to be the best hustler that you could be or the best stick-up man that you could be, or whatever your thing was, you've got that in you. Now you've just got to flip that mentality from a criminal mentality to an entrepreneur mentality and I would hope to a revolutionary mentality to join us in this fight." So I would remind them that you already got that make-up in your character. Now you've just got to change the game.

Many leaders seek out situations enabling them to inspire hope in people in prison who face daunting transitions and challenges:

I am a living example. I do presentations. I was in a correctional facility today doing a presentation in their transitional program. It was definitely a boost for the women. I bring updated information of course, but it's also inspiring because some of them are new to the possibilities. They get excited about coming home. I love doing that, trying to be an inspiration.

Thus, the leaders' capacity to reach many different constituencies makes them superconductors of social capital, able to facilitate the multi-directional flow of information and support.

\section{The Multiplier Effect of Bonding, Bridging and Linking Social Capital}

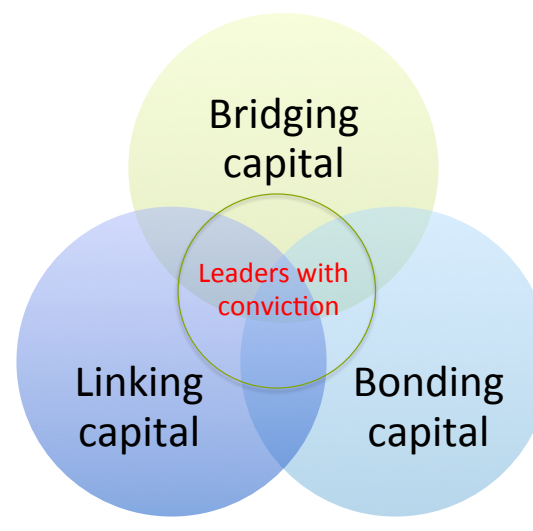

The leaders' positions in multiple social networks, along with their "multilingualism" and legitimacy, enables them to serve as brokers of social capital. Brokers tie people to other people, other organizations, and to the resources of both (Sharkey, 2013). These ties enable knowledge and support to reach ordinarily disconnected groups of people.

Researchers and policy makers have identified three types of social capital that are particularly salient to how brokers connect different kinds of people to each other: bonding capital, bridging capital, and linking capital: 
- Bonding social capital refers to relationships among members of a network or community that share a common history, identity, and social position. (Putnam, 2000; Bourdieu, 1986). It forms among tight-knit groups and builds trusting and reciprocal relationships. Bonding capital is particularly good at providing social and psychological support, and helping people deal with challenges and crises. At the same time, networks with bonding capital tend toward being inward-looking and insulated from other groups. Bonding capital does not connect individuals to external assets and information.

- Bridging social capital refers to relationships of respect and mutuality among people who differ from each other along significant axes of identity, such as age, socio-economic status, race/ethnicity, or religion (Putnam, 2000; Szreter and Woolcock, 2006). Bridging enables different groups to share and exchange information, ideas, and opportunities. It is more outward-looking and better for linkage to external assets, such as job or funding opportunities, and for diffusion of information across social cleavages. It provides The synergy of experience, education, activism, and employment enables the leaders with conviction do something unusual: they combine bonding, bridging, and linking social capital, in service of reducing incarceration and building thriving communities. opportunities to forge broader identities defined by common purpose. People with these ties may connect through working together, being in school together, or connecting through a referral by a shared acquaintance. This widens social capital by increasing the 'radius of trust' in Fukuyama's terminology (Fukuyama, 2003). Bridging ties tend to be weaker in terms of reciprocity and trust, but have been shown to be more valuable than strong ties in providing access to resources needed for mobility and policy influence.

- Linking social capital refers to relationships of trust and respect between people who are interacting across explicit, formal or institutionalized power or authority levels in society. In the leaders' context, linking social capital connects people with justice involvement with individuals and institutions in positions to make institutional and public policy and to shape public opinion, such as legislators, commissioners, foundation leaders, and media hosts. (Szreter and Woolcock, 2003). It opens up opportunities for those belonging to less powerful or excluded groups to influence policy and public opinion.

The synergy of experience, education, activism, and employment enables the leaders with conviction to do something unusual: they combine bonding, bridging, and linking social capital, in service of reducing incarceration and building thriving communities. They do this by:

- Remaining deeply tied to individuals and communities affected by incarceration as they become upwardly mobile, thus preserving their bonding capital, while infusing these 
relationships with resources and relationships developed through their education, employment, and activism. They may provide the only meaningful connection that justice-involved individuals and communities have to high quality social capital.

- Bringing their narrative and multiple forms of knowledge into venues where they form relationships with influential people who have had little or no direct contact with people who have been in prison, and who have had no exposure to people who have turned their lives around and become leaders. Their education and boundary-spanning employment brings them in contact with many high-impact situations and people beyond the reach of many people who have been to prison.

- Developing relationships with people who influence institutional and public policy and shape public discourse and have had limited interaction with those directly affected by mass incarceration, and linking them with each other and with communities directly affected by mass incarceration.

In many situations, they are the only bridge between the communities affected by incarceration and people in positions of influence or who have significant access to resources.

In many situations, they are the only bridge between the communities affected by incarceration and people in positions of influence or who have significant access to resources. This section describes each of these patterns, and concludes with examples of the kind of impact leaders have had when they are in a position to broker social capital in these ways.

\section{A. Bonding Capital Backed By Bridges and Linkages}

The leaders with conviction exhibit two significant qualities that enable them to leverage bonding social capital. First, as they gain social mobility, they remain personally connected to individuals and communities affected by incarceration. They thus maintain strong ties, defined as a combination of the amount of time, emotional intensity, intimacy, and mutual sharing of resources (Granovetter, 1973). Second, they hold a strong commitment to sharing resources and opportunities with people affected by the criminal justice system, and to building capacity and leadership within those individuals and communities. Many occupy formal and informal roles that facilitate this resource and power sharing in the context of relationships of trust. They thus serve as "home-grown social capital" (Sturm and Nixon, 2015).

\section{(1) Life-long bonders}

For a variety of reasons, many leaders with conviction have remained deeply involved with people and communities affected by incarceration, notwithstanding the social mobility that accompanies their educational achievement, employment, and advocacy work. Unlike upwardly mobile people whose education and employment opportunities lead them to reduce their identification and contact with their communities of origin, many leaders with conviction continue to function as hubs connecting their communities with resources, networks, and 
support. This pattern enables the leaders to strengthen pre-existing bonds of trust and support while also opening up their community to new sources of social capital.

Almost all of the leaders experience a collective identity of being formerly incarcerated change agents. That collective identity was forged by living through the trauma of incarceration, the struggle of coming to terms with that experience and the circumstances leading up to it, and the process of finding the strength to forge a meaningful future under very difficult circumstances.

I have to continue to live the reality. I don't have the luxury of disassociating myself from the reality that we're studying and assessing and analyzing and attempting to transform. I have to be the change that I want to see. I have to be part and parcel of the very thing that I'm examining, and I have to apply whatever the methodology that I'm using both on myself as well as on the other subjects of my analysis all at the same time.

They are driven by a focused urgency and motivation that keeps them connected to each other and to those still enmeshed in the system. The leaders describe this connection as a visceral one borne out of embodying the need, struggle, and hope for transformation.

The stigma still associated with a criminal record tethers the leaders to each other and to their shared identity as people with criminal convictions, even as they build ties to people in positions of power. Many of the leaders continue to face stereotyping, discrimination, and exclusion due to their criminal record, long after they have left prison and achieved positions of considerable social stature. Many of the leaders have reached a status where they thought they could put their criminal history behind them, only to re-experience some form of stigma or exclusion. From the vantage point of change agents, however, the leaders have learned to process that recurring exclusion through a social justice lens and reconnect anew with the community of people affected by incarceration.

One woman spoke reverently about her bonds with other women who had served time in prison:

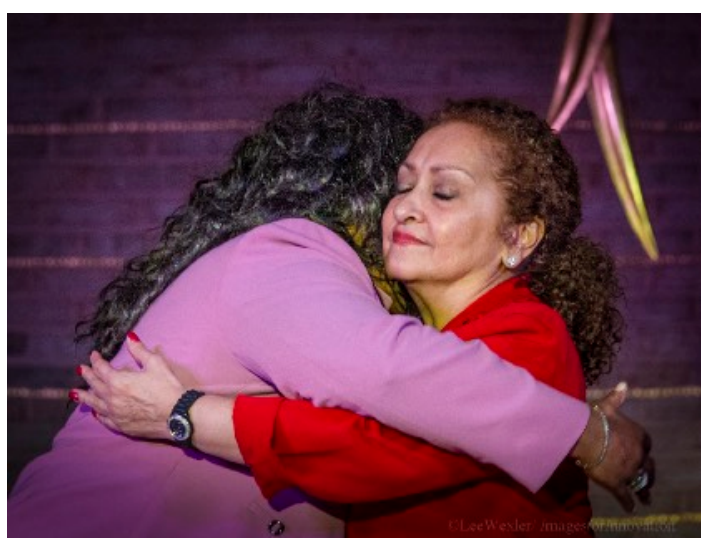

Women embrace at College and Community Fellowship Event
That kind of passion and loyalty keeps us connected as women who have served time together, and when we meet other women we have this unspoken language. There's just unspoken things when you meet a person who's formerly incarcerated, because there's a certain bond that you have.

For many of the formerly incarcerated leaders, working with the community affected by incarceration was critical to their wellbeing. As one leader stated, 
"people feel that "I can't breathe if I don't do this." Another leader described this work as his fuel. Many of the leaders we interviewed said their commitment to a movement for change defines their identities and gives their lives meaning:

What I have, I can't even turn it off. I eat it; I sleep it; I dream it. I'm constantly thinking how, how, how, how? What is the magic potion that's going to change the minds of a whole state? Not just a whole state, a whole country, because I feel like this is far-reaching. That passion is what equips me to do the work that I am doing.

These strong bonds grew out of their own experience of receiving support from those that came before them. Every person we interviewed expressed deep gratitude to those who made it possible for them to find the strength and hope in themselves, particularly for relationships with peers who experienced prison and helped them discover their voice and leadership capabilities. Among the leaders, this common experience produced an ethos of giving back, of identifying with this community of struggle and transformation, as well as an obligation to elevate the voices and value of those who remain in prison.

Many leaders used the same language to express simple yet compelling ideas about maintaining strong ties and giving back. One common phrase was "each one teach one." Some leaders also referred to the idea of "paying it forward":

I remember reading this book, Pay it Forward, and it just took me to a whole other level. The women that I met who are all incarcerated ... we're all part of contributing to having an influence on my life

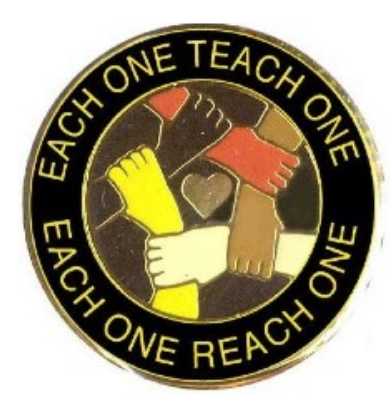
because the experiences are literally touching on my soul. And I carry it with me every day.

People spoke about "a sisterhood," a family, and a role model. One person described herself as having a moral responsibility "to use my voice, my education, the ability that I had to articulate things, the ability I had to write, and the reach that I had with the people that I still knew, to raise my voice to say, "this is wrong and we need to stop it."

Many of the leaders described close relationships with friends or family members who are still incarcerated. One leader described the importance of his ongoing interactions with people he connected with while he was in prison: 
Obviously there are my guys on the inside and those people who l'm still in touch with today. To be able to develop those relationships over the years has been crucial, and to know everybody's worst possible moment, darkest secret, and yet to be able to build a lasting friendship. I mean I get calls from prison every other day.

Before they left prison, several of the leaders who were returning to professional and policy communities made explicit commitments to sustain their connections to people inside and issues involving incarceration; these commitments stuck with them years later:

Right before I was going to leave, these guys asked me to come to the chapel. They made me come up on the stage, and the chaplain and a whole bunch of these guys got around and made me promise that once I get out I will help do the same kind of work I do generally to help advance these issues and deal with mass incarceration.

Over half of the individuals we interviewed framed their work in terms of building coalitions and networks, and many placed their efforts in the context of building a movement, with those closest to the problem at the center:

I'm also part of something called the Formerly Incarcerated Convicted People's Movement. And even then I'm trying to reach out to other organizations that are led by formerly incarcerated people so we can coalesce in a way that gives us an actual body and actual numbers so we can move public policy.

We have already described the emphasis of several leaders on building networks with clergy; others have focused on building bridges between directly affected communities and social workers, lawyers, and other professionals. Several described using legal services as a hook for movement building. Some have organized around constituencies such as youth, families, or women who have been affected by the criminal justice system. Some have organized networks to advance a long-term goal, such as banning the box in employment, education, and other settings and making education central for people with criminal justice involvement.

The leaders thus share an identity that binds them together as formerly incarcerated people who are committed to fundamental change. They also institutionalize networks that bond people to each other, cultivate collaborative leadership, and connect them to a larger movement. This identity was reinforced by continuing relationships that also put the leaders in a position to share their valuable social capital with The leaders' connections with communities that typically lack resources make them a potent source of home-grown social capital. resource-starved communities. 


\section{(2) Home-grown social capital}

Almost all of the leaders were involved in some form of activity that enabled them to share their own social capital with individuals and communities affected by mass incarceration. Their connections with communities that typically lack these resources make these leaders a potent source of home-grown social capital.

One leader illustrated how he used his social capital to expose kids to a wider world and set of choices than they have observed at home or on the street:

I go into the home; I talk to parents. If the home really is a broken home with a lot of drugs and the father is incarcerated, I become a mentor to those kids. I take them outside of the neighborhood and they spend a lot of time with me at the YMCA. I give them exposure to something outside of the home and the community, while helping them compete with other children [in school].

For some, informal mentorship relationships evolved into formal roles and programs with opportunities to produce broader impact. One leader created an organization and position as a peer support worker for the probation department, which enables her to help women navigate a path out of the criminal justice system. Several others began their journey by mentoring while behind bars and have since created programs aimed at reducing gun violence and cultivating youth leadership. Some have built college access and success programs for young people and people in prison.

Several leaders described using their own stories of stigma, struggle, and change to inspire family members to reconnect with people in their families who are or were incarcerated and have been out of touch. Some of the leaders have begun building networks among family members of people experiencing incarceration:

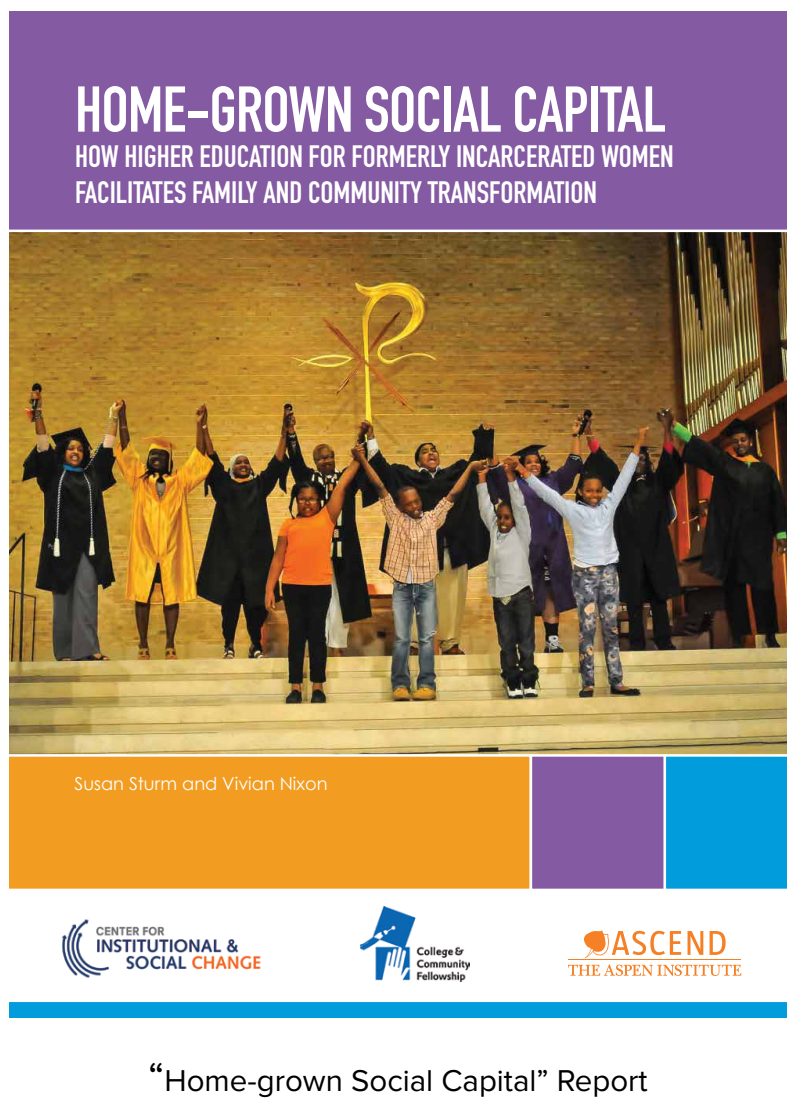

The family members are actually organizing themselves now and getting involved in policy change and advocating and being a voice to a loved one inside. Many times they lived in fear of retaliation. And so it's building the family network to get more involved to have a say in sentencing reform and policy change affecting the treatment of the incarcerated person as well.

The importance of this advocacy has not gone unnoticed. Andrea James, the Founder and Executive Director of Families For Justice As Healing and the National Council For Incarcerated 
and Formerly Incarcerated Women and Girls, along with Glenn Martin, recently received the Robert F. Kennedy Human Rights Award in recognition of their "indispensable work to equip currently and formerly incarcerated women and men to be at the frontlines of reform efforts in the United States to end the

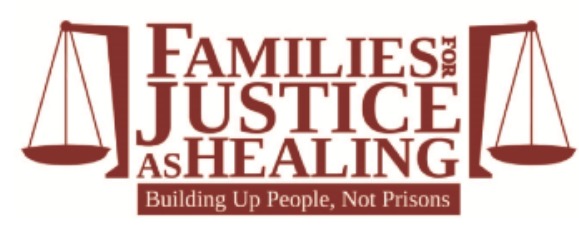
racial and socioeconomic inequality perpetuated by the criminal justice system" (Johnson, 2016).

Many leaders have used their social capital to involve religious and civil rights communities in reducing mass incarceration. They have thus helped expand the community of concern about incarceration, and increased the support networks for people while they are in prison and when they come home.

Thus, the leaders play a bonding role by solidifying the community of people who have been directly affected by the criminal justice system and serving as important sources of social capital in that community. The next section adds their bridging capital to the mix.

\section{B. Bridging Capital Enhanced by Strong Ties with Directly Affected Communities}

The leaders operate at the intersection of a tight-knit community of formerly incarcerated people and a more diffuse network of stakeholders and key actors who have valuable information and resources. By virtue of their education, employment, and activism, the leaders form what social capital theorists would call weak ties: relationships with people who have social capital and are outside their communities of affinity (Granovetter, 1973). Weak ties link people who differ from each other in important identity characteristics that make it less likely they will become part of an embedded network of people who are connected to each other. Although weak ties are not as effective in providing ongoing social support, they have been found to be much more effective than strong ties as conduits of valuable social capital (Crowell, 2004). Because they are both bonders and bridgers, the leaders can effectively diffuse external resources within their close-knit communities. They also bring their unique body of knowledge, experience, and commitment to people with whom they interact through work, school, and advocacy.

\section{(1) Connecting people who have experienced incarceration with outside resources and relationships}

The leaders connect formerly incarcerated people with people and organizations outside that community who have valued social capital, such as jobs, college knowledge, or decision-making power. They may do this by introducing community members to their contacts, inviting community members to meetings or events with these external stakeholders, or bringing them together to work on a project or campaign. In this manner, they spread the resources generated through their weak ties among those in their close-
The leaders connect formerly incarcerated people with people and organizations outside that community who have valued social capital, such as jobs, college knowledge, or decisionmaking power. 
knit communities. Through their formal organizational positions as mentors, leadership developers, and organizers, they can regularize these interactions, and multiply their individual capacity to share these resources with the community.

Higher education proved to be an important source of new relationships in social services, policy, and public arenas. Relationships with professors provided the leaders with access to both subject-area expertise and practical knowledge. They also give the leaders entrée to jobs, grants, speaking opportunities, and policy makers. Through higher education, many of the individuals we interviewed gained access to these relationship-based resources so crucial to social mobility and effective leadership.

Many leaders also cited higher education as a particularly potent forum for developing ties with people from different social classes, backgrounds, and races. They described interactions with people who had never met anyone who went to prison, or even who came from a poor community. For some of the leaders, college classes were the first opportunity they had to interact as peers with privileged white people who grew up in middle-class neighborhoods. The cross-class relationships developed in college provided a whole new source of social capital.

The leaders described a variety of techniques that enhance their capacity to bring these new resources to their communities, such as peer mentoring, participatory workshops, and theater for social change. They also described many instances of using their credibility and organizational position to vouch for people with criminal records so they can overcome stigma and presumptions against them and gain access to opportunities, such as jobs, speaking engagements, or admission to school. Over and over, they have made it possible for individuals and groups to enroll in college, get jobs, and become involved in activism to improve their communities.

Some of the leaders have created organizations that explicitly share social capital as part of their change strategy. These organizations have produced concrete positive outcomes for people who have had contact with the criminal legal system. For example, College and Community Fellowship (CCF), an organization led by Vivian Nixon, provides formerly incarcerated women with academic and social support to enable them to access and succeed in college through building a community invested in each other's success. CCF reports that the women they have helped have earned more than 300 higher education degrees, and "less than $2 \%$ have gone back to prison in the organization's 16 years of operation." That statistic compares to an overall re-arrest rate of more than two-thirds of incarcerated people within three years of release.

Several of the leaders draw on their roles as licensed ministers and their strong ties to religious communities to broaden the web of support for people in prison. For example, Divine Pryor, the Director of the Center for NuLeadership on Urban Solutions (CNUS), described the launch of "the first ever faith-based tele-visitation network, involving ten churches in Brooklyn where 
Bridging capital enables the leaders to build the capacity of service providers, administrators, and policy makers to make decisions informed by their impact on those who inhabit the systems they manage.

individuals will actually be able to come into the sanctuary and visit their loved ones in designated prisons throughout the state of New York." Almost two years of negotiating and coordinating with the New York State Department of Corrections and the black churches in Brooklyn culminated in this network of churches that provides training, infrastructure, and organizing needed to sustain this family preservation program.

Thus, the leaders infuse communities affected by incarceration with resources they have developed through their multi-faceted activities as organizational catalysts.

\section{(2) Diffusing "ground truth" within non-justice involved communities}

Social capital travels through the leaders in the other direction as well. Many of them have formed relationships with people who have not previously interacted informally with anyone who has experienced incarceration. In addition to connecting different groups of people, the leaders also connect with people from a multiplicity of systems-healthcare, criminal justice, higher education, organized religion, and others. These bridging relationships provide muchneeded information and insight to judges, corrections officials, lawyers, students, teachers, social workers, foundation leaders, policy makers, and other decision makers.

These weak ties build others' capacity and will to address the needs and interests of communities and individuals affected by mass incarceration, and reduce the stereotypes that keep formerly incarcerated people outside the circle of public concern.

\section{(3) Sharing knowledge to build capacity to promote change}

Bridging capital enables the leaders to build the capacity of service providers, administrators, and policy makers to make decisions informed by their impact on those who inhabit the systems they manage. The leaders have provided individuals working in areas of criminal justice, education, and community development with insight on the needs and barriers facing currently and formerly incarcerated people. They have shared advice on issues ranging from designing facilities for people coming out of drug trafficking to reimagining prisons to enabling colleges to develop climates that support students returning from prison. One leader related how CEOs consulted with him to develop contracts for parolees. Many of the leaders have been invited to serve as consultants to inform the design of programs, policies, and even entire prison systems.

Some of the leaders have been in a series of positions over time, enabling them to build longterm relationships with people in city and state government, the corrections system, community based organizations, and the advocacy community. For example, one leader negotiated a contract involving multiple court systems, the district attorney, and the drug courts to enable 
individuals convicted of non-violent crimes to be sentenced to college. "It took us five years to negotiate that. We got everybody to sign off." These relationships, developed and sustained over time, enable the leaders to pursue outcomes that require long-term commitments and trust.

Colleges and universities provide a significant venue for the leaders playing this bridging role. Many of the leaders described interactions both inside and outside

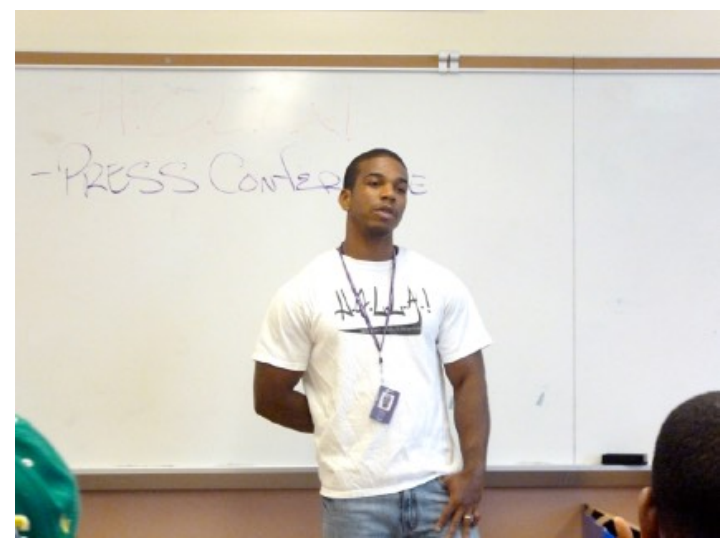

Cory Greene speaks to students about H.O.L.L.A.! class in which they shared their experience, and in the process had a significant impact on non-justice-involved students' understanding and commitment. Cory Greene, who earned a Bachelor of Science in Applied Psychology at NYU, illustrated the way this bridging role facilitated the development of a robust learning community cutting across class and background:

I think in a very short time we have a core group of people. We've created a network and we really have honed in on our analysis and on our message. And we come from very different places. This is NYU so people are really privileged; and then you've got people who are formerly incarcerated or people who fall in the middle of being really privileged and formerly incarcerated, not that all people who are formerly incarcerated are poor, but the majority are. So I think that this group is so different on many different levels-classwise, political-wise, education-wise, and experience-wise. And for us to challenge each other in those small meetings on agenda, on politics, on whose voice is most important, to really have those deep conversations and then come to a collective understanding, I think that process is really special.

Several of the leaders developed curriculum in which they both share their own insights and bring in other formerly incarcerated individuals to expand students' understanding of the criminal justice system's impact on individuals, families, and communities. One leader, along with her partner who is also formerly incarcerated, was able to reach the entire class of first-year social work students in this way:

I had all three hundred students divided into five sections. And so it just really played a catalytic role within the school to have all the first-year students be exposed to thinking about issues of incarceration, and how much punishment is enough, and what about kids? It was really exciting.

The leaders have shared their own stories in churches, prisons, boardrooms, and classrooms, from individual meetings to large gatherings. Leaders cited the importance of "counteracting the dominant narrative" with their own realities. 
Another leader has played a similar role in a graduate school of education; several have played that role in law schools. While one individual was pursuing his doctorate, he developed and implemented a curriculum to train social work students to understand the historical and contemporary facets of mass incarceration. He then used his knowledge and contacts to build a partnership with the Philadelphia prison system, which created internships for social work students working both pre-release and post-release. That curriculum has been adopted in four other higher education institutions.

Thus, the leaders use their bridging social capital to inform people who work in criminal justice and related areas and may do so in the future.

\section{(4) Reducing stereotypes and expanding the circle of concern}

Because of their bridging social capital, formerly incarcerated leaders are uniquely positioned to influence how key stakeholders view people who have experienced incarceration. In their interactions, they embody qualities and values that challenge prevailing stereotypes. Many of the leaders described interactions that produced observable shifts in decision-makers' understanding and perspective.

The leaders have shared their own stories in churches, prisons, boardrooms, and classrooms, from individual meetings to large gatherings. Leaders cited the importance of "counteracting the dominant narrative" with their own realities.

Several examples illustrate this general pattern. One leader described an interaction with a juvenile court judge who for years had taken a hardline approach to juveniles. This judge would "pound them hard and try them as adults" because she thought "they really are... the scum of the earth." In a one-on-one conversation with the leader, the judge bemoaned the fact that "she just sees no good in the children." In response, the leader walked the judge through the history of their city, the civil rights movement, and the connection between the social policies of disinvestment and the intergenerational poverty and neglect that surround the youth she sentences:

Here we are almost 50 years [after the fight for civil rights] and in those same communities, people are still asking for better schools, better homes, better housing. And I said, "The products of each of those generations are the children that we're dealing with." I said, "What other choice do they have?" I said, "You're looking at the second, third generation of a family of drug dealers." I said, "This child has been born into that situation." I said, "let's look at the school system that they were sent to. Those are the same schools that had been begging for equal rights and justice and books for years."

That conversation prompted the judge to stop, reflect, and realize that she had never before looked at the issue in that way. The leader then invited the judge to take the time to ride through some of the local communities with him, including ones like where the leader grew up. 
Many examples emerged in the interviews: an undergraduate fellow who, as a result of interacting with one of the leaders, decided to work with the reentry population; a corporate lawyer who decided to become a defense lawyer devoted to reducing mass incarceration; a victims' advocate who changed her stance on the effectiveness of incarceration.
As they rode, he narrated what it was like to live in these neighborhoods, drawing both on his own experience growing up and his current work with youth. The judge recalled her own earlier interactions with those communities as a young lawyer before she became a judge, when she saw first-hand the struggles that people in those communities faced. She had seen those communities on the decline then, and realized that she had not been back since, that she was 40 years removed from the struggle those families had lived through, and that those families and communities still face the same challenges that contribute to their involvement with the criminal legal system. At the end of their journey, the judge told the leader that this experience really changed her perspective. The leader reported that "after that point she became my chief advocate for an alternative center for juveniles. She's even influenced the judges that came under her."

Leaders often built relationships of mutual respect with fellow students and colleagues before disclosing that they had been in prison. Sometimes an incident or remark reflecting a misconception or stereotype prompted the leader to self-disclose. That disclosure in turn prompted people to rethink their views and, just as importantly, to care about the people who experience prison. That shift created a foundation for the leaders to provide nuanced information about what led them into prison or how the system actually works. One leader's example illustrates this more widely shared experience:

I changed the mind of my whole class. I got up and said, "I just wanted to share with you all that I'm a convicted felon. I spent 13 years in prison." And that got their attention. And I just started telling them about what was happening to me from the time I got out of prison. I shared with that I couldn't go to this college because they told me I had to pay out-of-state fees even though I've been incarcerated all my life. So I gave them a different perspective of what it is to be a person with a felony conviction. First of all, they were shocked ... They were like, "You? You spent 13 years?" Yes, I did 13 years. They just see me as one of their very smart classmates. And they just can't believe that, and so that's how I got them engaged.

Some of the leaders created occasions for their peers to get directly involved with people who are incarcerated. Their classmates later let them know that these interactions had a profound impact on them, and prompted some of them to pursue jobs and participate in a larger movement to reform the criminal justice system: 
Some of the incarcerated guys and the women students from both places now are doing work within criminal justice. A lot of them have told me that the program played a big role in their doing the work that they do now in policy, in programs, in different places in New York City but also in other states and even other countries. And I think that makes me proud.

The interviews revealed that relatively brief interactions with the leaders sometimes had ripple effects on those who heard their stories. Many examples emerged in the interviews: an undergraduate fellow who, as a result of interacting with one of the leaders, decided to work with the reentry population; a corporate lawyer who decided to become a defense lawyer devoted to reducing mass incarceration; a victims' advocate who changed her stance on the effectiveness of incarceration.

The leaders' bridging capital enables them to connect groups of people who otherwise lack the opportunity to interact. Many are using their bridging roles as door-openers for other directly impacted people, as well as to connect people in decision-making positions with much-needed information and insight about the criminal justice system and the people who have been through it.

\section{Linking Communities and Influencers to Make Institutional and Policy Change}

Finally, some of the leaders have developed relationships of trust and respect with individuals in positions to make institutional and public policy and to shape public opinion, such as legislators, commissioners, foundation leaders, and media hosts. Scholars have called these kinds of relationships "linking social capital," a close cousin of bridging capital. Linking capital enables leaders with conviction to catalyze change on a much wider scale.

For many years, leaders with conviction influenced policy primarily as outside advocates who engaged in lobbying, protest, litigation, and public speaking aimed at raising consciousness and pressuring change. As public policy makers have begun to realize the value of designing policy informed by direct experience, a growing group of leaders with conviction now occupy boundary-spanning positions where they have direct ties to policy and media insiders with resources, information, influence, and formal decision-making power. These positions enable leaders to share their ground truths with thought leaders in a position to influence the public narrative about incarceration. They also link these thought leaders and policy makers to organized networks and coalitions that are building a movement to reduce incarceration, with leadership by people closest to the problem.

\section{(1) Ground truthing policy}

The leaders' boundary spanning roles have enabled them to provide information to policy makers at a point when they can have an impact on important decisions. One leader provided a picture of how relationships facilitate this timely sharing of information:

So also having legislators text me from a hearing and say, "what do you think about what this guy's saying right here?" Or having a Tea Party member co-sponsor the ban the box bill 
The leaders' boundary spanning

roles have enabled them to provide information to policy makers at a point when they can have an impact on important decisions. after I reached out to them and we had a long conversation. Having the leader of the Republicans lean over in a hearing and say, "I just want to let you know that I totally support this bill, but I just have to leave because I have a bill in another committee but I'm totally voting for it. Don't worry. Good work."

Another leader involved in a variety of task forces on gun violence brought lessons from his own experience on the street to his interactions in these venues, buttressed by those he has worked with since prison:

And I'm in those spaces now, and I feel my voice there in bringing up some of the deeper issues that I believe are the root causes of gun violence. I'm able to bring it into these spaces in a much more persuasive way, weaving in issues of generational trauma and how it evidences itself as this kid shooting another kid on the corner. I think that plays a role in informing much deeper reflections on how we can address this epidemic of gun violence.

An interaction between legislators and one of the leaders, who had been sentenced to lifetime parole, illustrates how linking capital enables leaders to destabilize the assumptions held by a group of legislators about the face of crime and criminals:

When people meet person to person, they don't see that person as a criminal. And when I said, "But l'm one of those people who will be on lifetime parole," it just changes the conversation. I think other times we don't see people as people once they have gone afoul of the law. And you don't see people on the front page of the Post. You see them in your office when they're talking to you and they're making sense. And then we say, "But l'm one of them." And I think many of the senators really had to rethink this whole idea of what the face of crime looks like.

The leaders' close bonds with community members also enabled them to mobilize large groups of people on short notice. Sometimes the mobilization made possible by a leader's eclectic social capital simultaneously provides support for that leader in the face of a crisis and, in the process, drives larger policy change. Khalil Cumberbatch illustrates this dynamic. Cumberbatch built a network of relationships through Sometimes the mobilization made possible by a leader's eclectic social capital simultaneously provides support for that leader in the face of a crisis and, in the process, drives larger policy change. his work mentoring and supporting higher education access for people who had been involved with the criminal justice system, along with doing various kinds of policy advocacy at the intersection of immigration, education, and criminal justice. Despite his many contributions and widely recognized leadership, Cumberbatch suddenly faced deportation because of the nature of his previous offense. When he was 
detained by Immigration and Customs Enforcement (ICE), a network quickly coalesced of policy makers, corrections officials, community based organizational leaders, academics, and activists, who used their connections and resources to push for Cumberbatch's release. Against all odds, that mobilization was successful. ICE released Cumberbatch from detention in October 2014; two months later Governor Cuomo granted him a pardon, making him eligible for citizenship.

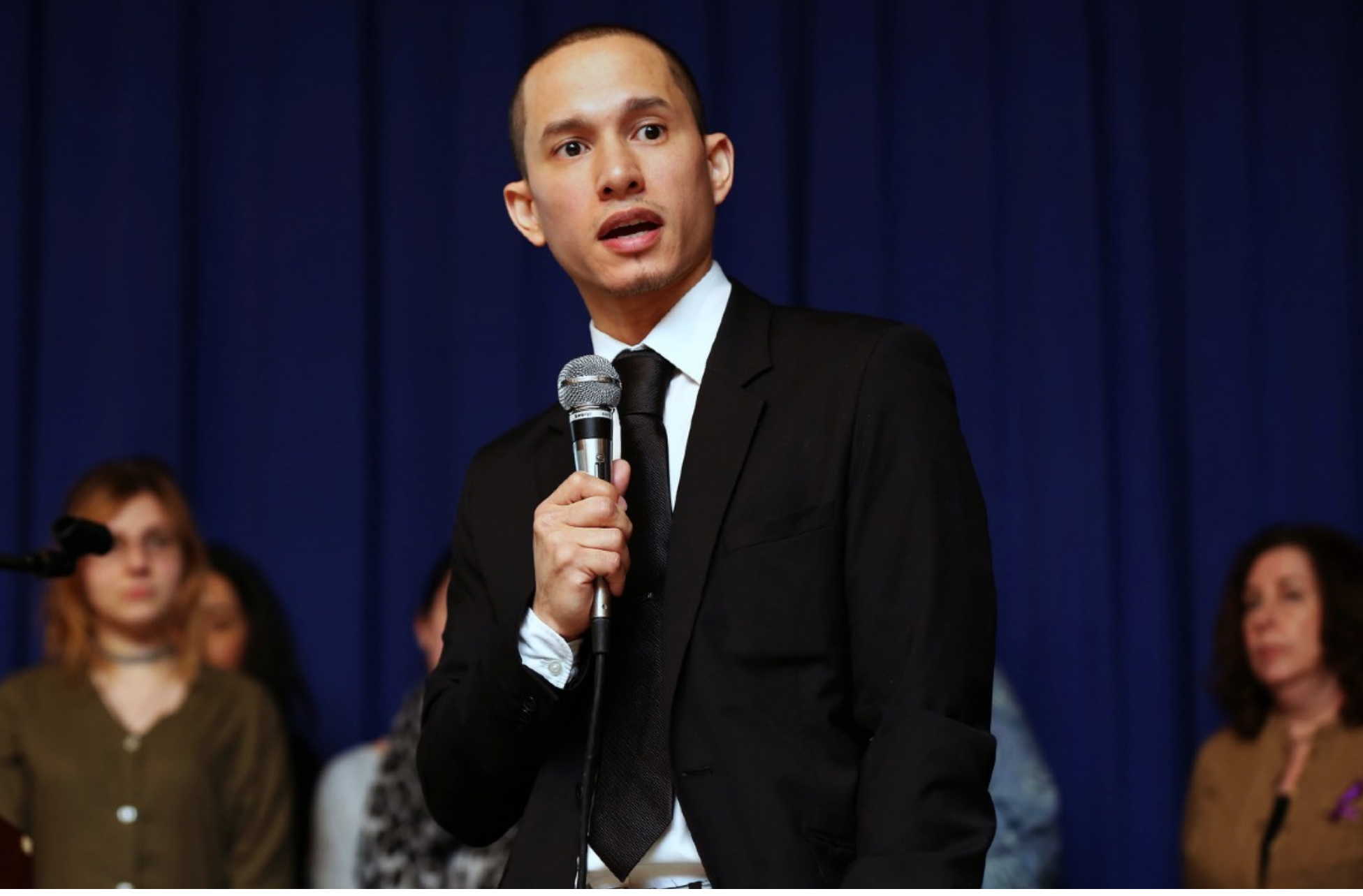

Khalil A. Cumberbatch speaking at Fordham University

The leaders also share their access to policy makers with grass roots organizations, particularly those led by people with criminal justice involvement. One leader illustrates the use of social capital to increase the effectiveness other formerly incarcerated leaders and activists in the policy arena:

The other day someone from a grassroots organization calls me up and says, "we're trying to get this meeting with [a legislator]," and so I instantly go into, "okay, let's lay out what you want to do at this meeting. I think that this is the way to approach it." Laying out, for instance, he's not one of our local politicians that we can just say, here's a bill that we want passed. Those scenarios are based on years of trust and knowing that this is what we do and how we do it. 
Indeed, JLUSA's mission revolves around building the capacity of leaders with conviction to have impact. The opportunity to influence policy builds and strengthens the community of people committed to positive change. The leaders provided many examples of community members whose sense of the possibility for turning their own lives around emerged through participating in a successful, community-led policy initiative.

\section{(2) Feedback loops}

In effect, the leaders serve as a multi-directional feedback loop between those creating and implementing the policies and those being impacted by them. When they have had the opportunity to be at the policy table as full participants, the leaders could shape the design of reentry programs to take account of the experiences that people actually have. For example, one leader characterized his role as a "bumper guard" of the design process, thus avoiding pitfalls that people actually face in their transition from jail:

I offered my experiences of the many times I was coming home from Rikers and getting on the bus and couldn't make it past Queens Plaza before I picked up a drug or relapsed. So we talked about how we could make sure people get access to services, and create those bumper guards.

These linking relationships also enabled the leaders to provide a reality check, drawing on their ongoing contact

When they have had the opportunity to be at the policy table as full participants, the leaders could shape the design of reentry programs to take account of the experiences that people actually have. with people still in the system to reveal gaps between policy on the books and practice on the ground. One leader illustrated how this use of social capital enabled him to head off the adoption of a policy that would have permitted corrections officers with a history of abuse to determine who would be

These linking relationships also enabled the leaders to provide a reality check, drawing on their ongoing contact with people still in the system to reveal gaps between policy on the books and practice on the ground. denied family visits. He provided detailed information about ongoing abuses of discretion by corrections officers, and showed how the existing incentive system encouraged such abuses. His membership on a corrections commission enabled him to share this knowledge with other commissioners who lacked knowledge of how policies actually are implemented in the prison:

There is the interpretation by the department, and then there is the interpretation by the officer. The department has a number of policies, but how those policies get implemented across facilities is different. And what I said to the Commissioner is, if the policies we have right now all say the same thing but they are interpreted differently, how do we have confidence that when we have this policy around visits, that it will be interpreted the right way? We have evidence by the way policy is being 
implemented now that it doesn't get interpreted at the very front end of the system in the way it was intended.

Thus, the leader was able to prevent the adoption of a policy that would have arbitrarily blocked family members from visiting their incarcerated relatives, and heightened tensions within the prison in the process.

Another leader prevented the passage of a regulation that would have required that "juveniles who get into a fight at the juvenile facility will be transferred immediately to adult jail and tried as adults." He drew on his own experiences and those of many youth he worked with to show policy makers that the proposed change in policy "would be ineffective, and also ultimately would lead to less public safety because of the recidivism rates of kids who end up in prison." Those proposing the regulation had not appreciated the long-term human impact of this punitive regulation. After hearing from this leader, the policy makers ultimately decided not to pass that new regulation.

Yet another leader used her access to both families and policy makers to communicate widespread concern about a proposed standard that would have banned any outside mail other than postcards. She knew from her own experience, as well as her experience working with many incarcerated people, that people need pictures of their kids and other visuals or else "you can get lost in there and will not make it out in the right mind frame." In fact, she had just published an article about mail "being the lifeline to people who are

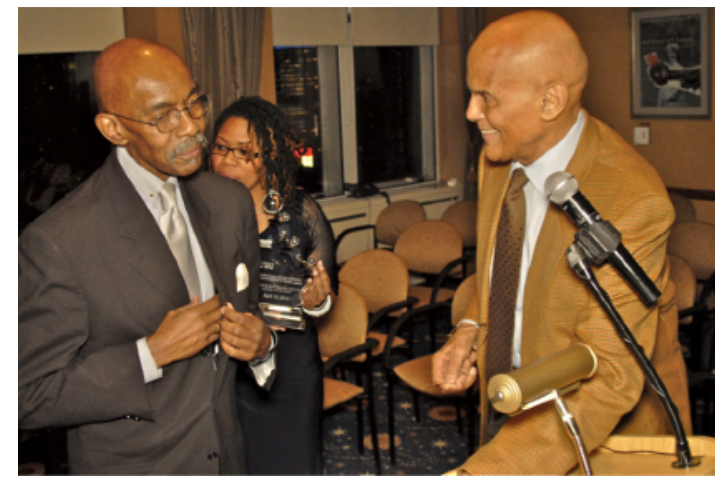

Eddie Ellis Receives Human Justice Award from Harry Belafonte, 2012 incarcerated." This leader used her links to policy makers to head off this change in policy that she knew would be disastrous for women and their families:

Ellis' letter has been credited with catalyzing a movement to humanize the references to and treatment of people with criminal justice involvement.
So I decided to talk to everyone that I had been in contact with because people had told me, if there's ever anything that I need help with to let them know. So I started asking around and then we made this huge ordeal about it, and we rallied up all these people who were to be affected by this and we had a sit-down with the Department of Corrections, and with the chief and everybody. And it was a community forum for this issue. And we pretty much had everyone involved-politicians, people, lawyers. They were saying why this is not a good thing and why we don't want this imposed in our county jail. 
This leader's access to policy makers, coupled with her knowledge and experience, enabled her to communicate the impact of the rule, and to prevent the rule's adoption. Her position also enabled her to circulate the information about the positive result within the jail, and thus to prevent the escalation of protest into violence and retaliation.

\section{Organizational Catalysts In Action}

The most extensive impact comes when leaders have this combination of bonding, bridging, and linking social capital. Consider the following three examples: (1) The language campaign to change the language referring to people who have been in prison, (2) the Second Chance Fellowship, and (3) efforts to increase access to college both inside prison and for returning citizens.

\section{(1) The Language Campaign}

Eddie Ellis started the language campaign as the founding director of CNUS, the first-ever "independent research, training and advocacy Human Justice think tank, ... founded and developed by academic professionals with prior experience within the criminal punishment system." For decades while in prison and after he was released, Ellis built a network of people who experienced prison, and did so in collaboration with Divine Pryor and other formerly incarcerated scholars and leaders "by providing research, advocacy and leadership training to formerly and currently incarcerated people, their families, communities, allies and criminal justice professionals." Part of CNUS' mission involves "reshaping the media portrayal and public opinion of people with criminal records by humanizing their popular image and offering language alternatives to counter current negative stereotypes, beliefs, misinformation and myths."

Ellis, who died in 2014, launched the language letter campaign with the aim of changing the language used to refer to people who have spent time in prison by publishing an open letter on CNUS's website. Ellis' letter offered a simple yet powerful request:

In an effort to assist our transition from prison to our communities as responsible citizens and to create a more positive human image of ourselves, we are asking everyone to stop using these negative terms [such as inmates, convicts, prisoners and felons] and to simply refer to us as PEOPLE. People currently or formerly incarcerated, PEOPLE on parole, PEOPLE recently released from prison, PEOPLE in prison, PEOPLE with criminal convictions, but PEOPLE.

This letter circulated widely among the networks that had been cultivated by Ellis and others at CNUS. Ellis' relationships with people in positions of influence propelled the letter-and the mission behind it-to people in positions to implement this change in terminology. For example, in direct response to the letter, Danielle Sered, the Director of Common Justice, a demonstration project at Vera Institute, changed her use of language: 
As someone who also believes deeply in the power of language, I quickly joined the ranks of those moved by Eddie and his letter. And when I was planning the demonstration project that is now Common Justice and seeking to develop language that reflected the humanity, dignity, and potential of all our participants-both those harmed by and responsible for crime-Eddie was one of the first people whose counsel I sought. Since then, we at Common Justice have consistently used the language I shared with him that day and that he celebrated as consistent with the spirit of his language letter. Instead of "victim" and "offender," we say "harmed party" and "responsible party."

Ellis' letter has been credited with catalyzing a movement to humanize the references to and treatment of people with criminal justice involvement. Most recently, that movement reached the White House. In April of 2016, the Justice Department's Office of Justice Programs, which supports law enforcement and criminal justice efforts across the country, issued a new policy statement announcing that it would no longer use the words "felon" or "convict" on its website, in grant solicitations or in speeches, but would instead use "person who committed a crime" or "individual who was incarcerated." As Karen Mason, the head of the Justice Department's Office of Justice Programs noted, this change "would no doubt have moved Eddie Ellis."

\section{(2) The Second Chance Fellowship}

In October of 2015, in response to a proposal by Dorsey Nunn to President Obama and Attorney General Holder for a national strategy session hosted by formerly incarcerated people, a meeting took place at the U.S. Department of Justice with a group of those advocates -all formerly incarcerated-and the Federal Interagency Reentry Council. A Department of Justice official in the Obama administration credited that meeting with prompting the Justice Department to hire a Second Chance Fellow-a formerly incarcerated individual who has substantial policy expertise and whose role is to provide expertise and perspective to inform the federal government's reentry policy making.

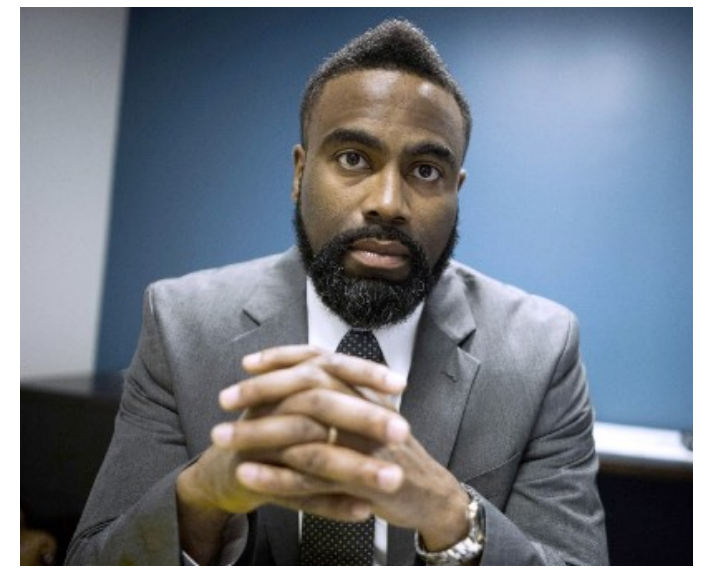

Daryl Atkinson, Senior Staff Attorney, Southern Coalition for Social Justice, White House Second Chance Fellow
Daryl Atkinson became that first Second Chance Fellow. In his role, he advised a federal reentry council that represents more than 20 government agencies. Atkinson's public service involvement followed in the footsteps of family members who were deeply involved in public health and civil rights work. His route from college to prison crystallized after an injury forced him to abandon his basketball ambitions and return to Alabama, where he replaced the validation he had gotten from sports with dealing drugs. He was caught selling cocaine and sentenced to a mandatory minimum of 10 years in prison for a first offence. 
While in prison, Atkinson was transferred to a maximum security facility, where he met James, ${ }^{9}$ a jailhouse lawyer who changed his life. All kinds of people, including Crips, Bloods, Viceroys, Disciples, and Aryan Nation members, wanted James to do their legal work because he was so good. Instead of asking for payment in the form of cigarettes or coffee, James asked anyone seeking his services to "drop their colors, enroll in education, and join the law collective." James had 40 to 50 predominantly black men conducting research, pouring through

As the Second Chance

fellow, Atkinson connected his networks, insights, and expertise to the design and implementation of Second Chance programs on a national level. trial transcripts, and typing briefs. Atkinson became involved, and had the chance find strength in his own capabilities and character. He became convinced to try to go to law school because, in his words, "I wanted to use the legal hook as an organizing opportunity for our people. And so that's where my inspiration came from."

After spending three and a half years behind bars, Atkinson finished college, earned his law degree, and rose to become a Senior Staff Attorney at the Southern Coalition for Social Justice, where he focused on criminal justice reform issues, particularly removing the legal barriers triggered by contact with the criminal justice system:

Daryl is a founding member of the North Carolina Second Chance Alliance, a burgeoning statewide coalition of advocacy organizations, service providers, and directly impacted people that came together to achieve the safe and successful reintegration of adults and juveniles returning home from incarceration. Daryl serves on the North Carolina's Indigent Defense Services Commission and the Commission for Racial and Ethnic Disparities in the Criminal Justice System.10

Before taking his position as the Second Chance Fellow, Atkinson launched a series of initiatives including "Clean Slate" - an initiative that he described as "replicating James." This work aims at restoring licenses, expunging records, and representing individuals before licensing boards. Like James, Atkinson used this work as an organizing opportunity, "to meet that direct need so we can do some consciousness raising, so we can do organizing."

Atkinson also has been a leader in the Ban the Box effort in North Carolina, leading to the implementation of administrative policies banning the box at the city and county level. He led the development of an online searchable database to inform people about the collateral consequences of a conviction in North Carolina; that tool served as the model for the tool that the American Bar Association created on behalf of the National Institute of Justice. He also created a mechanism enabling the state of North Carolina to collect data showing that the ban the box policy is effective-making it one of the few jurisdictions in the country that's actually quantifying the data to show that this particular policy change is effective. He co-authored a

\footnotetext{
9 James' last name omitted to preserve confidentiality.

${ }^{10}$ https://www.southerncoalition.org/portfolio-item/daryl-v-atkinson-staff-attorney/.
} 
report documenting the strategies and impact of these efforts, and the crucial role of formerly incarcerated leadership in their success.

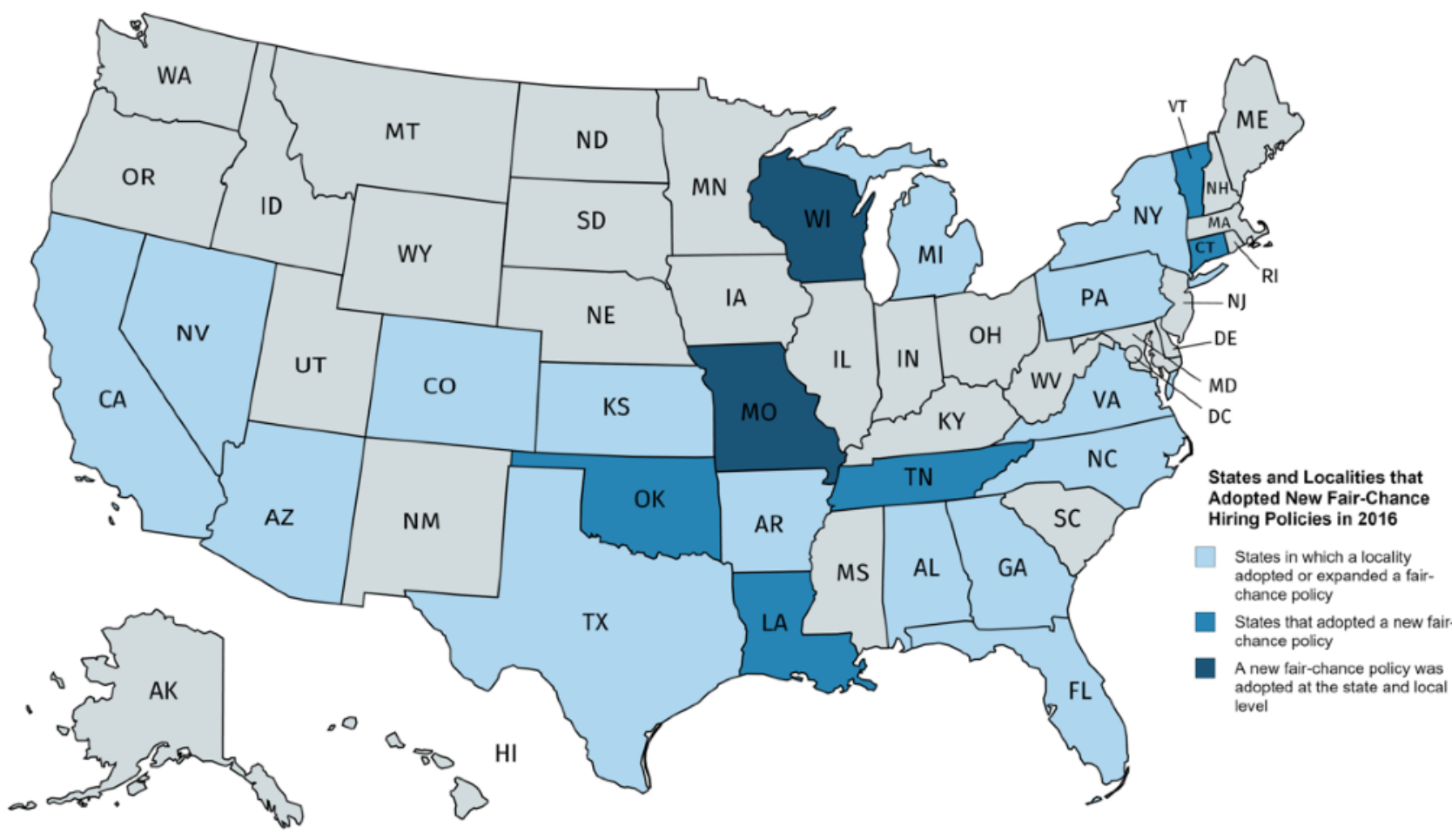

Created with mapchart.net $\odot$

Map of Ban the Box Policies across the United States

Source: http://www.prisonerswithchildren.org/2017/01/ban-the-box-policies-adopted-in-7-states-28-localities-in-2016/

The Ban the Box movement has taken off, yielding adoption of similar ordinances in over 100 cities and counties and 23 states across the country since the first one passed in 2014 and winning endorsements from Attorney General, the editorial board of the New York Times, and U.S. President Barack Obama. President Obama directed the establishment of the Federal Interagency Reentry Council, and charged that body with working across executive departments and agencies to reduce unwarranted barriers to successful reentry, rehabilitation, and reintegration of formerly incarcerated individuals. As the Second Chance fellow, Atkinson connected his networks, insights, and expertise to the design and implementation of Second Chance programs on a national level.

\section{(3) Expanding Post-Secondary Access and Success}

Vivian Nixon is one of a group of formerly incarcerated leaders who parlayed their prison experience into a life-long commitment to making higher education a reality for people affected by mass incarceration. Her story exemplifies the central role of leaders with conviction in the quest to make higher education a reality for people who experience incarceration.

Nixon started out in public housing in what is known as the Gold Coast on Long Island. In her words, "there really were two towns of extremes divided along racial lines-one for white 
people who were among the wealthiest people in the country and the other for people of color who were living in poverty." The school system for the predominantly white, upper class community was among the best in the country. Out of 700 high school students, 12 were African American. Nixon was one of them.

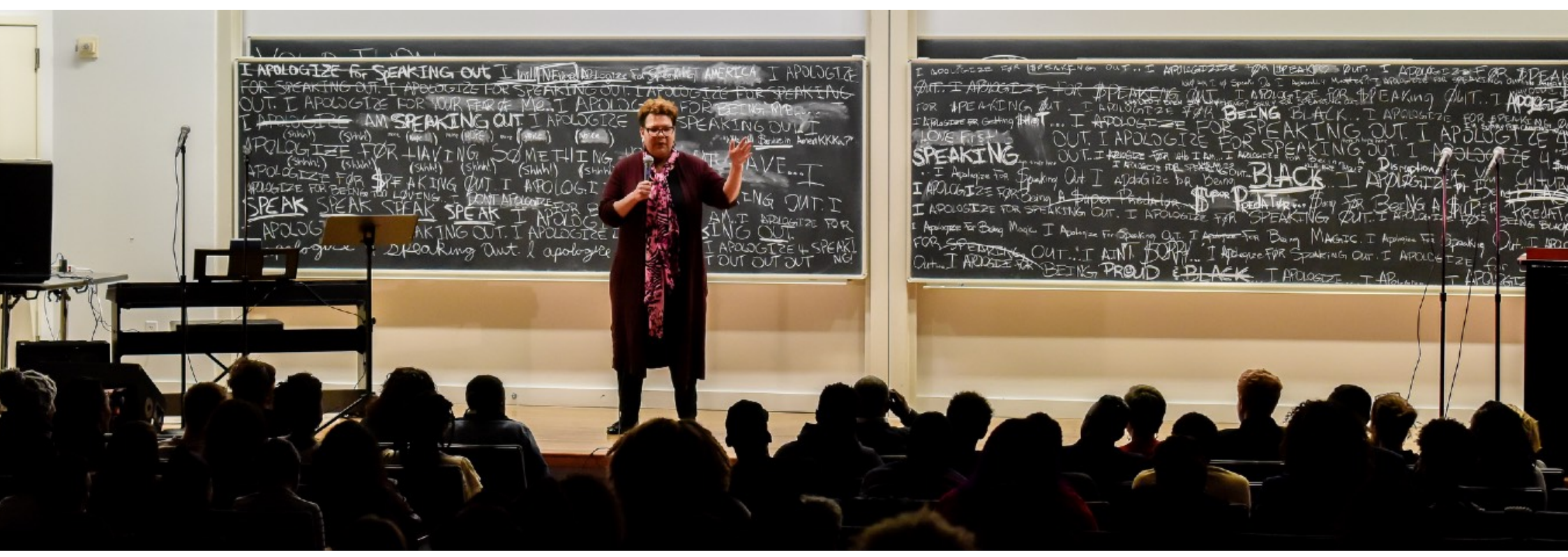

Vivian Nixon speaks at the Broadway Advocacy Coalition's “The American Hangover” event, December 2016

Nixon's life progress was interrupted by drug use, which led to her incarceration. She did not finish college before she went to prison, and that was a big disappointment to her family, as well as to herself; her family always expected that she would go to college. When Nixon first got to Bedford Hills prison, college was available, but before she could enroll, she was transferred to another prison where college education was unavailable. She, like so many other people who were incarcerated, lost her chance at higher education when lawmakers eliminated federal Pell Grant eligibility for incarcerated students in 1994 and for New York State Tuition Assistance in 1995. Because Nixon had her high school diploma and some college credits, no other educational programs were available to her.
Nixon has become a national spokesperson for the value of higher education in transforming the lives of people who have experienced prison, as well as for the capacity of people with criminal records to serve as "home-grown social capital," positioned to support the development of their families and communities.

Losing the chance to pursue her college education was devastating, but Nixon decided she was not going to waste her time while in prison. She started teaching the adult basic education and high school equivalency classes to other women in prison-something she was able to do because she had been, in her words, "really lucky" growing up to attend good schools. Her students-women her age and older from the South Bronx, Brooklyn and Harlem-could barely read and write. She was shocked by the quality of education that so many people in prison had 
received. "Somebody has to do something about this," she thought. That somebody would be her.

Nixon learned about empowerment to make change from her family, whose protests and civic work to improve the community's quality of life taught her early on that "you don't have to sit by and be oppressed, that you had power." Nixon now heads College and Community Fellowship (CCF), an organization that has helped women with criminal justice histories achieve over 300 higher education degrees. She was named an Aspen Ascend Fellow for her national leadership in making higher education available to people in prison and after they come home. She has become a national spokesperson for the value of higher education in transforming the lives of people who have experienced prison, as well as for the capacity of people with criminal records to serve as "home-grown social capital," positioned to support the development of their families and communities. ${ }^{11}$ She blogs regularly for the Huffington Post, and speaks frequently at conferences and in national media and policy venues.

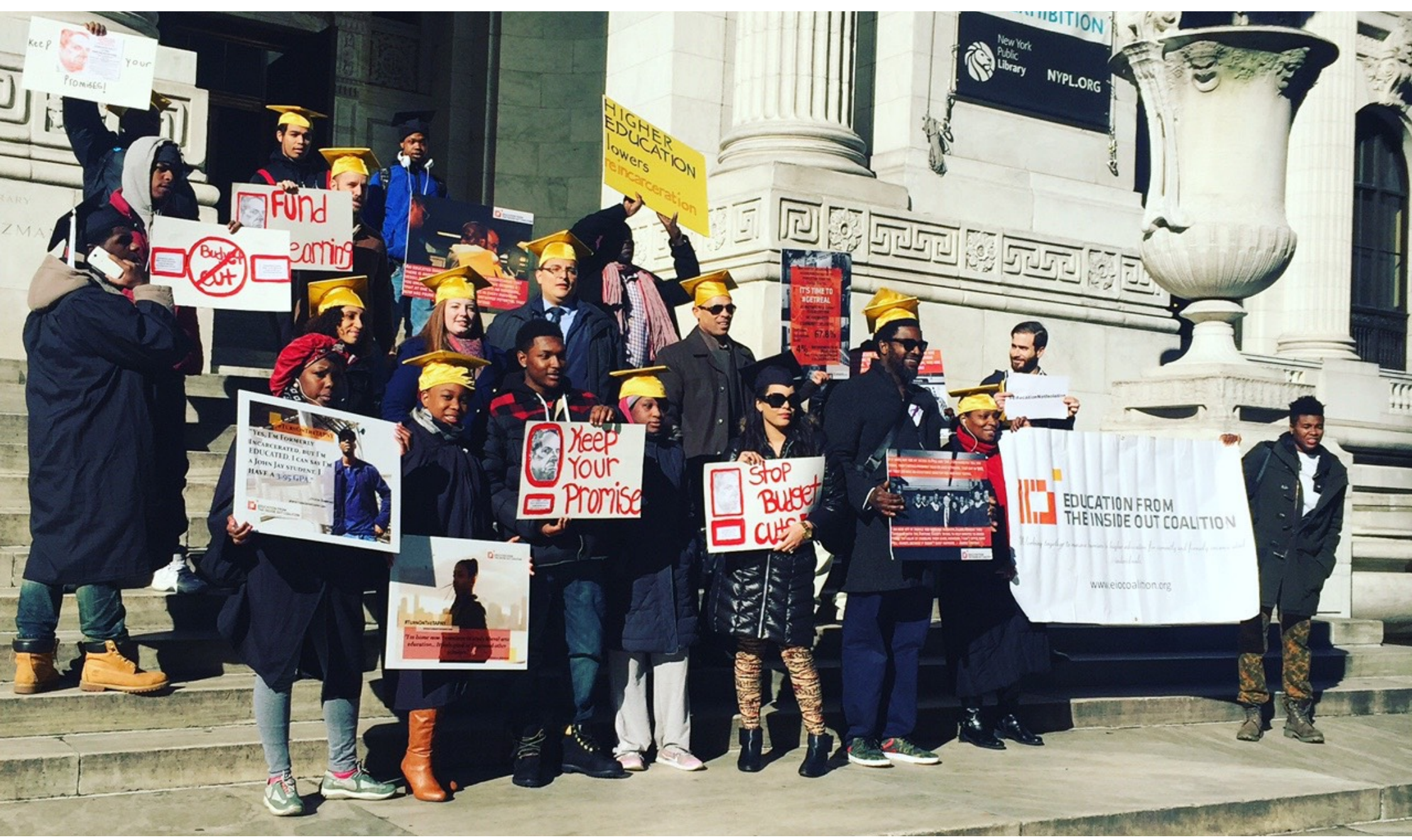

Education from Inside Out Coalition protest outside of New York Public Library, December 2015

${ }^{11}$ S. Sturm and V. Nixon (2015). Home Grown Social Capital. Retrieved from http://b.3cdn.net/ascend/d6f46bacfa0aa7a587_sfm6brfxf.pdf. 
Not content to navigate around the policy barriers limiting access to higher education for people in prison, Nixon partnered with Glenn E. Martin to co-found Education from the Inside Out Coalition (EIO). According to its website, the EIO coalition is "a national, nonpartisan collaborative of advocates working to remove barriers to higher education facing students while they are in prison and once they come home." Martin and Nixon built on the different experiences they each had with college in prison. Unlike Nixon, Martin earned a 2 year liberal arts degree while he was in prison, but also was cognizant that the program he participated in was a skeleton of what it used to be before Pell grant eligibility was taken away from incarcerated students. Both of their experiences underscored the importance of higher education in prison.

Nixon's and Martin's idea for creating the EIO Coalition began at a conference co-sponsored by CCF, the Legal Action Center, where Martin served at the time as a Vice President, and the Correctional Association of New York. The occasion was the Correctional Association's publication of a report marking the 20-year anniversary of the removal of Pell Grants from prison. Martin and Nixon decided to build on the tremendous interest in restoring college to people in prison, which was evident at that convening. They launched the EIO Coalition, without yet knowing where they would get the resources and support to sustain it.

The EIO Coalition has come a long way from its beginnings as a shoestring organization with two volunteer leaders hoping to enlist greater interest and support. The Coalition now includes three organizational leaders, and over $\mathbf{4 0}$ member and supporting organizations, many of them led by people who have experienced incarceration. The Coalition had their biggest win about a year ago. They had recognized through their research and advocacy a few years earlier that the regulations governing Pell grants give flexibility to the Department of Education to do pilot research projects within the existing regulatory language. The Coalition, under the leadership of Nixon, Martin, and other formerly incarcerated leaders, continued working with the US Department of Education to help them think through how to do this, building on the research establishing the value in providing education, and seeking to measure the best way to deliver higher education. Nixon and Martin were part of the launch event, led by the US Attorney General and the US Secretary of Education, of the Second Chance Pell pilot program, which will "test new models to allow incarcerated Americans to receive Pell Grants and pursue the postsecondary education with the goal of helping them get jobs, support their families, and turn their lives around."

These kinds of collaborations between government and formerly incarcerated leaders offer a benchmark to be pursued vigorously at the state and local level, and to hold the federal government accountable for backsliding to the mass incarceration policies that a bipartisan coalition has rejected. 
I feel that the people that have helped me most even to be able to articulate my own personal goals have been the people who themselves have had similar experiences to me. And so Glenn has been an extreme support/mentor/friend since l've been released. And I have other mentors who themselves have been people who have been formerly incarcerated, people who have had contact with the justice system. So in many ways the people that have probably been most instrumental in helping me to realize my own personal and professional goals have been people themselves who have been formerly incarcerated, people who have done work with justice-involved populations and are extremely committed to doing that work.

One leader joined a Facebook page set up for members of his work release unit when they were released, and members used that page to support each other. Another built an advocacy community on the outside from the networks formed in prison:

One of the most powerful communities I have known is a network of fellow prisoners that I have coordinated since my release. This network grew from friendships forged in California state prison facilities. While incarcerated, I organized other women to assert our rights through group complaints and demonstrations within the prison. Among us, we also organized mutual support groups to assist those most vulnerable among us with seeking health care, better housing conditions, appealing negative disciplinary decisions, organizing against racialized discipline, and demanding action against abusive CO's. The experience was powerful for all of us, and we agreed to continue to keep in touch on the outside, and we continue to support each other.

For some, one or more family members became crucial sources of support during and after incarceration, whether financial, psychological, or educational. One leader described the support system anchored by his family as the distinguishing factor enabling him to succeed when he came home:

The only thing that separates me from a thousand men that I left behind the walls is that I returned to a viable support system where I didn't have those immediate pressures of food, clothing and shelter pressing down upon me and I could think. I could devise a plan and in fact my plan was really, I was already devising it prior to getting out. Most cats don't have that luxury. As a result, they revert back to instinct and they start playing checkers instead of chess.

For those who did not have biological family members who provided this support, others played this pivotal role. The leaders identified educators as another group in a position to cultivate resilience and leadership. College in prison enabled these relationships to develop before the leaders reentered the community: 


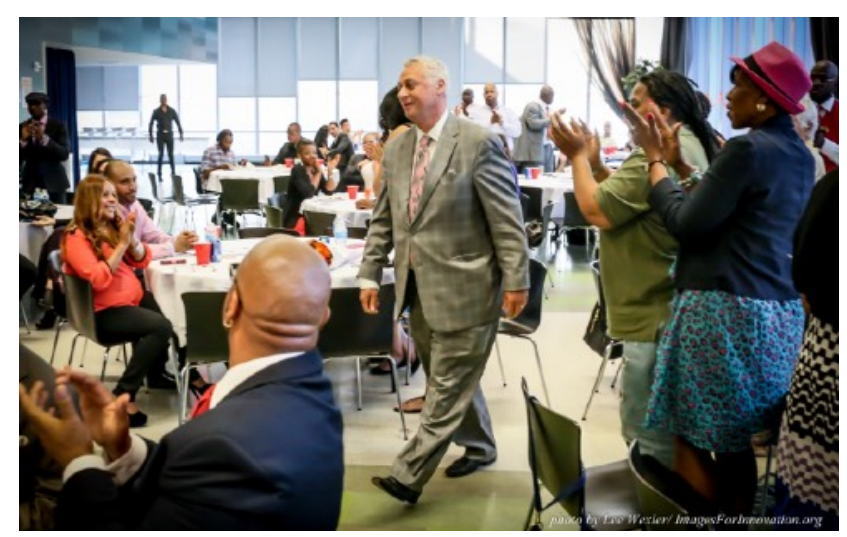

Carl Mazza, a professor at Lehman College, receiving the "Person of the Year" award at College Initiative's graduation ceremony

"Okay, so what's a community organizer and how do I you know how do I become that?"

I did a master's degree when I was on the inside. And I remember one of the professors there asked us to describe ourselves. And I was like, "Oh okay, I was a dope dealer. And I polluted the community. I usually get easy access and I'm bilingual and I know how to survey the territory and all these criminal things that go along with that stuff." And he said, "Wow, that sounds like a community organizer to me." And I think one of the first times people were telling me, wow, there are some other skills that you have, that you're totally overlooking." And when I heard that I said,

Several leaders described interactions with professors who had personal experience with the justice system, and were willing to support students following in their footsteps:

And the professor was like, "Can you stay back after class? And the professor was this tall, older, bald-head black cat, wearing a dark gray suit every day. So I go talk to him and he was like, "You really were in prison?" I said I did eight and a half years. He was like, "Damn, you know I did two years?" I said, No. I'm like no, but I'm like ... And he's like, "Yeah, you know I did two years and I did community college and then I went to Howard." And then he got his Master's and his Ph.D. and so the dude became a mentor to me... . And so he had a huge influence on me because one, he made me see somebody in a position of authority and who had been highly successful with a prison record. And then two, he made me conceptualize what I might do with my life in a way that I hadn't yet been considering.

Another leader attributed his success and leadership to a law professor who served on the admissions committee of a law school to which this leader had applied. Every other committee member had planned to reject this individual without discussion. Based on his application, this law professor believed strongly that this leader had strengths and experiences that would enrich the law school community and the profession:

And so in the meeting she said, "Absolutely, he's in". The others didn't want me there. She physically got up out of her chair and went over and took my file out of the "no" pile and put it in the "yes" pile, in the top pile. And that's how the story goes. And so they accepted me... . And [this] Professor to this day is really like my second mother... . If I had anything that goes on in my life where I need some support, guidance, mentoring, the first person I call is [this professor]. 
A third leader showed how a teacher used the classroom to help him acknowledge and embrace his leadership capabilities:

So the teacher made me lead reader and she asked me to explain all of the poems. And she later explained to me that she felt the students would follow my leadership and she used my enthusiasm and my love for poetry to inspire the rest of the class. And she was actually the first person to tell me that I actually had a lot of ability to lead if I would just take hold of it. So that was the first time I ever heard anybody say that to me. She was the one that said it, like "You are a leader; just take hold of the reigns of leadership," and she told me at that time that that would save my life.

Individuals who provided employment opportunities after prison also proved crucial to the leaders' transformation. These supporters gave the leaders a chance, stood by them even when they struggled, and invested in their progress along the path to leadership. As one leader's example shows, support came from people of all different backgrounds:

God has placed some amazing people in my path who are able to look past my criminal record history. [JM], a white man from [my state], surely did not have any kind of racial justice or equity analysis, but he saw something in me and gave me my first permanent job.

These individuals ran the gamut in their positions-from judges to corrections officers to professors to attorneys to heads of nonprofits. They shared a willingness to use their own social capital to start people along a pathway of continued growth:

This dude knew I did eight years.... He hired me as an assistant manager. I'm doing the daily deposits. It's enough money where you think that in the larger society, when you're talking about the consequences of incarceration, you don't get that job. So that's one guy that had a huge impact on me because it's just his willingness to be really imaginative about what he expected me to be in the world and about not reducing me to my incarceration despite the fact that he fed his kids with that business.

Several leaders included prison officials among the group that provided this invaluable support, especially in finding that first position after release from prison:

When I went for the job, this superintendent of the last prison I was in wrote me a reference and sent it in, and that supported me to get a new job. So, right then and there it was how networking impacted my life and then, it just continued on.

Also crucial have been the interventions of people who use their own social capital to enable people to succeed in the face of biases that often stand in the way of opportunities for people with criminal records. People in these key roles included professors, program directors, government leaders, probation and parole officers, and judges. One highly successful leader, 
whose first job after prison was on a military base, recalled his manager's response to the news of his felony conviction: "He was like, "Look, don't worry about it; I'll go to bat for you and we'll be able to work through that."

Another leader described how a former boss tapped him to assume a leadership position in a new organization:

She reached out and said "Listen, I think that

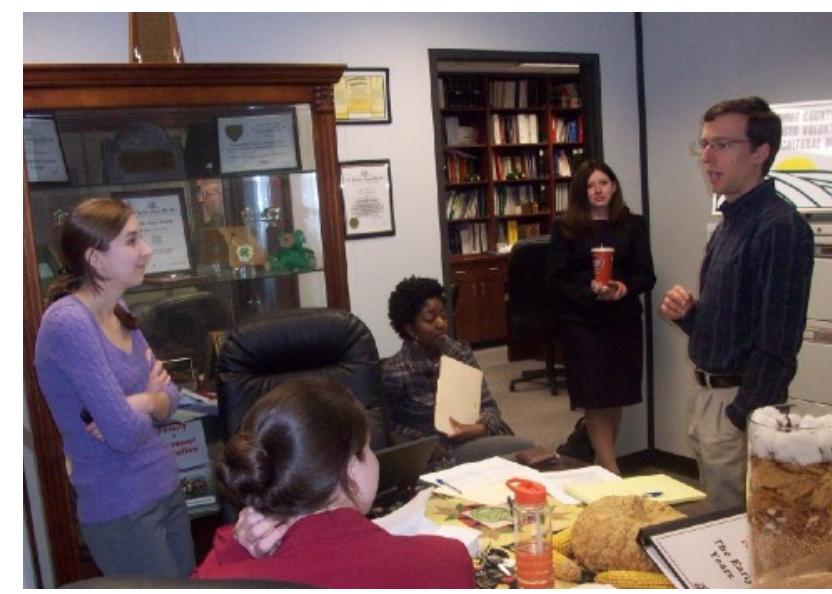

Students receive advice from SCSJ's Chris Heaney you would be a great manager for a program like this." So I went to the [nonprofit organization], and sure enough I was able to turn that program around and increase enrollment outcomes, placement outcomes. So it was that relationship with her, her moving on and her pulling me up and saying, "I think because of your method of leadership, you would be able to actually lead this department."

A third example involved an executive director of a community development organization who facilitated the opportunity for a leader to do trainings with the department of corrections "behind the wall":

So the executive director pulled me aside and said, "Listen, we think you have some expertise to support developing this curriculum and design," and I was like, "Really? I never thought that I was an expert. I don't know." But I started doing some of that work for them, going into the classroom, talking about transition from incarceration to back into the community and gaining employment.

The leaders found particularly valuable the employers, coworkers, and others who stuck by them even when they faced challenges, setbacks, and roadblocks that continue to affect people who have spent time in prison.

And then I came home and I had certain obstacles and challenges and fears, mainly a fear of judgment, rejection, and discrimination. I was worried that no one would give me a chance because of my criminal record. And eventually I landed at [my current job]. I've been supported by peers and colleagues that have given me the confidence to take risks and make mistakes. And that has been where l've grown the most and what has really impacted or supported me the most in my success in my current role. 
One leader described the crucial role of her boss in enabling her to improve the situation of her son, who had been incarcerated in solitary confinement. She then used the skills she learned through that experience (with the support of her employer) in advocacy work on behalf of others facing similar challenges. Her employer also provided sufficient flexibility with her schedule and use of office space to enable her to pursue activism and organizing work. Leaders also singled out employers who afforded them the flexibility and support they needed to go back to school, graduate, and move into positions with greater responsibility.

Many of these life-changing opportunities arose fortuitously through informal relationships with people who were willing to play this role. The leaders noted the dearth of these kinds of relationships for many people who have experienced incarceration. They suggested introducing greater incentives for individuals to play these roles, and rewarding them when they do. They also discussed their interest in collective leadership development that would equip leaders with conviction to be effective on a broader scale, and to be in a position to exercise leadership at this pivotal point in the movement to reduce incarceration.

Education and training often track people to dead-end jobs, regardless of their interests and leadership potential. The trackrecords of the leaders interviewed for this report demonstrates the missed opportunities represented by programs designed with the narrow goal of reducing recidivism, rather than enabling individuals to realize their full potential.

\section{B. Education and Training to Cultivate Leadership}

The report has documented the crucial role of education and training that focuses on empowering people who have been incarcerated to discover their potential as leaders and assume roles enabling them to exercise that leadership. For many of the leaders, education pushed them to reflect, to think critically and systemically, and to assume responsibility for having a positive impact in their communities. The benefits of higher education thus go far beyond the individuals who participate. These individuals become organizational catalysts uniquely positioned to facilitate individual and systems change, and mobilize a broad-based movement to reduce incarceration.

Often, education and training associated with corrections and reentry is far more limited in its goals, if it is included at all in the policy agenda. Education and training often

track people to dead-end jobs, regardless of their interests and leadership potential. The track records of the leaders interviewed for this report demonstrates the missed opportunities represented by programs designed with the narrow goal of reducing recidivism, rather than enabling individuals to realize their full potential.

Leaders also highlighted the importance of a long-term investment in people, and in sticking with them when they have setbacks. Too often, education and training programs insist on immediate success. As one leader observed: 
I think sometimes we pull people into the movement so quickly that they end up breaking themselves in the movement. And so there are lot of guys who meant well about becoming street workers to serve gang involved youth but didn't realize that they have not yet recovered internally from their challenges and ended up falling off while doing the work, because they weren't ready yet.

This leader emphasized the value of sticking with support for people over an extended period of time, enabling them to fail and recover, and providing resources that will be there for people over the long run. This work includes providing increasing funding for counseling services in and after prison for formerly incarcerated individuals. As Abrigal Forrester noted, trauma recovery is very important in enabling formerly incarcerated people to transform their lives while developing leadership skills. With support in addressing the continuing effects of trauma, these leaders can derive unusual strength and resilience. Without that support, individuals who make it to the change agent phase of their transition are more likely to experience setbacks.

The report also highlights the value of education and training that equips leaders to work effectively in the local, state and national policy arenas. Some of the most far-reaching impact reported by the leaders comes from those who have been exposed to the way these systems work, as well as to the opportunity to develop communication and leadership skills needed be effective in these arenas. That kind of high-level policy training and leadership development has been in short supply, and is a focus of JLUSA's work.

\section{Building Leaders with Conviction into Institutional and Policy Design}

Finally, policy makers and institutional leaders can enhance the impact of leaders with conviction by building those leaders into their decision-making processes as full participants. This kind of participation goes beyond inviting them to be a token participant on a panel, testify at hearings, or give feedback on policies and programs designed without their participation. Full participation means that formerly incarcerated leaders have the opportunity to sit at the policy table and directly influence the process of agenda and strategy setting.

Several notable examples from the interviews illustrate the importance of this design feature. Organizations

This kind of participation goes beyond inviting them to be a token participant on a panel, testify at hearings, or give feedback on policies and programs designed without their participation. Full participation means that formerly incarcerated leaders have the opportunity to sit at the policy table and directly influence the process of agenda and strategy setting. such as Legal Services for Prisoners with Children, the Ford Foundation, the Vera Institute, the Nathan Cummings Foundation, and the Justice Department have created fellowships for people with criminal justice involvement and policy expertise. The Open Society Foundations has awarded 10 percent of its Soros Justice Fellowships to formerly incarcerated people, developing a national network of those most impacted by mass incarceration advocating for justice. 
Another example illustrates the growing recognition-as well as the value-of leaders with conviction as full collaborators in policy making and implementation. The philanthropic community recently took up a challenge, posed by the Executive Alliance for Men and Boys of Color, to adopt fair-chance hiring practices. In response, close to 50 foundations have banned the box and issued a challenge to other foundations to eliminate barriers to employment for people with arrest and conviction records. As part of this initiative, the alliance decided to put together a policy tool kit for foundations.

Formerly incarcerated leaders' first exposure to this initiative was at the Justice Roundtable announcing the tool kit. During the discussion, several leaders asked which experts had participated in generating the tool kit. It turned out that, although one formerly incarcerated leader had been consulted, he had played a minimal role, and leaders who had been central to the movement for over a decade had not participated. At that moment, the philanthropic organizers recognized a blind spot in their approach to formerly incarcerated leadership. The organizers only nominally involved those with direct experience and expertise, who had been in the trenches crafting Ban the Box policies for over a decade. As one foundation leader put it, "We were looking for legitimacy instead of true guidance and expertise."

On the spot, the organizers committed to changing course. The staffers met with Daryl Atkinson within a week. In the process, they learned that Atkinson and Nunn were part of a national network of formerly incarcerated leaders and families who had been building a movement since 2003. Conversations between Atkinson and the foundation leaders helped make clear that directly affected advocates were the ones who helped in developing those tools in the first place, and their role was largely missing from the narrative.

Moreover, it turned out that the ground truth of formerly incarcerated leaders had already improved the quality and efficacy of public policies. For example, in the Durham, NC Ban the Box campaign, an issue arose concerning where the government would get its criminal background information. Should the government use the official state criminal justice databases, which are more accurate and will probably put people in the best position to get a job? Or should the government get its information from private data providers, which are less accurate but are covered by the Fair Credit Reporting Act, thus potentially affording people a private right of action if those providers incorrectly report criminal record information? The legal organization that drafted the toolkit for the philanthropic collaborative took the view, "never give up the right to sue." But the movement leaders' experience counseled otherwise. They wanted the most reliable source for the background check. In the words of one leader, "I would rather have a job than a law suit."

In fact, an account of the Durham campaign, described in a report co-authored by Daryl Atkinson and published by the Southern Coalition for Social Justice, showcases what policy looks like when it develops policy solutions in deep collaboration with "the people closest to 
the problem." SCSJ had formerly incarcerated people on staff as leaders. It worked closely with a focus group of people with criminal records.

People with criminal records shaped the contours of the policy choices throughout the campaign, which allowed the coalition to adapt its strategy to meet the needs of the community while simultaneously responding to the government (Atkinson and Lockwood, 2014).

These examples illustrate the distinction between cosmetic participation to "check the box" and full participation that enables leaders to help shape priorities and strategies. The organizers of the foundation collaborative toolkit had good intentions, but initially failed to include formerly incarcerated leaders as a meaningful part of the process; when this blind spot came to their attention, they corrected the mistake to create more robust participation. Their willingness to learn from this process-and to share publicly that learning-exemplifies the way policy makers can build strong and mutual collaborations that do justice to the involvement of leaders with conviction.

\section{Conclusion and Recommendations}

This report has shown the role that leaders with conviction play as organizational catalysts in bonding, bridging, and linking social capital. Their alchemy of experience, education, and employment, fueled by deep commitment, equips them to play a crucial role in shifting the public narrative and empowering community leadership with the capacity to collaborate effectively with people at every level of government and civic participation. They also are uniquely able to keep the nation's attention focused on the imperative of reducing incarceration and revitalizing communities that have been affected by mass incarceration.

Three policy recommendations flow from the extensive findings reported here:

1. Design public policy to encourage and reward individuals and organizations who use their social capital to support the recovery and leadership development of people who have experienced incarceration or are at risk of doing so.

2. Make high quality higher education available as a matter of policy to people in and after prison. Support education, training, and counseling that provides opportunities for individuals to discover and develop their strengths and leadership capacities, including their capacity to participate in public policy making and organizational leadership, and to enable people to advocate for themselves.

3. Incorporate the direct and meaningful participation of leaders with conviction into agenda setting, decision-making, and implementation of policies related to criminal justice and community change. 


\section{Appendix A: Methodology}

This Report is the result of a research collaboration between CISC and JLUSA that began in January of 2014. Researchers conducted a total of 53 confidential, one-on-one interviews beginning in January 2014 and ending in February 2015. The sample comprised the following:

- 48 formerly incarcerated leaders

- 5 policy makers, selected based on their prominence in criminal justice policy and their experience working closely with formerly incarcerated leaders.

\section{Sampling Strategy}

The sampling strategy for selecting interviewees was "purposeful" or "theoretical" sampling, where the aim is to illuminate and understand rather than to predict or determine causation (Maxwell, 2013). This is the dominant sampling strategy used in qualitative research. Specifically, the researchers selected a sample that was likely to reveal variation; it was important to conduct interviews with people from different geographic regions, demographic groups, and positions. We used a process of snowball sampling, starting with individuals who had been identified through our social networks and contacts and building out from there.

For purposes of selecting individuals to participate in the study, leadership was defined to include individuals who occupy positions where they are involved in advancing change related to the issue of mass incarceration that goes beyond improving the lives of individuals they directly serve, and who reached these positions after having been incarcerated and going through a process that enabled them to assume their leadership position.

\section{Interview Process and Protocols}

Research questions and interview guides were developed collaboratively with Glenn Martin and informed by the experience of other formerly incarcerated leaders and by the literature on social capital, networks, leadership, and the experiences of communities affected by incarceration.

The research focused on understanding: (1) how individuals who have experienced incarceration became leaders, (2) whether they share particular roles, strategies, or strengths related to their experiences with the criminal justice system, (3) what kinds of changes resulted from their leadership, and (4) how policies and practices enable people to exercise their roles as leaders with conviction in ways that enhance their impact.

The interviews were semi-structured; interviewers used a protocol to pursue a consistent set of themes, but explored additional, relevant themes as they arose in the course of the interview. Interviews lasted, on average, approximately one-and-a-half hours. 
The interviews explored the following themes:

- Family, educational, and community background

- Employment, community, and activist roles

- Pathway from criminal legal involvement into leadership roles

- Turning points along the pathway: decisions, barriers, opportunities or events that had an impact on their trajectory

- Significant relationships affecting leaders' development

- How leaders collaborate

- Challenges faced in developing and exercising leadership

- Activities or work that are important to the leaders

- Goals in the leaders' work and activism, and examples of success and failure in achieving them

- Interactions in which leaders drew on their experience with criminal legal system

- Examples of interactions where leaders observed change in others

- Experiences, programs that have been particularly helpful in cultivating leadership

\section{Coding and Analysis of Interview Data}

Interviews were tape-recorded, transcribed and coded, using NVivo qualitative software. We followed a standard qualitative-data coding and analysis procedure involving overlapping phases, beginning with "open coding," which entailed assigning descriptive codes to each line of the transcribed interviews; then "axial coding," whereby codes were aggregated into larger concepts and themes; and, finally, conceptualization, which involved an iterative process of mapping and remapping concepts and themes, their properties and dimensions, and their interrelationships, until a coherent narrative tightly linked to the data emerged.

To indicate the weight of evidence for any given finding, we chose to use adjectives such as "most," "many," and "some" to convey the prevalence of a theme (i.e., a coded account, experience, or view) across the interviews rather than reporting exact percentages of people mentioning the theme in their interview. References to particular themes are technically countable, but reporting percentages would lend a false precision to the data; in addition, percentages do not take into account the strength of people's statements. Instead, we use "most" to denote the vast majority of interviewees. We refer to "many" to indicate about half of the interviewees. "Some" people means that, although the theme was not representative of the referent group as a whole, it was shared by more than a few people, suggesting a noteworthy pattern. Every finding presented in the report had multiple sources of support. No quotation was included if it expressed a unique point of view.

\section{Confidentiality}

This study was conducted in accordance with the Human Subjects approval process. All participants were informed about the benefits and risks accompanying participation in the research, in accordance with the protocols approved by the Columbia Institutional Review 
Board for this project. We took particular care to protect the confidentiality of all interviewees. When necessary to preserve confidentiality, we omitted potentially identifying information, such as the gender, race, geographic location, or position of the interviewee.

\section{Study limitations}

The researchers did not undertake to interview a representative sample of people who have had involvement with the criminal legal system. Those interviewed had been identified in advance as formerly incarcerated people who had achieved positions of leadership. 


\section{Appendix B: Study Participants}

The following list contains the names, positions, organizations, and websites of the Leaders with Conviction who requested in writing that they be listed as individuals who were interviewed as part of this study. An additional 27 individuals were interviewed, and their confidentiality has been maintained, consistent with the requirements of the Columbia University Human Subjects requirements.

\section{Daryl Atkinson}

Senior Staff Attorney

Southern Coalition for Social Justice (SCSJ)

White House Second Chance Fellow

\section{Reginald Dwayne Betts}

Liman Fellow

Division of Public Defender Services

State of Connecticut.

\section{Kathy Boudin}

Director of the Criminal Justice Initiative:

Supporting Children, Families and Communities

Columbia School of Social Work

Founding Director, Coming Home Program,

Center for Comprehensive Care, St. Lukes-

Roosevelt Hospital

\section{Khalil A. Cumberbatch}

Manager of Training and Communications

JustLeadershipUSA

www.justleadershipusa.org

\section{Flores A. Forbes}

Associate Vice President

Strategic Policy and Program Implementation

Office of Government and Community Affairs

Columbia University in the City of New York

faf2106@columbia.edu

\section{Abrigal Forrester}

Director of Community Action

Madison Park Development Corporation

http://www.madison-park.org

\section{Alex Friedmann}

Managing Editor, Prison Legal News

www.prisonlegalnews.org

\section{Kevin Grant}

Violence Prevention Network Coordinator, City of

Oakland

Kevin Grant consulting

www.kevingrantconsulting.com

\author{
Corey Greene \\ Community Relations/Training Manager \\ Center for Nu Leadership \\ Co-founder, How Our Lives Link Together \\ https://holla-inc.com
}

\section{Norris Henderson \\ Executive Director \\ VOTE From Chains to Change. \\ vote-nola.org}

\section{Donna Hylton, B.S., M.A.}

From Life to Life, Founder/Director

Criminal Justice Advocate, Speaker,

Humanitarian

www.donnahylton.com

\section{Andrea C. James}

Founder and Executive Director

Families For Justice As Healing and the

National Council For Incarcerated and Formerly Incarcerated Women and Girls

justiceashealing.org

\section{Yolanda Johnson-Peterkin}

Board Member

College and Community Fellowship

\section{Sara J. Kruzan}

Incarcerated Children's Advocacy Network, (ICAN)

Campaign for the Fair Sentencing of Youth http://fairsentencingofyouth.org/incarceratedchildrens-advocacy-network/

\section{Glenn E. Martin}

Founder and President

JustLeadershipUSA

w. JustLeadershipUSA.org, CLOSErikers.org

\section{Julio Medina}

Executive Director

Exodus Transitional Community, Inc.

website: www.etcny.org 


\section{Vivian Nixon}

Executive Director

College and Community Fellowship

Co-founder, Education from the Inside Out

Coalition

\section{Dorsey Nunn}

Executive Director

Legal Services for Prisoners with Children

Co-Founder of All of Us or None

http://www.prisonerswithchildren.org/our-

projects/allofus-or-none/

\section{Divine Pryor}

Executive Director

Center for Nu Leadership on Urban Solutions

http://centerfornuleadership.org/

\section{Stanley Richards}

Senior Vice President

The Fortune Society, Inc.

www.fortunesociety.org

Ronald Simpson-Bey

Alumni Associate / JustLeadershipUSA

www.justleadershipusa.org

John Valverde

Executive Director

Youth Build

www.youthbuild.org 


\section{Appendix C: Leading with Conviction \& Emerging Leaders}

This section lists the state in which each Leading with Conviction Fellow resided during the time of their respective training.

\section{Leading with Conviction Fellows}

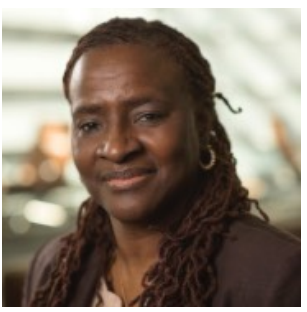

Carole Eady

New York

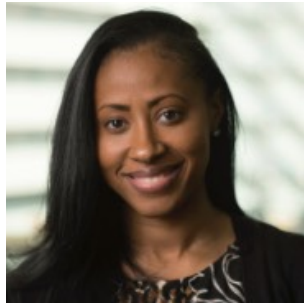

Jamira Burley

Pennsylvania

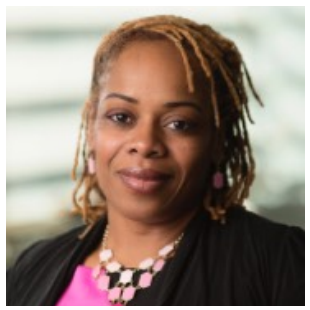

Martha Lynn

Shearer

Alabama

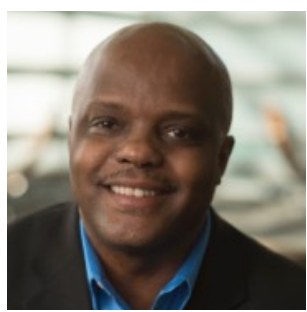

Ronald

Simpson-Bey

Michigan
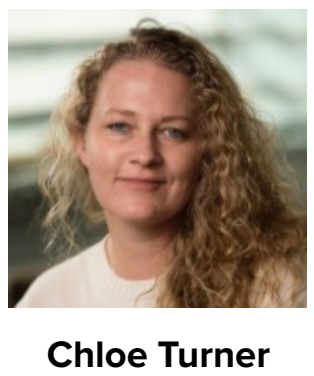

California

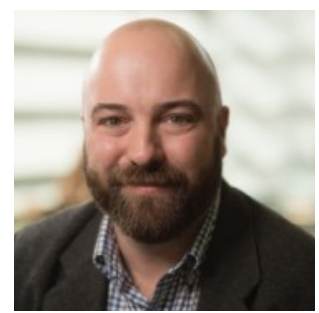

Jason Cleveland

Missouri

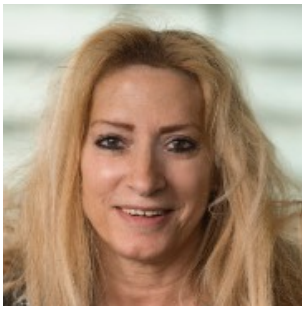

\section{Monica Jahner}

Michigan

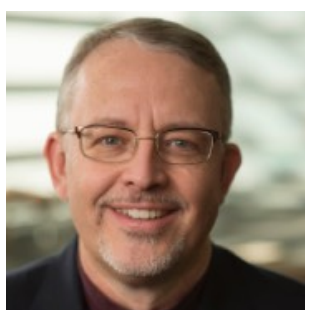

Steve Gordon

Texas

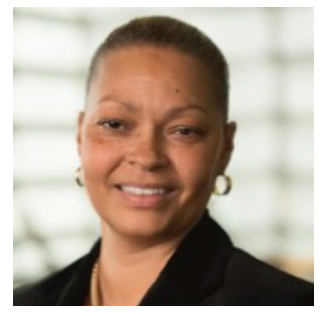

\section{Donna Hylton}

New York

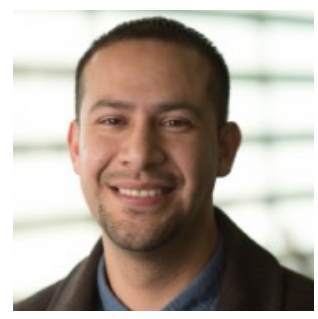

Juan Gomez

California

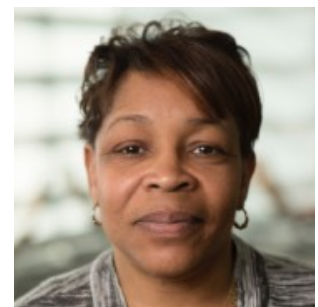

Pamela Allen

Connecticut

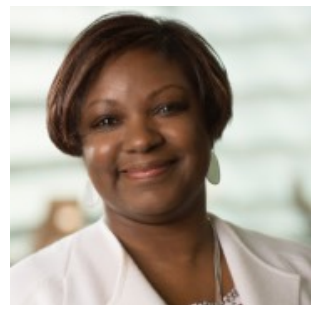

Teresa Y. Hodge Maryland

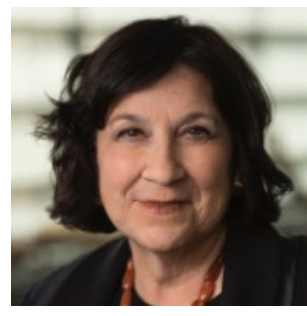

Evie Litwok

New York

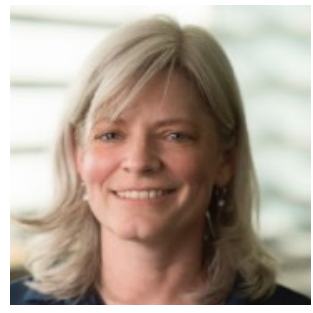

Kathleen Culhane

Massachusetts

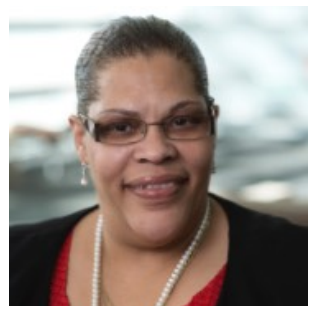

Dr. Patrice Palmer Ohio

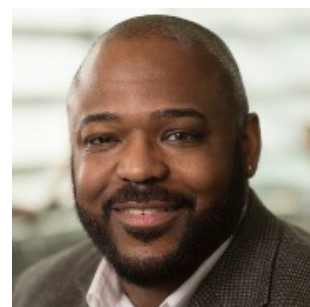

William "Bill" Cobb

Pennsylvania

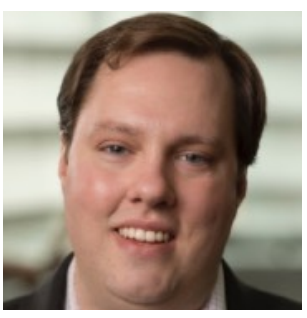

Galen Baughman Virginia

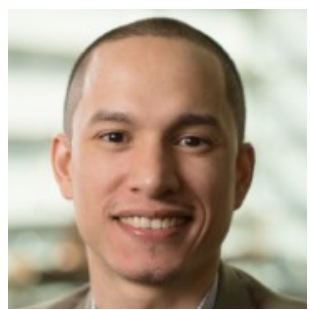

Khalil A.

\section{Cumberbatch}

New York

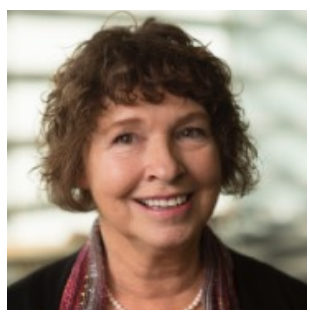

Patty Katz

Oregon 


\section{Leading with Conviction Fellows}

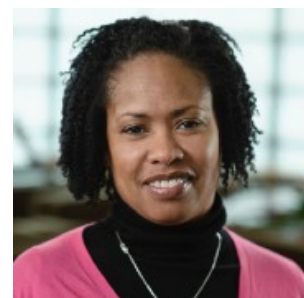

Colette Payne

Illinois

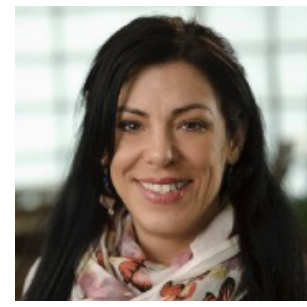

Kara Nelson

Alaska

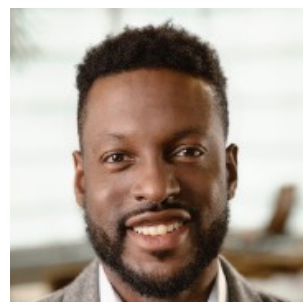

Marc Carr

Washington, D.C.

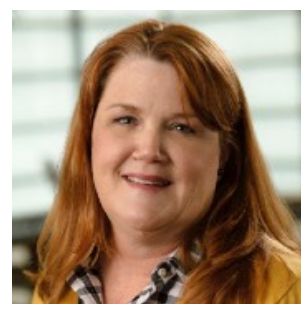

Theresa

Sweeney

Oregon

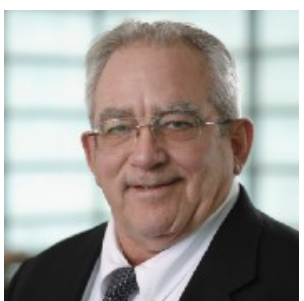

Dale White

Florida

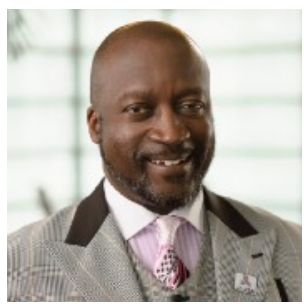

Ken Moss

Ohio

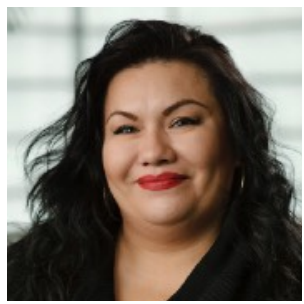

Maria Morales

California

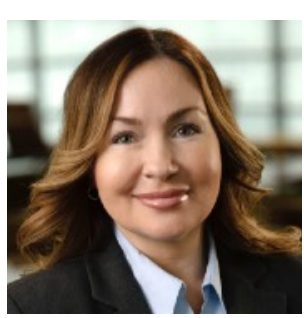

Toni Bunton

Michigan

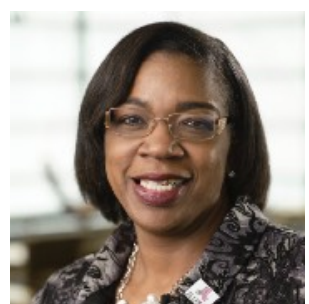

DeAnna Hoskins Ohio

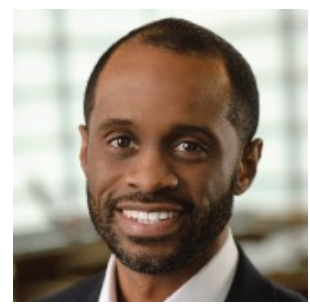

Kyle D. Bacon Washington, D.C.

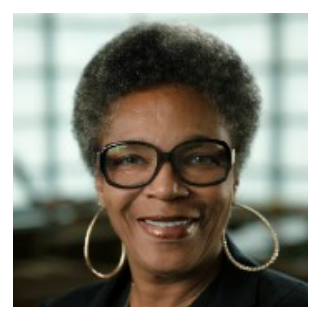

Marilynn B. Winn Georgia

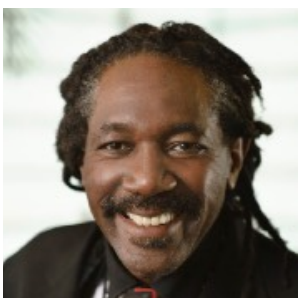

J. Jondhi Harrell Pennsylvania

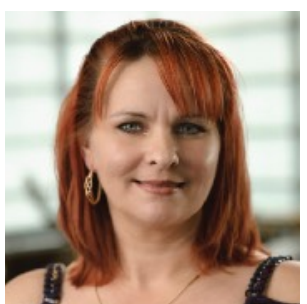

Lauren Johnson Texas

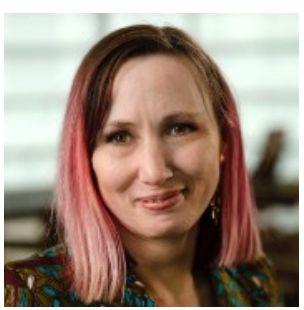

Misty

Beruberojo

California

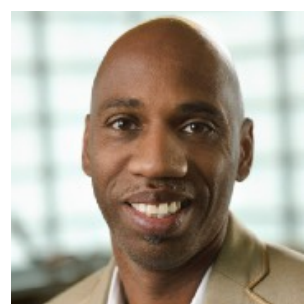

Jerry Blassingame

South Carolina

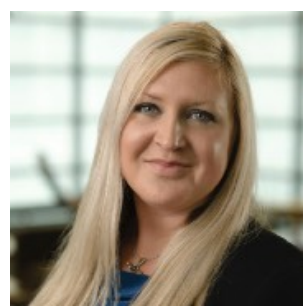

Layne Pavey

Washington

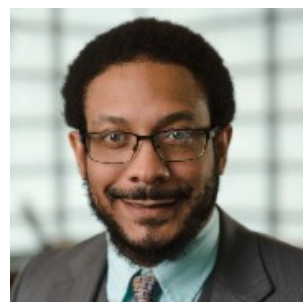

Shelton T.

McElroy

Kentucky 


\section{Leading with Conviction Fellows}

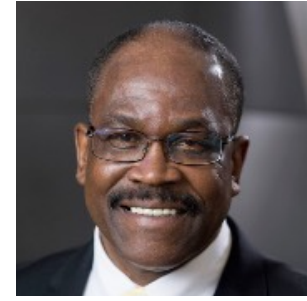

Albert Dancy

Virginia

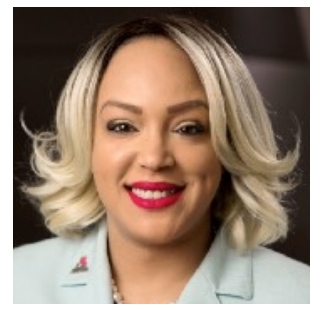

Dawn Harrington

Tennessee

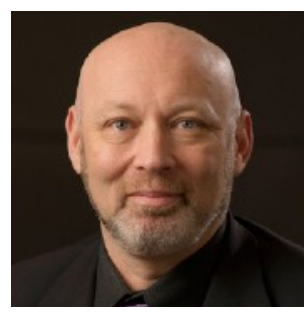

LaMonte Morgan

Oregon

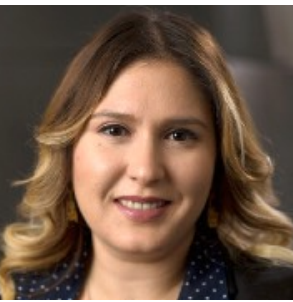

Lily Gonzalez

California

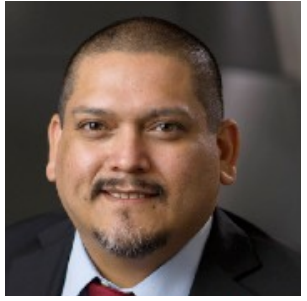

Alberto

Vasquez

California

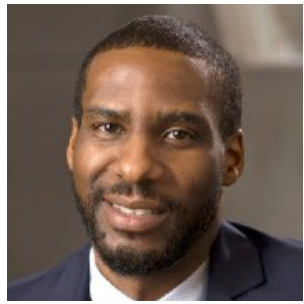

Emanuel Price

Oregon

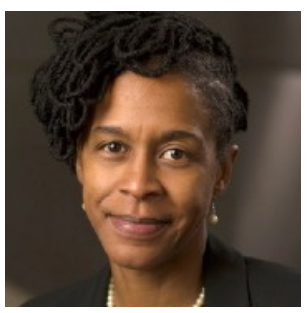

Lashonia

Thompson-EI

Washington,

D.C.

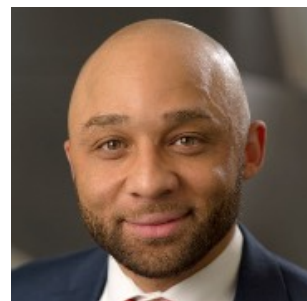

Louis Reed

Connecticut

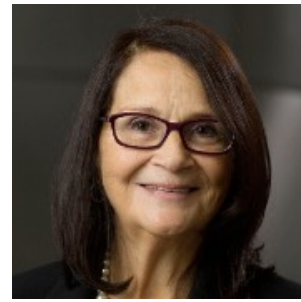

Beatrice

Codianni

Connecticut

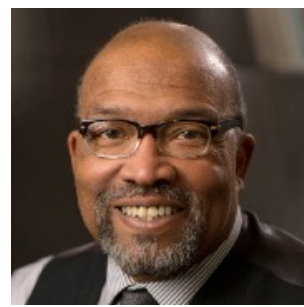

Harold Dean

Trulear, Ph.D.

Connecticut

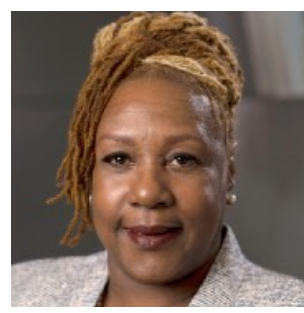

Leslie

Mathews

Michigan

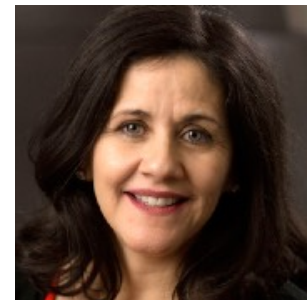

Maria Ford

Ohio

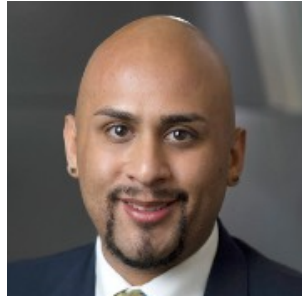

Caleb Martinez

Arizona

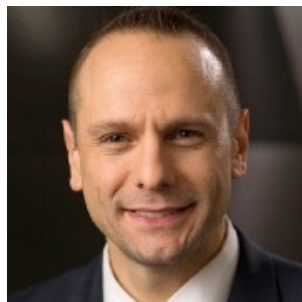

John Koufos

New Jersey

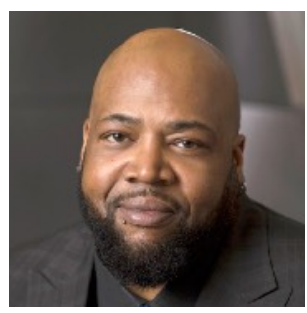

Lewis Conway, Jr. Texas

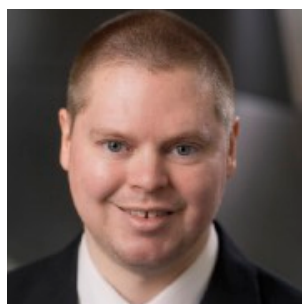

Mark Rice

Wisconsin

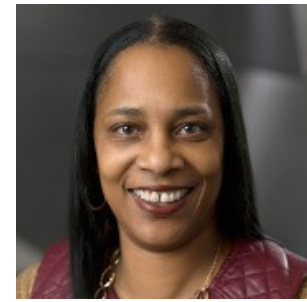

Carolyn

"Freda" King

Florida

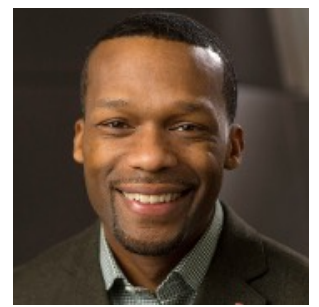

Johnny Perez

New York

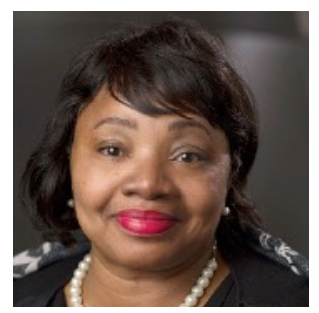

Lillie

Branch-Kennedy Virginia

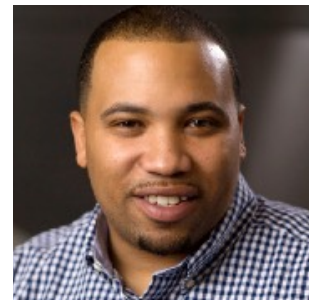

Nicholas

Buckingham

Michigan 


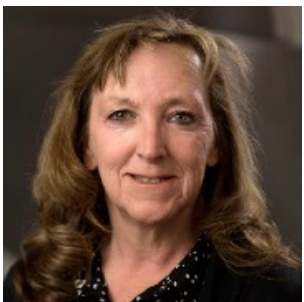

Pamela Clifton

Colorado

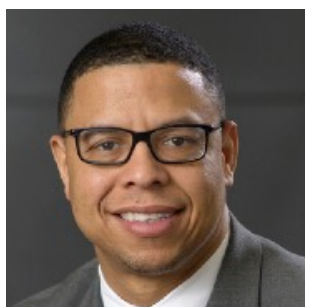

Richard Smith

New York

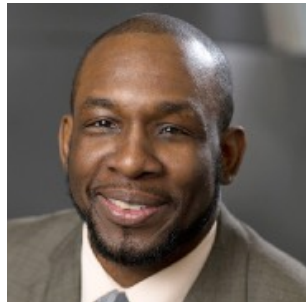

Shawn Gardner Kentucky

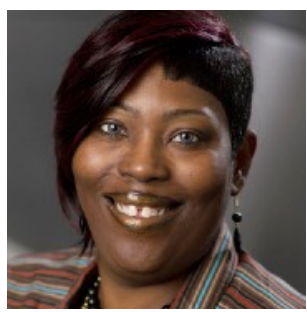

Waleisah Wilson Georgia

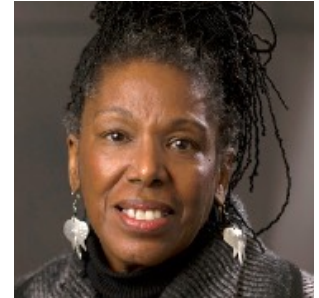

Pamela

Kennebrew

Pennsylvania

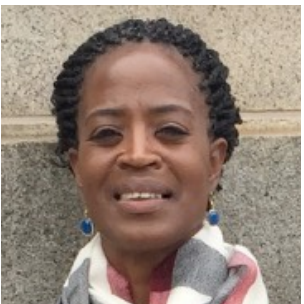

Romarilyn

Ralston

California

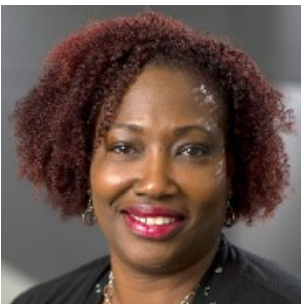

Tari Williams

Maryland

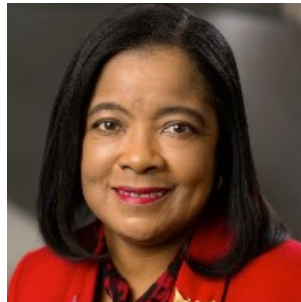

Patricia McCray

Florida

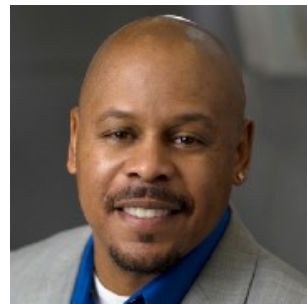

Samuel Lewis

California

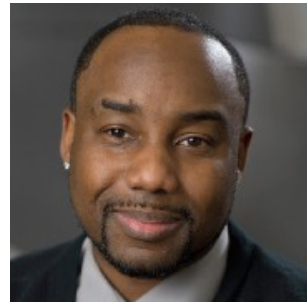

Tony Funchess Oregon

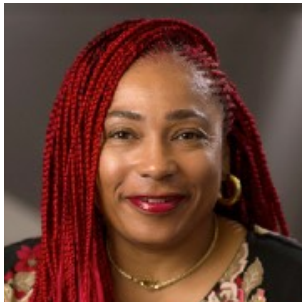

Pamela Winn

Georgia

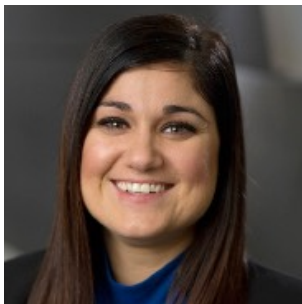

Sandy

LoMonico

Connecticut

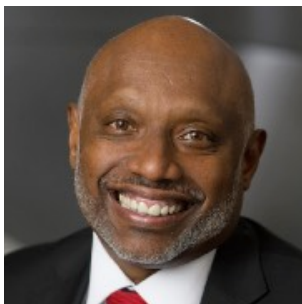

Troy F. Vaughn California

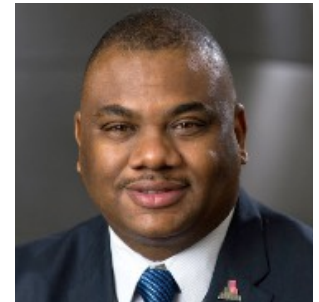

Reuben Jones

Pennsylvania

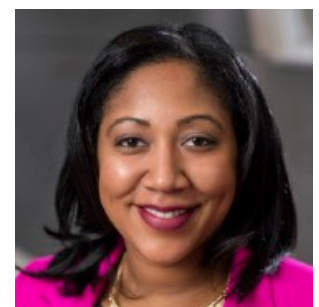

Shae Harris

Washington,

D.C.

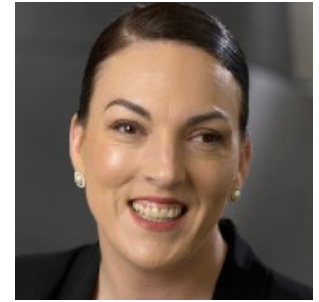

Venus Woods

Alaska 


\section{Emerging Leaders}

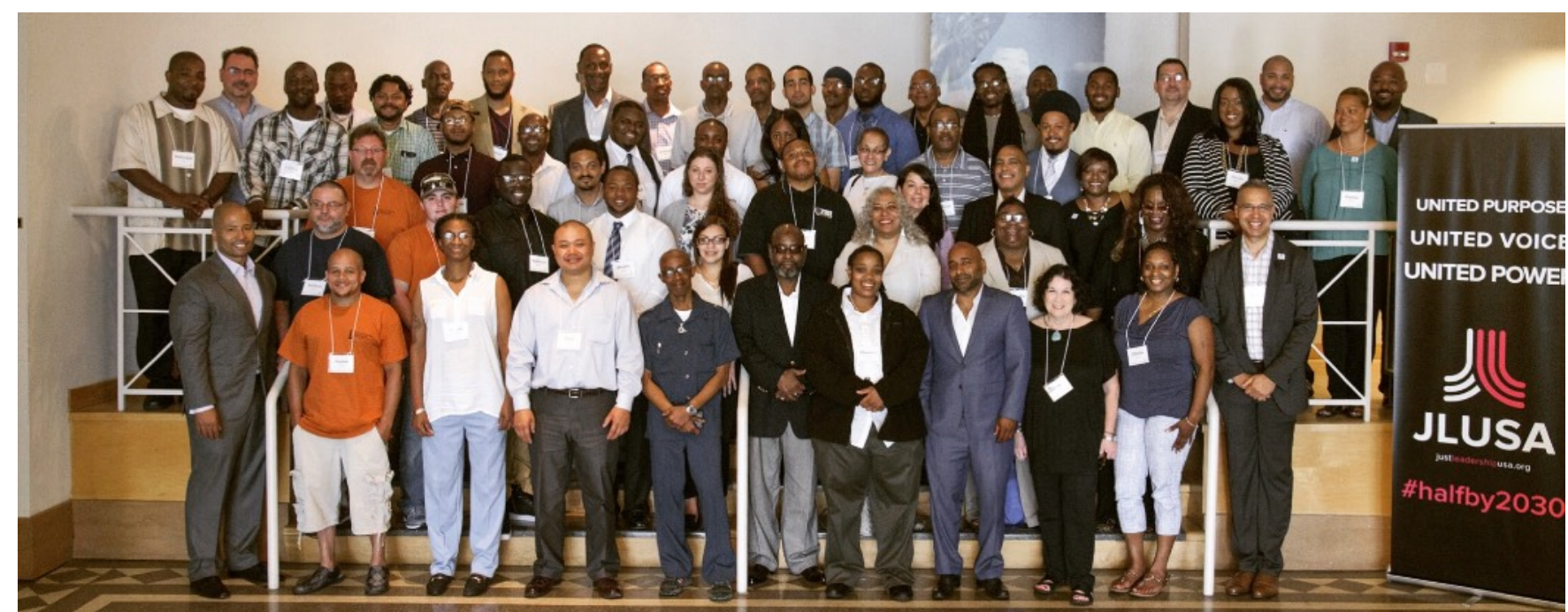

2015 Emerging Leaders: New York, NY

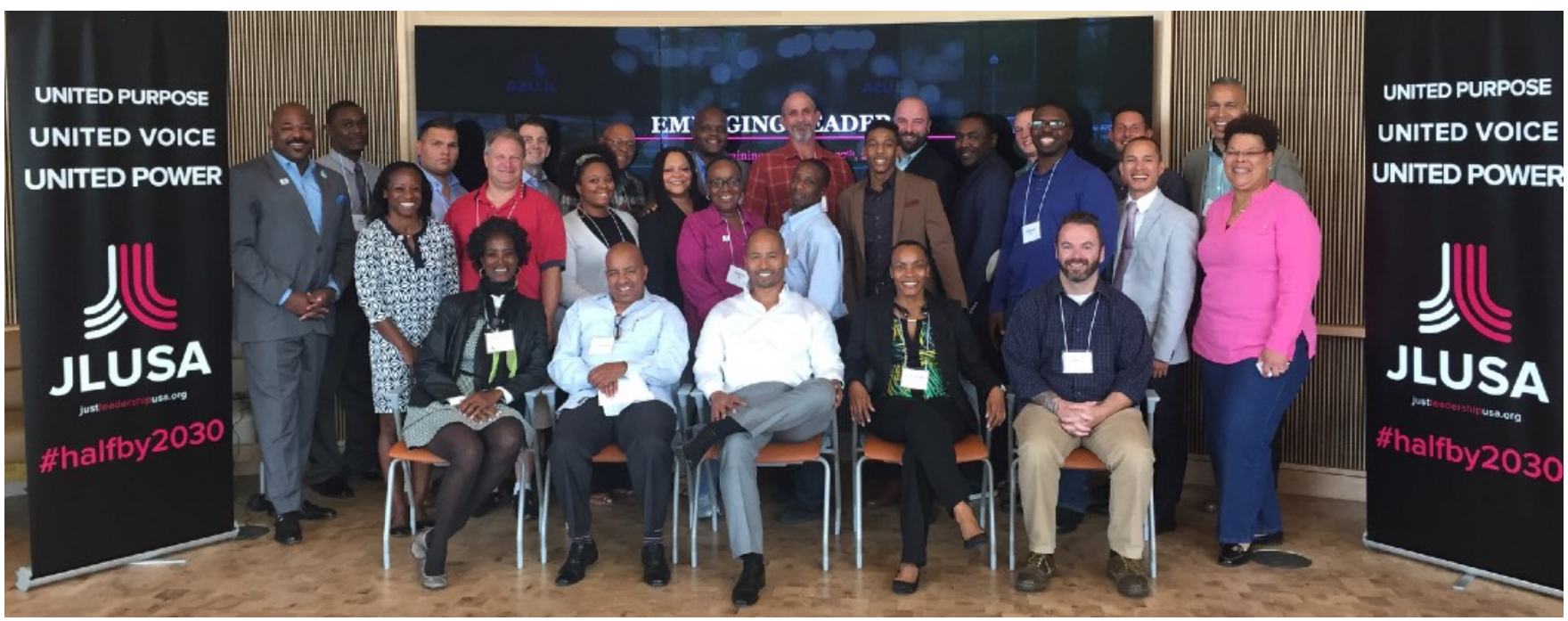

2015 Emerging Leaders: St. Louis, MO

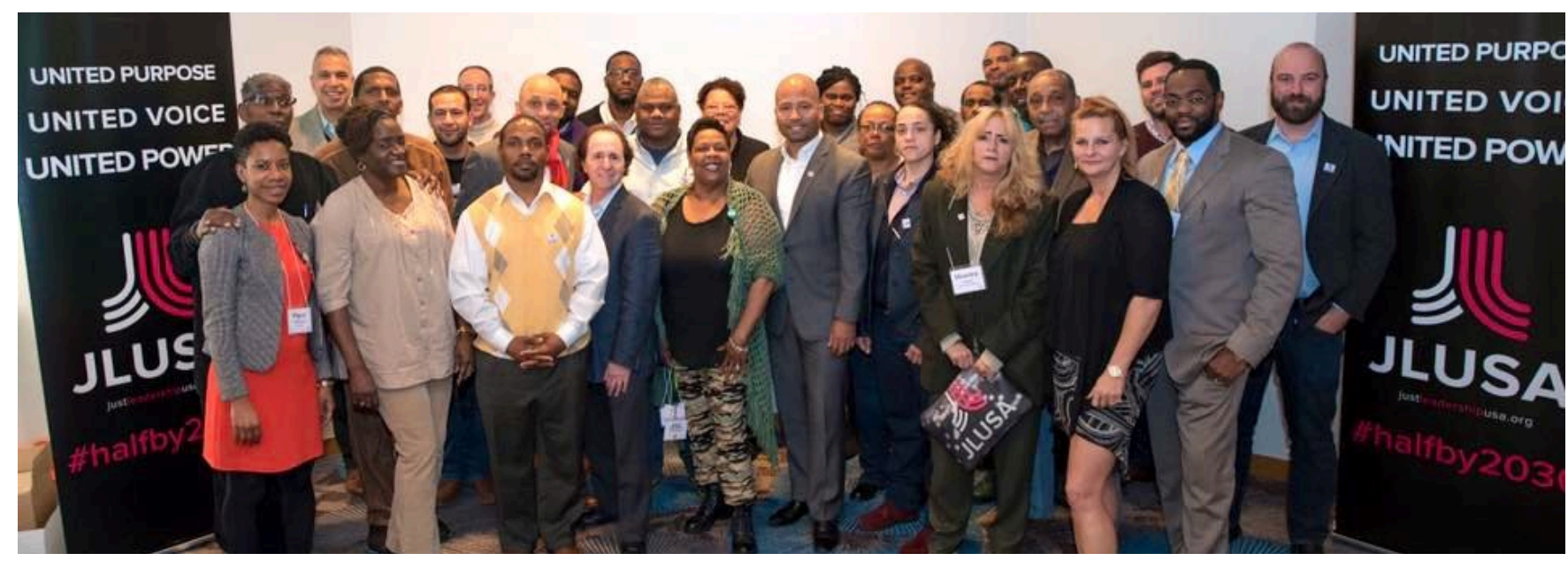

2015 Emerging Leaders: Washington, D.C. 


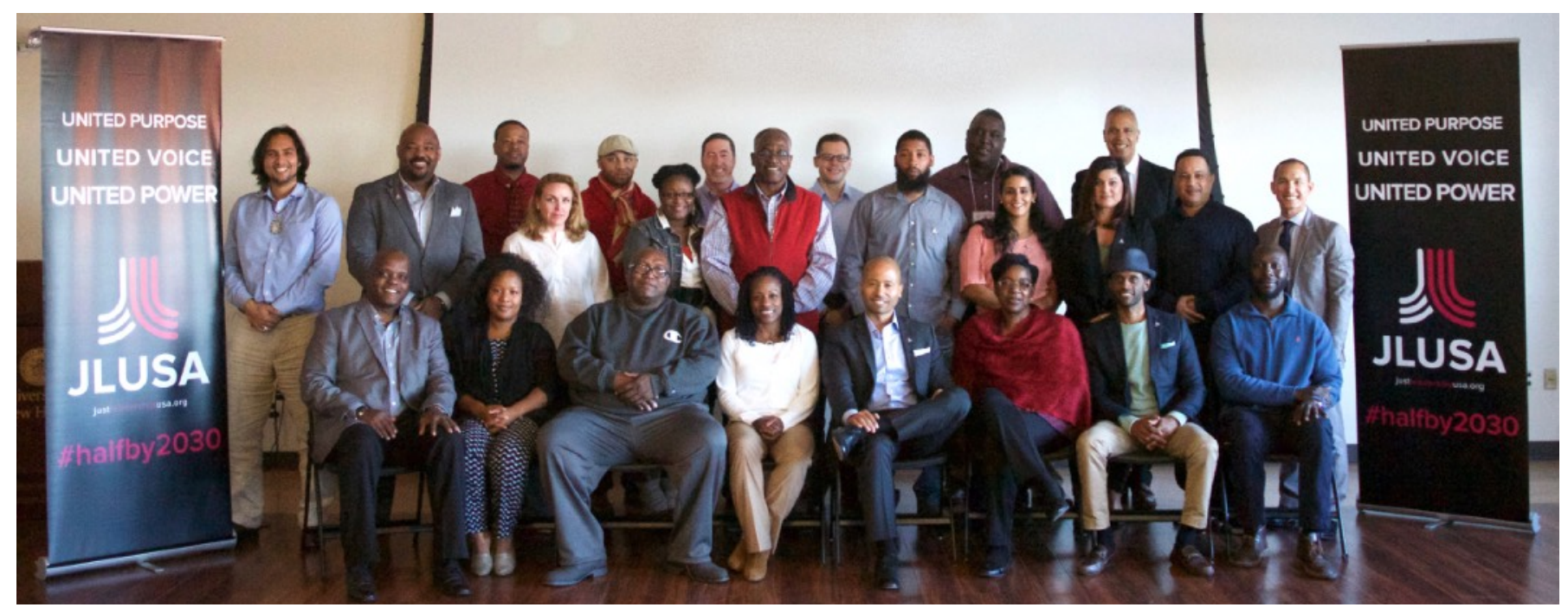

2016 Emerging Leaders: New Haven, CT

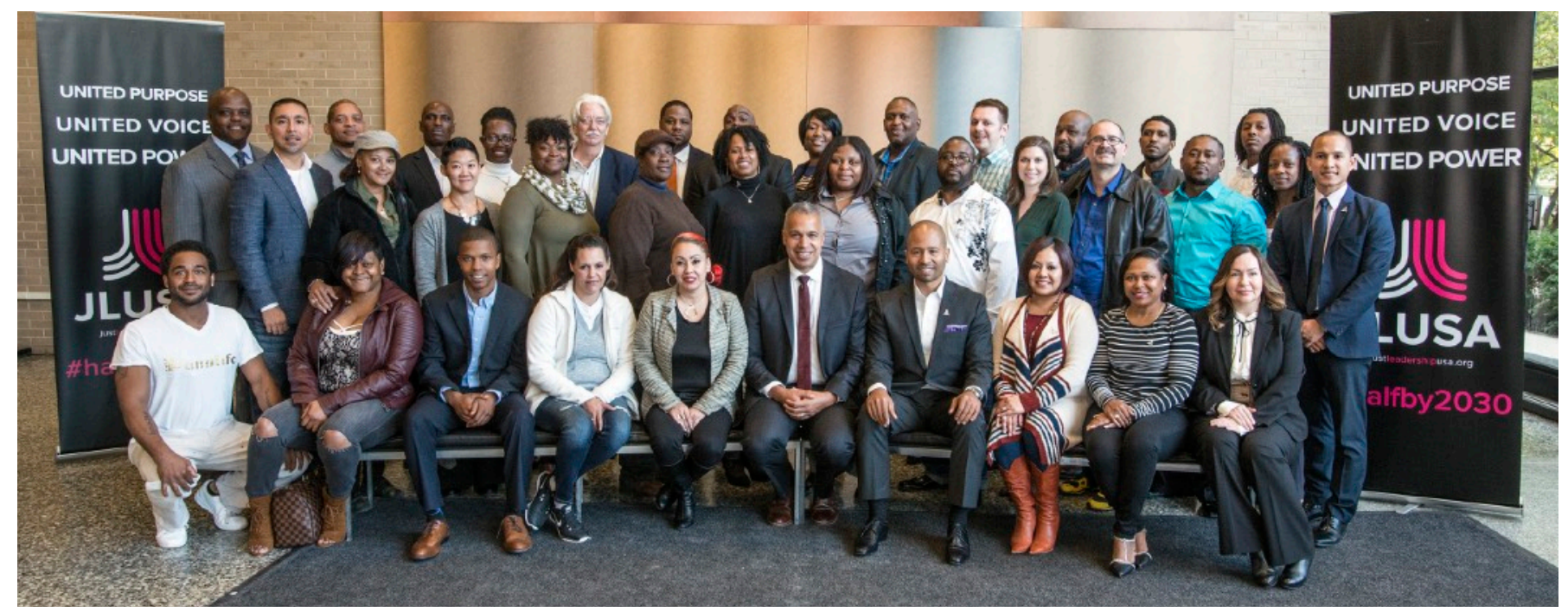

2016 Emerging Leaders: Chicago, IL

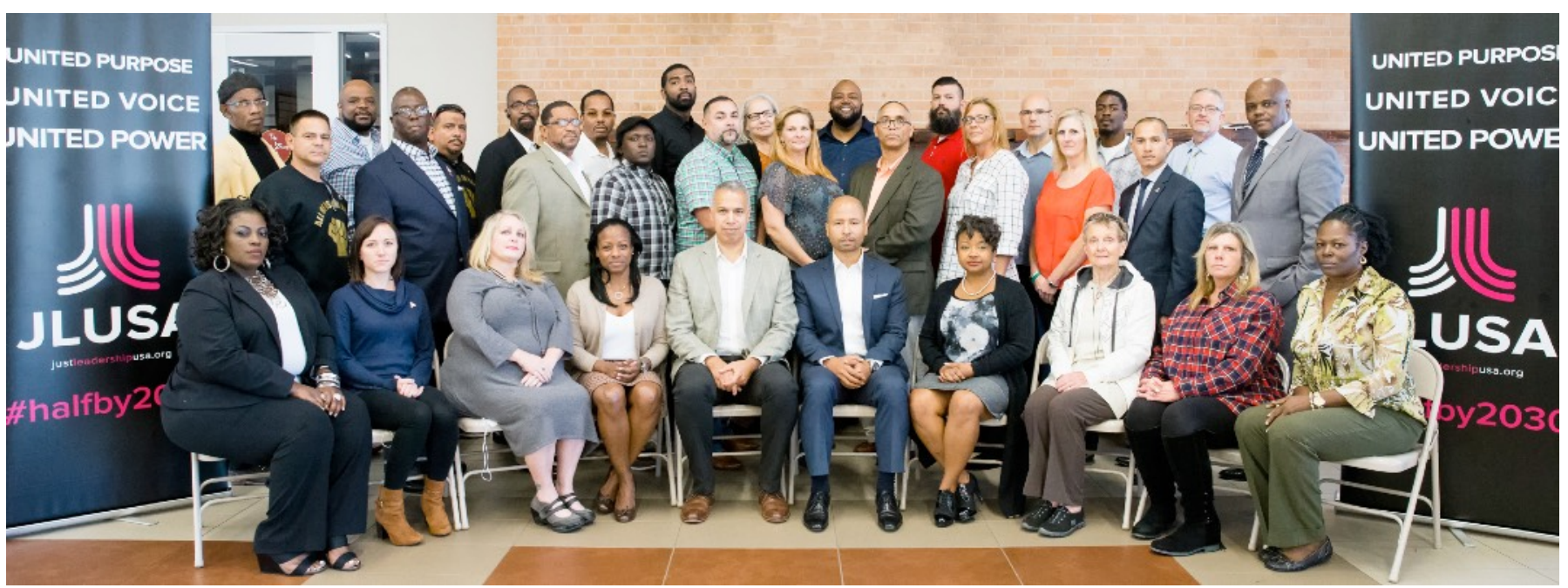

2016 Emerging Leaders: Austin, TX 


\section{References}

Atkinson, D. \& Lockwood, K. (2015). The benefits of Ban the Box: A case study of Durham, NC. Durham, NC: The Southern Coalition for Social Justice. Retrieved from https://www.southerncoalition.org/wp-content/uploads/2014/10/

BantheBox_WhitePaper-2.pdf.

Bourdieu, P. (1986). The forms of capital. In J. Richardson (Ed.) Handbook of Theory and Research for the Sociology of Education. 241-258. (New York, Greenwood).

Burton, L.K. \& Welsh, W. (2014). Inequality and opportunity: The role of exclusion, social capital, and generic social processes in upward mobility. Retrieved from http://wtgrantfoundation.org/resource/inequality-and-opportunity-the-role-ofexclusion-social-capital-and-generic-social-processes-in-upward-mobility.

Coleman, J.C. (1988). Social capital in the creation of human capital. The American Journal of Sociology, Vol. 94. pp. S95S120.

Coleman, J.C. \& Hoffer, T. (1987). Public and Private High Schools: The Impact of Communities. New York: Basic Books.

Corbin, J. \& Strauss, A. (2013). Basics of Qualitative Research: Techniques and Procedures for Developing Grounded Theory 214 (3d ed.) Thousand Oaks, CA: Sage.

The Federal Interagency Reentry Council (2016). A record of progress and a roadmap for the future. Retrieved from https:// csgjusticecenter.org/wp-content/uploads/2016/08/FIRC-Reentry-Report.pdf.

Fernandez, R.M., Castilla, E. \& Moore, P. (2000). Social capital at work: Networks and employment at a phone center. American Journal of Sociology 105 (5). 1288-1356.

Fukuyama, F. (2002). Social capital and development: The coming agenda. SAIS 12(1), 23-37.

Granovetter, M. (1973). The strength of weak ties. American Journal of Sociology 78(6), 1360-1380.

Gamson, W.A. (1991). Commitment and agency in social movements. Sociological Forum 6(1), 27-50.

Hawkins, R.L. \& Maurer, K. (2010). Bonding, bridging and linking: How social capital operated in New Orleans following Hurricane Katrina. British Journal of Social Work 40, 1777-1793.

Johnson, A. (2016). Roxbury native receives RFK Human Rights Award. Boston Globe. November 18, 2016. https:// www.bostonglobe.com/metro/2016/11/17/roxbury-native-receives-rfk-human-rights-award/7GI3AipKYHyJAyFJwlcaqK/ story.html

Kitsak (2010). Identifying influential spreaders in complex networks. Nature physics 6(11). 888-893.

Lin, N. (2001). Social capital: A theory of social structure and action. New York, NY: Cambridge University Press.

Maxwell, J.A. (2013). Qualitative research design: An interactive approach (3d ed. 2013).

Minkoff, D.C. (1997). Producing social capital: National movements and civil society. American Behavioral Scientist 40(5). 606-619. 
J. Travis, B. Western, and S. Redburn, Editors (2014). National Research Council, The Growth of Incarceration in the United States: Exploring Causes and Consequences. Washington, DC: The National Academies Press.

Nixon, V., Sturm, S. \& Levere, A. (2016). Breaking the cycle of mass incarceration: A strategy for investing in individuals, families and communities, in What It's Worth: Strengthening the Financial Future of Families, Communities and the Nation.

North, O. (2016, September 13). Hundreds gather in Oakland to address prison reform. SFGate. Retrieved from http:// blog.sfgate.com/inoakland/2016/09/13/hundreds-gather-in-oakland-to-address-prison-reform/.

Pascarella, E. T., \& Terenzini, P. T. (1991). How college affects students: Findings and insights from twenty years of research. San Francisco: Jossey-Bass.

Putnam, R.D. (2000). Bowling alone: The collapse and the revival of America community. New York: Simon and Schuster.

Rubineau, B. \& Fernandez, R.M. (2013). Missing Links: Referrer Behavior and Job Segregation. Management Science 59(11): 2470-2489. http://dx.doi.org/10.1287/mnsc.2013.1717

Sampson, R.J. (2012). Moving and the neighborhood glass ceiling. Science 337: 1464-1465.

Sharkey, P. (2013). Stuck in place: Urban neighborhoods and the end of progress toward racial equality. Chicago, IL: University of Chicago Press.

Small, M. (2009). Unanticipated gains: Origins of network inequalities in everyday life. New York, NY: Oxford University Press.

Szreter, S. \& Woolcock, M. (2004). Health by association? Social capital, social theory, and the political economy of public health, International Journal of Epidemiology, 33(4), pp. 650-67.

Strauss, A., \& Corbin, J. (2013). Basics of qualitative research: Techniques and procedures for developing grounded theory, 3rd ed. Thousand Oaks, CA: Sage Publications.

Sturm, S. (2006). The Architecture of Inclusion: Advancing Workplace Equality in Higher Education, Harvard Journal of Law and Gender. 29(2), 247-334.

Sturm, S., Skolnick, K, and Wu, T., (2013). Building pathways of possibility from criminal justice to college: College Initiative as a catalyst linking individual and systemic change. New York: Center for Institutional and Social Change. Retrieved from http://change-center.squarespace.com/publications/.

Sturm, S. and Nixon, V. (2015). Home grown social capital: How higher education for formerly incarcerated women facilitates family and community transformation. Washington D.C.: Aspen Ascend. Retrieved from http://b.3cdn.net/ascend/ d6f46bacfa0aa7a587_sfm6brfxf.pdf.

Sturm, S., Eatman, T., Saltmarsh, J., and Bush, A. (2011). Full participation: Building the architecture for diversity and community engagement in higher education. Retrieved from http://imaginingamerica.org/wp-content/uploads/2015/07/ fullparticipation.pdf.

Visher, C.A., \& Travis, J. (2012). The characteristics of prisoners returning home and effective reentry programs and policies. In J. Petersilia \& K. R. Reitz (Eds.), The Oxford handbook of sentencing and corrections. pp. 684-706. New York, NY: Oxford University Press. 


\section{JLUSA

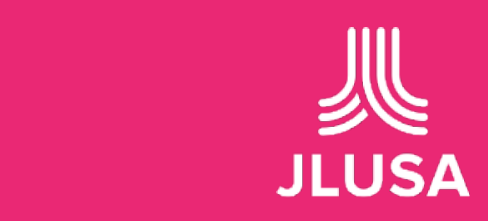

justleadershipusa.org

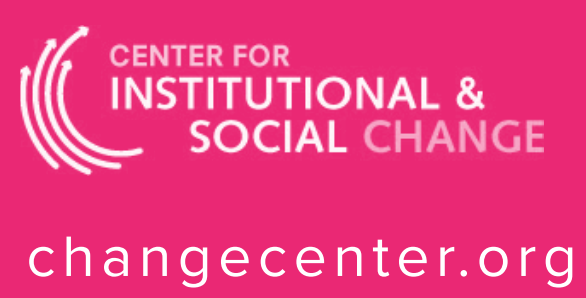

changecenter.org 